\title{
Chemistry of $\mathrm{CS}_{2}$ - and SCNPh-Adducts of the Pyramidal Phosphinidene-Bridged Complex $\left[\mathrm{Mo}_{2} \mathrm{Cp}\left(\mu-\kappa^{1}: \kappa^{1}, \eta^{5}-\right.\right.$ $\left.\left.\mathrm{PC}_{5} \mathrm{H}_{4}\right)(\mathrm{CO})_{2}\left(\eta^{6}-\mathrm{HMes}^{*}\right)\left(\mathrm{PMe}_{3}\right)\right] \cdot \dagger$
}

\author{
Isabel G. Albuerne, M. Angeles Alvarez, M. Esther García,* Daniel García-Vivó and \\ Miguel A. Ruiz* \\ Departamento de Química Orgánica e Inorgánica/IUQOEM, Universidad de Oviedo, \\ E-33071 Oviedo, Spain.
}

\begin{abstract}
The title complex reacted readily with $\mathrm{CS}_{2}$ and $\mathrm{SCNPh}$ to give the phosphinidenecumulene adducts $\left[\mathrm{Mo}_{2} \mathrm{Cp}\left\{\mu-\kappa_{\mathrm{P}}^{1}: \kappa_{\mathrm{S}}^{1}, \eta^{5}-\mathrm{P}\left(\mathrm{CS}_{2}\right) \mathrm{C}_{5} \mathrm{H}_{4}\right\}(\mathrm{CO})_{2}\left(\eta^{6}-\mathrm{HMes}^{*}\right)\left(\mathrm{PMe}_{3}\right)\right]$ and $\left[\mathrm{Mo}_{2} \mathrm{Cp}\left\{\mu-\kappa_{\mathrm{p}}^{1}: \kappa_{\mathrm{S}}^{1}, \eta^{5}-\mathrm{P}(\mathrm{C}(\mathrm{NPh}) \mathrm{S}) \mathrm{C}_{5} \mathrm{H}_{4}\right\}(\mathrm{CO})_{2}\left(\eta^{6}-\mathrm{HMes}^{*}\right)\left(\mathrm{PMe}_{3}\right)\right]$ respectively (Mes* $=2,4,6-\mathrm{C}_{6} \mathrm{H}_{2}{ }^{t} \mathrm{Bu}_{3}$ ), as a result of formal insertion of the $\mathrm{C}=\mathrm{S}$ bond of the heterocumulene into the metallocene Mo-P bond of the phosphinidene complex. The newly formed species bear a pyramidal $\mathrm{P}$ atom with a lone electron pair involved in fast inversion, and displayed strong nucleophilicity which enabled easy addition at the P site of carbon-based electrophiles and chalcogen atoms, while the uncoordinated $\mathrm{S}$ and $\mathrm{N}$ atoms also were competitive nucleophilic sites in these complexes. These air-sensitive materials readily added an $\mathrm{O}_{2}$ molecule in the solid state, to give the corresponding derivatives $\left[\mathrm{Mo}_{2} \mathrm{Cp}\left\{\mu-\kappa^{1}{ }_{\mathrm{O}}: \kappa^{1}{ }_{\mathrm{S}}, \eta^{5}-\mathrm{OP}(\mathrm{O})(\mathrm{C}(\mathrm{X}) \mathrm{S}) \mathrm{C}_{5} \mathrm{H}_{4}\right\}(\mathrm{CO})_{2}\left(\eta^{6}-\mathrm{HMes}^{*}\right)\left(\mathrm{PMe}_{3}\right)\right](\mathrm{X}=$ $\mathrm{S}, \mathrm{NPh}$ ), and the $\mathrm{CS}_{2}$ adduct reacted selectively with $\mathrm{S}_{8}$ in solution to give the sulfide derivative $\left[\mathrm{Mo}_{2} \mathrm{Cp}\left\{\mu-\kappa^{1}{ }_{\mathrm{p}}: \kappa^{1}{ }_{\mathrm{S}}, \eta^{5}-\mathrm{P}(\mathrm{S})\left(\mathrm{CS}_{2}\right) \mathrm{C}_{5} \mathrm{H}_{4}\right\}(\mathrm{CO})_{2}\left(\eta^{6}-\mathrm{HMes}^{*}\right)\left(\mathrm{PMe}_{3}\right)\right]$, which was stabilized through methylation, this yielding the cationic complex $\left[\mathrm{Mo}_{2} \mathrm{Cp}\{\mu\right.$ $\left.\left.\kappa_{\mathrm{P}}^{1}: \kappa_{\mathrm{S}}^{1}, \eta^{5}-\mathrm{P}(\mathrm{S})(\mathrm{C}(\mathrm{SMe}) \mathrm{S}) \mathrm{C}_{5} \mathrm{H}_{4}\right\}(\mathrm{CO})_{2}\left(\eta^{6}-\mathrm{HMes}^{*}\right)\left(\mathrm{PMe}_{3}\right)\right]^{+}$. The $\mathrm{CS}_{2}$ adduct could be methylated selectively at either the $\mathrm{P}$ or $\mathrm{C}=\mathrm{S}$ sites, depending on the reagent used, to give respectively the cationic complexes $\left[\mathrm{Mo}_{2} \mathrm{Cp}\left\{\mu-\kappa^{1}{ }_{\mathrm{p}}: \kappa_{\mathrm{S}}^{1}, \eta^{5}-\right.\right.$ $\left.\left.\mathrm{PMe}\left(\mathrm{CS}_{2}\right) \mathrm{C}_{5} \mathrm{H}_{4}\right\}(\mathrm{CO})_{2}\left(\eta^{6}-\mathrm{HMes}^{*}\right)\left(\mathrm{PMe}_{3}\right)\right]^{+} \quad$ or $\quad\left[\mathrm{Mo}_{2} \mathrm{Cp}\left\{\mu-\kappa^{1}{ }_{\mathrm{p}}^{1} \kappa^{1}{ }_{\mathrm{S}}, \eta^{5}-\right.\right.$ $\left.\left.\mathrm{P}(\mathrm{C}(\mathrm{SMe}) \mathrm{S}) \mathrm{C}_{5} \mathrm{H}_{4}\right\}(\mathrm{CO})_{2}\left(\eta^{6}-\mathrm{HMes}^{*}\right)\left(\mathrm{PMe}_{3}\right)\right]^{+}$. Further methylation could be accomplished through reaction with $\left[\mathrm{Me}_{3} \mathrm{O}\right] \mathrm{BF}_{4}$ to give the dipositive cation $\left[\mathrm{Mo}_{2} \mathrm{Cp}\left\{\mu-\kappa_{\mathrm{p}}^{1}: \kappa_{\mathrm{S}}^{1}, \eta^{5}-\mathrm{PMe}(\mathrm{C}(\mathrm{SMe}) \mathrm{S}) \mathrm{C}_{5} \mathrm{H}_{4}\right\}(\mathrm{CO})_{2}\left(\eta^{6}-\mathrm{HMes}^{*}\right)\left(\mathrm{PMe}_{3}\right)\right]^{2+}$. In contrast, the SCNPh adduct was only methylated at the $\mathrm{P}$ site to yield the phosphanylthioformamidato complex $\quad \mathrm{Mo}_{2} \mathrm{Cp}\left\{\mu-\kappa^{1}{ }_{\mathrm{p}}: \kappa_{\mathrm{S}}^{1}, \eta^{5}\right.$ -
\end{abstract} $\left.\left.\mathrm{PMe}(\mathrm{C}(\mathrm{NPh}) \mathrm{S}) \mathrm{C}_{5} \mathrm{H}_{4}\right\}(\mathrm{CO})_{2}\left(\eta^{6}-\mathrm{HMes}^{*}\right)\left(\mathrm{PMe}_{3}\right)\right]^{+}$, but was readily protonated at the $\mathrm{N}$ 
site upon reaction with $\left(\mathrm{NH}_{4}\right) \mathrm{PF}_{6}$, to give the phosphanylthioformamide-like derivative $\left[\mathrm{Mo}_{2} \mathrm{Cp}\left\{\mu-\kappa_{\mathrm{p}}^{1}: \kappa^{1}{ }_{\mathrm{S}}, \eta^{5}-\mathrm{P}(\mathrm{C}(\mathrm{NHPh}) \mathrm{S}) \mathrm{C}_{5} \mathrm{H}_{4}\right\}(\mathrm{CO})_{2}\left(\eta^{6}-\mathrm{HMes}^{*}\right)\left(\mathrm{PMe}_{3}\right)\right]^{+}$. In the presence of $\mathrm{Na}\left(\mathrm{BAr}_{4}{ }_{4}\right)$, this adduct was even able to displace chloride from the solvent (dichloromethane) to give the corresponding chloromethyl derivative $\left[\mathrm{Mo}_{2} \mathrm{Cp}\{\mu\right.$ $\left.\left.\kappa_{\mathrm{P}}^{1}: \kappa_{\mathrm{S}}^{1}, \eta^{5}-\mathrm{P}\left(\mathrm{CH}_{2} \mathrm{Cl}\right)(\mathrm{C}(\mathrm{NPh}) \mathrm{S}) \mathrm{C}_{5} \mathrm{H}_{4}\right\}(\mathrm{CO})_{2}\left(\eta^{6}-\mathrm{HMes}^{*}\right)\left(\mathrm{PMe}_{3}\right)\right]^{+}$. The structures of the new complexes were analyzed using spectroscopic, diffractometric and, in some cases, density functional theory methods.

\section{Introduction}

The chemistry of transition-metal complexes having phosphinidene ligands (PR) has been a subject of continuous interest over the last decades. Extensive research carried out on mononuclear complexes, particularly on those displaying bent-terminal ligands (B and $\mathbf{C}$ in Chart 1), has revealed remarkable reactivity towards a great variety of organic reagents, whereby a large number of unusual organophosphorus molecules can be built on. ${ }^{1,2}$ In contrast, the chemistry of binuclear phosphinidene-bridged complexes has been comparatively less explored, but this situation has been changing in the last years. ${ }^{3}$ In its three known coordination modes (D to $\mathbf{F}$ ), the $\mu_{2}$-PR ligand displays either a lone electron pair at the $\mathrm{P}$ site or $\mathrm{M}-\mathrm{P}$ multiple bonding, and this allows it to react easily with a large variety of unsaturated organics. Previous research in that direction, and involving binuclear complexes bearing pyramidal phosphinidene bridges of type $\mathbf{F}$, has been limited so far to studies on reactions of the diiron complexes $\left[\mathrm{Fe}_{2} \mathrm{Cp}_{2}(\mu-\mathrm{PR})(\mu-\right.$ $\left.\mathrm{CO})(\mathrm{CO})_{2}\right](\mathrm{Cy}, \mathrm{Ph}, \mathrm{Mes}, \mathrm{Mes} *)$ with alkenes, alkynes, diazoalkanes, azides and quinones, ${ }^{4}$ and those of the dimolybdenum complex $\left[\mathrm{Mo}_{2} \mathrm{Cp}\left(\mu-\kappa^{1}: \kappa^{1}, \eta^{5}-\right.\right.$ $\left.\mathrm{PC}_{5} \mathrm{H}_{4}\right)(\mathrm{CO})_{2}\left(\eta^{6}\right.$-HMes*) $\left.\left(\mathrm{PMe}_{3}\right)\right]$ (1) with maleic anhydride $\left(\mathrm{Mes}^{*}=2,4,6-\mathrm{C}_{6} \mathrm{H}_{2}{ }^{t} \mathrm{Bu}_{3}\right){ }^{5}$ These reactions are initiated by the nucleophilic attack of the phosphinidene $\mathrm{P}$ atom to the unsaturated organic molecule, with formation of new $\mathrm{P}-\mathrm{C}$ or $\mathrm{P}-\mathrm{N}$ bonds, sometimes followed by interesting rearrangements. Recently, we investigated reactions of the trigonal (type E) phosphinidene-bridged complex $\left[\mathrm{Mo}_{2} \mathrm{Cp}\left(\mu-\kappa^{1}: \kappa^{1}, \eta^{5}-\mathrm{PC}_{5} \mathrm{H}_{4}\right)(\mathrm{CO})_{2}\left(\eta^{6}-\right.\right.$ HMes*)] (actually the precursor of the pyramidal complex 1) towards several heterocumulenes, these including the sulfur-containing cumulenes $\mathrm{CS}_{2}$ and $\mathrm{SCNPh}^{6}$ The latter reactions resulted in formal $[2+2]$ cycloadditions of the organic substrate to the $\mathrm{Mo}=\mathrm{P}$ bond of the metal complex with specific formation of $\mathrm{P}-\mathrm{C}$ bonds. We noted at the time the lack of previous studies on the reactivity of phosphinidene-bridged complexes towards this type of heterocumulenes, actually limited to a recent report on the reaction of the type $\mathbf{D}$ scandium complex $\left[\mathrm{Sc}_{2}(\mu-\mathrm{PXyl})_{2} \mathrm{~L}_{2}\right]\left(\mathrm{L}_{2}=\right.$ bidentate diiminate ligand) with $\mathrm{CS}_{2}{ }^{7}$ It was then of interest to examine the reactivity of a pyramidal phosphinidene-bridged complex of type $\mathbf{F}$ (as compound 1) towards this sort of heterocumulenes, which is the purpose of the present paper. Indeed, previous studies 
have shown that $\mathbf{1}$ reacts readily with simple C-based electrophiles such as methyl iodide and ethylene sulfide $;^{8}$ clearly, such P-based nucleophilicity should warrant an easy formation of new $\mathrm{P}-\mathrm{C}$ bonds in the reactions of $\mathbf{1}$ with heterocumulenes, while the absence of Mo-P multiple bonding might enable subsequent evolutions different from the cycloadditions observed with trigonal complexes of type E. As shown below, this is indeed the case, since the reactions of $\mathbf{1}$ with $\mathrm{CS}_{2}$ and SCNPh eventually result in formal insertion of the $\mathrm{C}=\mathrm{S}$ bond of the heterocumulene into a Mo-P bond of the phosphinidene complex. This implies that the phosphinidene adduct retains a lone electron pair at the $\mathrm{P}$ site while adding a new reaction site ( $\mathrm{S}$ - or $\mathrm{N}$-donor) to the organophosphorus ligand, which enables further functionalisation upon subsequent reaction with other electrophiles.

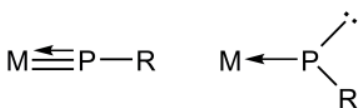

$\boldsymbol{B}$

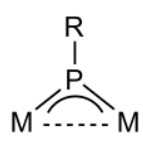

D<smiles>[R][PH]([R])=[M]</smiles>

E<smiles>[2H]P([18OH])I</smiles>

C

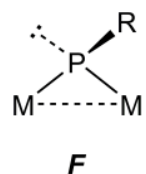

\section{Chart 1}

\section{Results and Discussion}

\section{Reactions of compound 1 with $\mathrm{CS}_{2}$ and $\mathrm{SCNPh}$}

Compound 1 reacts readily with $\mathrm{CS}_{2}$ even at $223 \mathrm{~K}$ to give the phosphanyl-like derivative $\left[\mathrm{Mo}_{2} \mathrm{Cp}\left\{\mu-\kappa^{1}{ }_{\mathrm{p}}: \kappa^{1}{ }_{\mathrm{S}}, \eta^{5}-\mathrm{P}\left(\mathrm{CS}_{2}\right) \mathrm{C}_{5} \mathrm{H}_{4}\right\}(\mathrm{CO})_{2}\left(\eta^{6}-\mathrm{HMes}^{*}\right)\left(\mathrm{PMe}_{3}\right)\right]$ (2a) in good yield. Its reaction with phenyl isothiocyanate proceeds analogously, now at room temperature, to give the related derivative $\left[\mathrm{Mo}_{2} \mathrm{Cp}\left\{\mu-\kappa_{\mathrm{p}}^{1}: \kappa_{\mathrm{S}}^{1}, \eta^{5}-\right.\right.$ $\left.\left.\mathrm{P}(\mathrm{C}(\mathrm{NPh}) \mathrm{S}) \mathrm{C}_{5} \mathrm{H}_{4}\right\}(\mathrm{CO})_{2}\left(\eta^{6}-\mathrm{HMes}^{*}\right)\left(\mathrm{PMe}_{3}\right)\right](\mathbf{2 b})$ in a selective way (Scheme 1$)$. We also examined analogous reactions of 1 with the O-bearing heterocumulenes $\mathrm{CO}_{2}$ (ca. 4 atm) and $p$-tolyl isocyanate, but in those cases no reaction was observed at room temperature, even after prolonged periods of time. 


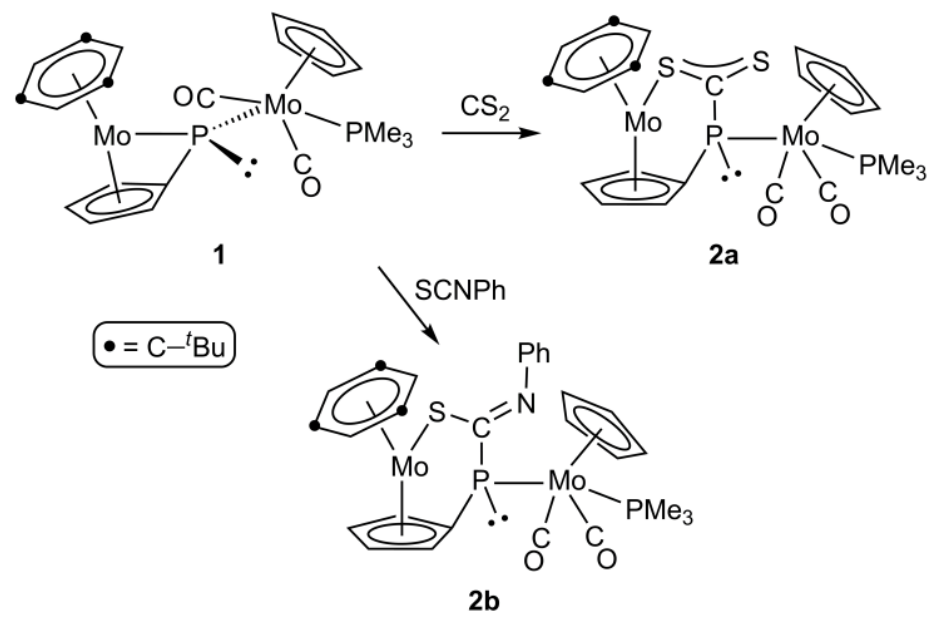

Scheme 1

The phosphinidene-cumulene adducts $\mathbf{2 a}, \mathbf{b}$ are formally derived from insertion of the $\mathrm{C}=\mathrm{S}$ bond of the heterocumulene into the Mo-P bond in the metallocene fragment, with specific formation of a new $\mathrm{P}-\mathrm{C}$ bond, a behaviour somewhat reminiscent of the one observed in related reactions of different mononuclear complexes bearing pyramidal phosphanyl ligands, which typically involve insertion of the heterocumulene into the corresponding $\mathrm{M}-\mathrm{P}$ bond. ${ }^{2 \mathrm{i}, 9,10}$ In the case of $\mathbf{1}$, this event is unlikely to be occurring in a single step. Because of the strong nucleophilicity of $\mathbf{1}$ already noted, ${ }^{8}$ it is more sensible to assume that these reactions are started by the nucleophilic attack of the $\mathrm{P}$ atom to the electrophilic carbon atom of the added organic molecule, to give an intermediate $\mathrm{I} 1$ with the newly formed $\mathrm{P}-\mathrm{C}$ bond placed in the $\mathrm{Mo}_{2} \mathrm{P}$ plane, according to the frontier orbitals of $\mathbf{1}$ (Scheme 2). ${ }^{8}$ Intermediates $\mathbf{I 1}$ would afterwards rearrange with formation of a new S-Mo bond and cleavage of the corresponding P-Mo bond, this eventually leaving a lone electron pair again at the $\mathrm{P}$ atom.

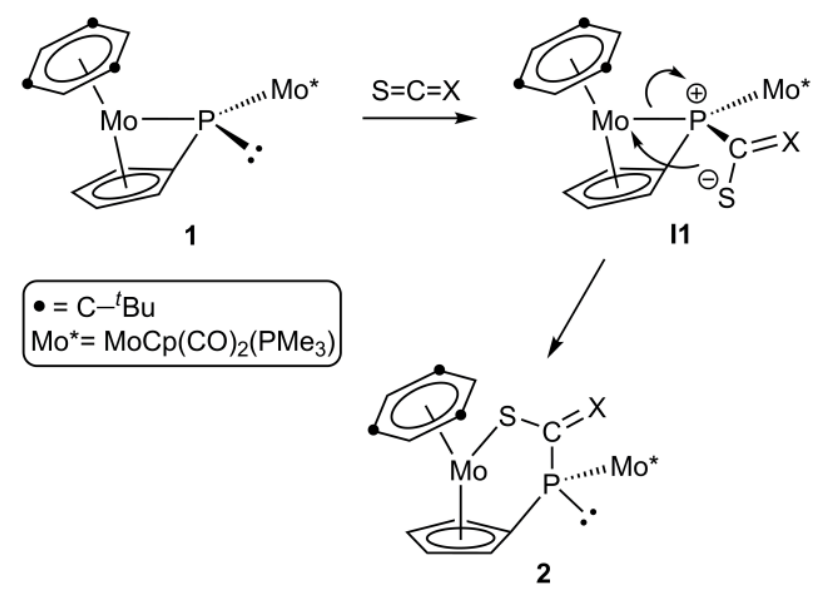

Scheme 2 


\section{Structural characterization of compounds 2}

The molecular structure of $\mathbf{2 a}$ in the crystal (Figure 1 and Table 1) confirms the presence of a polyfunctional $\mathrm{RPCS}_{2}$ ligand bridging the metal atoms via its $\mathrm{P}$ atom (bound to Mo1), and the $\mathrm{C}_{5} \mathrm{H}_{4}$ ring (in the usual $\eta^{5}$ fashion) and one of the $\mathrm{S}$ atoms of the added $\mathrm{CS}_{2}$ molecule (bound to Mo2). The environment around C3 is almost perfectly planar, a circumstance which allows for delocalization of $\pi$-bonding interactions over the $\mathrm{S}-\mathrm{C}-\mathrm{S}$ chain. Indeed, the $\mathrm{C}-\mathrm{S}$ distances are similar to each other (ca. $1.69 \AA$ ) and have values intermediate between the reference figures for single (1.78 $\AA$ ) and double bonds (1.62 $\AA$ ) between these atoms. ${ }^{11,12}$ This suggests extensive delocalization of a $\pi$-bonding electron pair over the $\mathrm{S}-\mathrm{C}-\mathrm{S}$ skeleton, as also found in $\mathrm{R}_{3} \mathrm{P} \cdot \mathrm{CS}_{2}$ adducts and many of their metal complexes. ${ }^{13}$ In contrast, the $\mathrm{P}$ atom retains significant pyramidalisation ( $\Sigma \mathrm{X}-\mathrm{P}-\mathrm{Y}$ ca. $\left.321^{\circ}\right)$, while the $\mathrm{P} 1-\mathrm{C} 3$ length of $1.804(3) \AA$ perfectly matches the reference figure of $1.80 \AA$ expected for a $\mathrm{P}-\mathrm{C}\left(s p^{2}\right)$ bond. ${ }^{11}$ The geometric features of the $\mathrm{RPCS}_{2}$ ligand in $\mathbf{2 a}$ are thus comparable to those recently found for the $\mathrm{CS}_{2}$ adduct of the trigonal phosphinidene complex $\left[\mathrm{Mo}_{2} \mathrm{Cp}\left(\mu-\kappa^{1}: \kappa^{1}, \eta^{5}\right.\right.$ $\left.\mathrm{PC}_{5} \mathrm{H}_{4}\right)(\mathrm{CO})_{2}\left(\eta^{6}\right.$-HMes*) ${ }^{*}{ }^{6}$ despite the different coordination modes of the P-donor ligand in these two complexes $\left(\mu-\kappa_{P, S}^{2}: \kappa^{1}{ }_{S}, \eta^{5}-\right.$ vs. $\mu-\kappa_{P}^{1}: \kappa^{1}{ }_{S}, \eta^{5}-$ in $\left.\mathbf{2 a}\right)$.

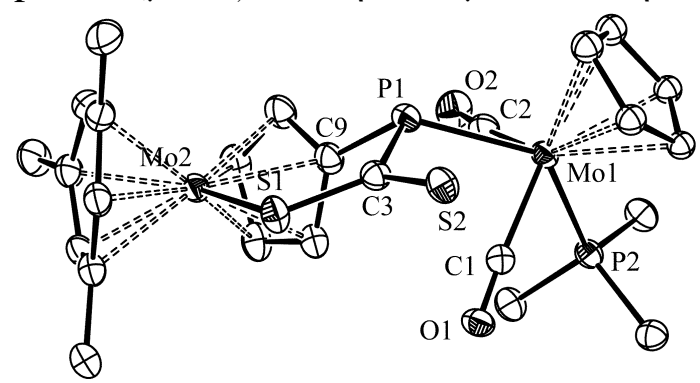

Figure 1. ORTEP diagram (30\% probability) of compound $\mathbf{2 a}$, with $\mathrm{H}$ atoms and ${ }^{t} \mathrm{Bu}$ groups (except their $\mathrm{C}^{1}$ atoms) omitted for clarity.

Table 1. Selected Bond Lengths $(\AA)$ and Angles $\left(^{\circ}\right)$ for Compound 2a.

\begin{tabular}{llll}
\hline Mo1-P1 & $2.543(1)$ & P1-Mo1-P2 & $134.34(3)$ \\
Mo1-P2 & $2.464(1)$ & C1-Mo1-C2 & $106.7(1)$ \\
Mo1-C1 & $1.979(3)$ & C1-Mo1-P1 & $74.9(1)$ \\
Mo1-C2 & $1.950(4)$ & C2-Mo1-P1 & $78.9(1)$ \\
Mo2-S1 & $2.5231(9)$ & Mo1-P1-C9 & $109.0(1)$ \\
P1-C3 & $1.804(3)$ & Mo1-P1-C3 & $114.8(1)$ \\
P1-C9 & $1.831(4)$ & C3-P1-C9 & $97.6(2)$ \\
C3-S1 & $1.703(3)$ & P1-C3-S1 & $118.3(2)$ \\
C3-S2 & $1.680(3)$ & P1-C3-S2 & $121.2(2)$ \\
& & S1-C3-S2 & $120.4(2)$ \\
\hline
\end{tabular}

The structure of $\mathbf{2 b}$ was computed using density functional theory (DFT) methods (see the Experimental Section and the ESI), and found to be similar to the one computed for $\mathbf{2 a}$ at the same level (Figure 2 and Table 2). First we note that the optimized structure of $\mathbf{2 a}$ is in reasonable agreement with the one determined crystallographically, 
although the computed distances involving the metal atoms are a bit longer than the experimental figures in the solid state, as usually found in this type of calculations, ${ }^{14}$ and the degree of delocalization over the $\mathrm{S}-\mathrm{C}-\mathrm{S}$ skeleton is somewhat lower than anticipated, as judged from the more dissimilar C-S lengths of 1.673 and $1.741 \AA$. Yet, inspection of the molecular orbitals for $\mathbf{2 a}$ reveals the presence of a $\pi$-bonding interaction significantly delocalized over the $\mathrm{S}-\mathrm{C}-\mathrm{S}$ skeleton, represented by the HOMO-15 orbital (Figure 3). In contrast, the geometrical parameters for the SCNPh adduct $\mathbf{2 b}$ suggest a minimal delocalization of $\pi$-bonding over the $\mathrm{S}-\mathrm{C}-\mathrm{N}$ backbone, because the $\mathrm{C}-\mathrm{S}(1.781 \AA)$ and $\mathrm{C}-\mathrm{N}(1.285 \AA)$ lengths now approach respectively the reference values for single $(1.78 \AA)$ and double bonds $(1.27 \AA)$ between the corresponding atoms. ${ }^{11,12}$ As concerning the acid-base chemistry of these molecules, we note in the case of $\mathbf{2 a}$ that, among the frontier orbitals, the HOMO-2 and HOMO-3 orbitals have significant lone-pair character (uncoordinated S- and P-based respectively, Figure 3), but only one frontier orbital with these characteristics is found for $\mathbf{2 b}$ (HOMO-2, P-based lone pair). On the other hand, the negative charge at the $\mathrm{N}$ atom in $\mathbf{2 b}$ is significantly larger than the charge at the uncoordinated $S$ atom of 2a (NBO charges -0.52 and $-0.13 e$, respectively). Then we should expect that, under conditions of orbital control, electrophilic attack on $\mathbf{2 a}$ might occur at either the P or S sites for $\mathbf{2 a}$, but preferentially at the $\mathrm{P}$ site for $\mathbf{2} \mathbf{b}$. In contrast, the electrostatic term would clearly favour electrophilic attack on $\mathbf{2 b}$ specifically at the $\mathrm{N}$ site. As shown below, the reactivity of these molecules matches the above expectations.
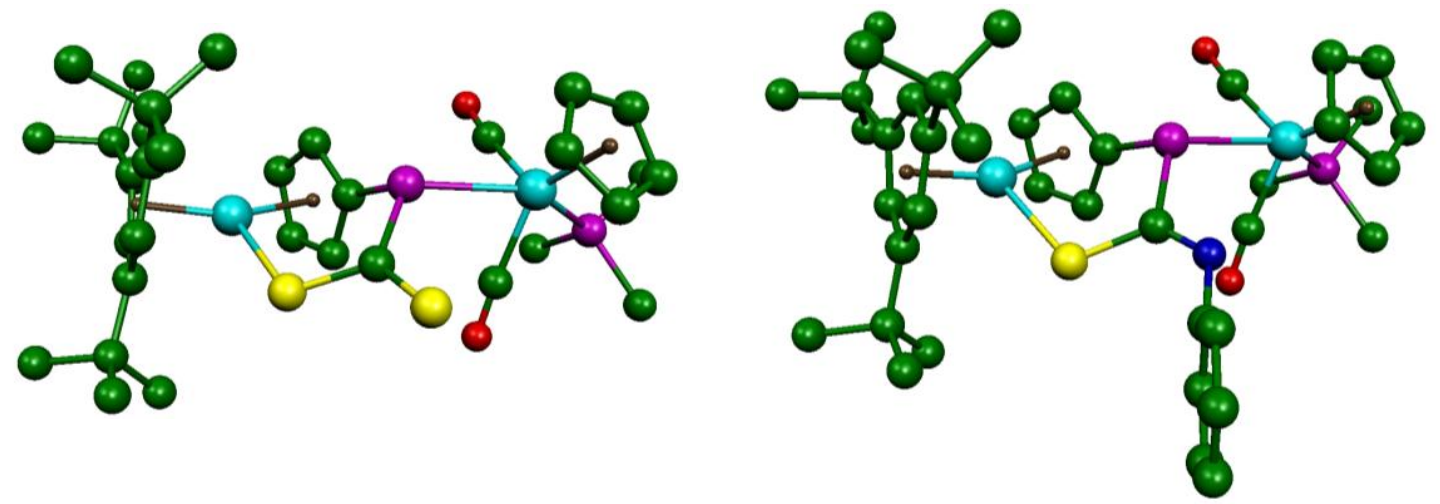

Figure 2. DFT-optimized structures for compounds $\mathbf{2 a}$ (left) and $\mathbf{2 b}$ (right) with H atoms omitted.

Table 2. Selected Bond Lengths $(\AA)$ computed for $\mathbf{2 a}$ and $\mathbf{2 b} .^{a}$

\begin{tabular}{llll}
\hline & 2a (exp) & 2a & 2b \\
\hline Mo1-P1 & $2.543(1)$ & 2.627 & 2.645 \\
Mo1-P2 & $2.464(1)$ & 2.490 & 2.484 \\
Mo2-S1 & $2.5231(9)$ & 2.601 & 2.606 \\
P1-C3 & $1.804(3)$ & 1.840 & 1.863 \\
P1-C9 & $1.831(4)$ & 1.830 & 1.829 \\
C3-S1 & $1.703(3)$ & 1.741 & 1.781 \\
C3-S2 & $1.680(3)$ & 1.673 & \\
C3-N & & & 1.285 \\
\hline
\end{tabular}

${ }^{a}$ Labeling scheme as shown in Figure 1 


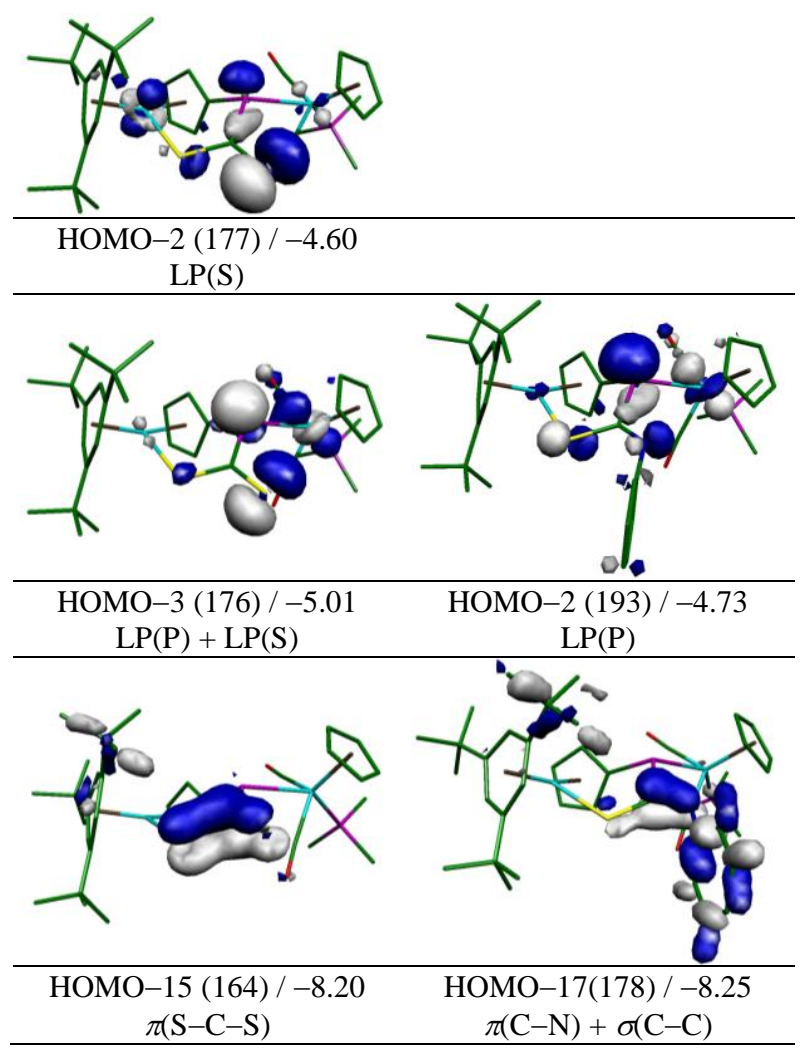

Figure 3. Selected molecular orbitals computed for compounds $\mathbf{2 a}$ (left) and $\mathbf{2 b}$ (right), with their energies (in $\mathrm{eV}$ ) and main bonding character indicated below. $\mathrm{H}$ atoms have been omitted.

Spectroscopic data in solution for compounds 2a,b (Table 3 and Experimental section) are consistent with the structures discussed above, but indicate the presence of dynamic effects for 2a. Their IR spectra display in each case two $\mathrm{C}-\mathrm{O}$ stretches with a pattern comparable to that of the parent complex $\mathbf{1}$, characteristic of transoid $\mathrm{M}(\mathrm{CO})_{2}$ oscillators, ${ }^{15}\left(\mathrm{C} 1-\mathrm{Mo} 1-\mathrm{C} 2=106.7(1)^{\mathrm{o}}\right.$ for $\mathbf{2 a}$ in the crystal), and their ${ }^{31} \mathrm{P}$ NMR spectra display quite shielded resonances for the bridging ligand at 21.6 and $-22.6 \mathrm{ppm}$ respectively, consistent with retention in solution of a phosphanyl-like pyramidal environment at a $\mathrm{P}$ atom bound to a single metal and bearing a lone electron pair. ${ }^{16} \mathrm{We}$ note that these shifts are comparable to the one measured for the molybdenum phosphanyl complex $\left[\mathrm{MoCp}\left(\mathrm{PPh}_{2}\right)(\mathrm{CO})_{2}\left(\mathrm{PMe}_{3}\right)\right](\delta \mathrm{P}-31.9 \mathrm{ppm}) .{ }^{17}$ The cumulene $\mathrm{C}$ atoms expectedly give rise to relatively deshielded and P-coupled resonances at 279.3 (2a) and 204.9 ppm (2b), not far from the values found for the related derivatives of the trigonal phosphinidene complex $\left[\mathrm{Mo}_{2} \mathrm{Cp}\left(\mu-\kappa^{1}: \kappa^{1}, \eta^{5}-\mathrm{PC}_{5} \mathrm{H}_{4}\right)(\mathrm{CO})_{2}\left(\eta^{6}-\mathrm{HMes} *\right){ }^{6}{ }^{6}\right.$ Other ${ }^{1} \mathrm{H}$ and ${ }^{13} \mathrm{C}$ NMR resonances of $\mathbf{2} \mathbf{b}$ are in agreement with the structure of the complex, devoid of any symmetry element. In contrast, the $\mathrm{CS}_{2}$ adduct $\mathbf{2 a}$ displays at room temperature single and broad resonances for each pair of $\mathrm{CO}$ and $\mathrm{CH}\left(\mathrm{C}_{5} \mathrm{H}_{4}\right)$ groups, thus indicating the occurrence in solution of a dynamic process creating an apparent plane of symmetry that bisects the $\mathrm{C}_{5} \mathrm{H}_{4}$ ring and the transoid $\mathrm{Mo}(\mathrm{CO})_{2}$ fragment. In agreement with this, the $\mathrm{CH}$ resonances further broadened on lowering the temperature, and eventually split into separated resonances, consistent with the static structure of the 
molecule. For instance, the averaged ${ }^{1} \mathrm{H}$ resonance at $5.36 \mathrm{ppm}$ yielded resonances at 5.71 and $4.85 \mathrm{ppm}$ at $223 \mathrm{~K}$, whereas the resonance at $4.51 \mathrm{ppm}$ split into resonances at 5.26 and $3.45 \mathrm{ppm}$. Although we did not measure the corresponding coalescence temperatures (certainly between $273 \mathrm{~K}$ and $233 \mathrm{~K}$ for the above resonances), still we can estimate a kinetic barrier of some $50 \mathrm{~kJ} / \mathrm{mol}$ for the corresponding dynamic process, ${ }^{18}$ which we assume to be a pyramidal inversion at the $\mathrm{P}$ atom. This proposal is sensible because, even if pyramidal inversion for tertiary phosphines usually involve high kinetic barriers above $130 \mathrm{~kJ} / \mathrm{mol},{ }^{19}$ pyramidal phosphanyl ligands bound to a single metal centre may undergo much faster inversion, ${ }^{20}$ with kinetic barriers comparable to the one estimated for $\mathbf{2 a}$ (cf. $45-55 \mathrm{~kJ} / \mathrm{mol}$ for different Pt complexes of type $\left[\mathrm{Pt}(\mathrm{dppe}) \mathrm{R}\left(\mathrm{PPhR}^{\prime}\right)\right]$, or $60 \mathrm{~kJ} / \mathrm{mol}$ for the tungsten complex $\left.\left[\mathrm{WCp}\left(\mathrm{P}^{i} \mathrm{Pr}_{2}\right)(\mathrm{CO})_{2}\left(\mathrm{PMe}_{3}\right)\right]\right) .^{21}$ 
Table 3. Selected IR, ${ }^{a}{ }^{31} \mathrm{P}\left\{{ }^{1} \mathrm{H}\right\}$ and ${ }^{13} \mathrm{C}\left\{{ }^{1} \mathrm{H}\right\}$ NMR Data ${ }^{b}$ for New Compounds

\begin{tabular}{|c|c|c|c|c|}
\hline Compound & $v(\mathrm{CO})$ & $\delta\left(\mathrm{PC}_{5} \mathrm{H}_{4}\right)$ & $\begin{array}{c}\delta\left(\mathrm{PMe}_{3}\right) \\
{\left[J_{\mathrm{PP}}\right]} \\
\end{array}$ & $\begin{array}{c}\delta(\mathrm{SCX}) \\
{\left[J_{\mathrm{PC}}\right]}\end{array}$ \\
\hline$\left[\mathrm{Mo}_{2} \mathrm{Cp}\left(\mu-\kappa^{1}: \kappa^{1}, \eta^{5}-\mathrm{PC}_{5} \mathrm{H}_{4}\right)(\mathrm{CO})_{2}\left(\eta^{6}-\mathrm{HMes}^{*}\right)\left(\mathrm{PMe}_{3}\right)\right](\mathbf{1})^{\mathrm{c}}$ & $1910(\mathrm{~m}), 1842(\mathrm{vs})^{d}$ & 122.0 & $27.3[26]^{e}$ & \\
\hline$\left[\mathrm{Mo}_{2} \mathrm{Cp}\left\{\mu-\kappa_{\mathrm{p}}^{1}: \kappa_{\mathrm{s}}^{1}, \eta^{5}-\mathrm{P}\left(\mathrm{CS}_{2}\right) \mathrm{C}_{5} \mathrm{H}_{4}\right\}(\mathrm{CO})_{2}\left(\eta^{6}-\mathrm{HMes}^{*}\right)\left(\mathrm{PMe}_{3}\right)\right](\mathbf{2 a})$ & $1929(\mathrm{~m}), 1850(\mathrm{vs})^{d}$ & 21.6 & $23.6[18]^{e}$ & $279.3[60]^{e}$ \\
\hline$\left[\mathrm{Mo}_{2} \mathrm{Cp}\left\{\mu-\kappa_{\mathrm{p}}^{1}: \kappa^{1} \mathrm{~s}, \eta^{5}-\mathrm{P}(\mathrm{C}(\mathrm{NPh}) \mathrm{S}) \mathrm{C}_{5} \mathrm{H}_{4}\right\}(\mathrm{CO})_{2}\left(\eta^{6}-\mathrm{HMes}^{*}\right)\left(\mathrm{PMe}_{3}\right)\right](\mathbf{2 b})$ & $1922(\mathrm{~m}), 1845(\mathrm{vs})^{d}$ & -22.6 & $24.3[16]^{e}$ & $204.9[25]^{e}$ \\
\hline$\left[\mathrm{Mo}_{2} \mathrm{Cp}\left\{\mu-\kappa_{\mathrm{o}}^{1}: \kappa_{\mathrm{s}}^{1}, \eta^{5}-\mathrm{OP}(\mathrm{O})\left(\mathrm{CS}_{2}\right) \mathrm{C}_{5} \mathrm{H}_{4}\right\}(\mathrm{CO})_{2}\left(\eta^{6}-\mathrm{HMes}^{*}\right)\left(\mathrm{PMe}_{3}\right)\right](\mathbf{3 a})$ & $1968(\mathrm{~m}), 1886(\mathrm{vs})$ & 13.0 & $18.5[<3]$ & $204.5[<2]$ \\
\hline$\left[\mathrm{Mo}_{2} \mathrm{Cp}\left\{\mu-\kappa_{\mathrm{o}}^{1}: \kappa_{\mathrm{s}}^{1}, \eta^{5}-\mathrm{OP}(\mathrm{O})(\mathrm{C}(\mathrm{NPh}) \mathrm{S}) \mathrm{C}_{5} \mathrm{H}_{4}\right\}(\mathrm{CO})_{2}\left(\eta^{6}-\mathrm{HMes}^{*}\right)\left(\mathrm{PMe}_{3}\right)\right](\mathbf{3 b})$ & $1958(\mathrm{~m}), 1875(\mathrm{vs})$ & 30.6 & $19.7[<3]^{e}$ & \\
\hline$\left[\mathrm{Mo}_{2} \mathrm{Cp}\left\{\mu-\kappa_{\mathrm{p}}^{1}: \kappa_{\mathrm{s}}^{1}, \eta^{5}-\mathrm{P}(\mathrm{S})\left(\mathrm{CS}_{2}\right) \mathrm{C}_{5} \mathrm{H}_{4}\right\}(\mathrm{CO})_{2}\left(\eta^{6}-\mathrm{HMes}^{*}\right)\left(\mathrm{PMe}_{3}\right)\right](4)$ & $1949(w), 1868(v s)$ & 102.0 & $22.2[24]$ & $268.4[<2]$ \\
\hline $\begin{array}{l}{\left[\mathrm{Mo}_{2} \mathrm{Cp}\left\{\mu-\kappa_{\mathrm{P}}^{1}: \kappa_{\mathrm{S}}^{1}, \eta^{5}-\mathrm{P}(\mathrm{S})(\mathrm{C}(\mathrm{SMe}) \mathrm{S}) \mathrm{C}_{5} \mathrm{H}_{4}\right\}(\mathrm{CO})_{2}\left(\eta^{6}-\mathrm{HMes}^{*}\right)\left(\mathrm{PMe}_{3}\right)\right]\left(\mathrm{BAr}_{4}{ }_{4}\right)} \\
\text { (5) }\end{array}$ & $1961(\mathrm{~m}), 1881(\mathrm{vs})$ & 107.4 & $19.5[24]$ & $233.7[<2]$ \\
\hline $\begin{array}{l}{\left[\mathrm{Mo}_{2} \mathrm{Cp}\left\{\mu-\kappa_{\mathrm{P}}^{1}: \kappa_{\mathrm{S}}^{1}, \eta^{5}-\mathrm{P}(\mathrm{S})(\mathrm{C}(\mathrm{SMe}) \mathrm{S}) \mathrm{C}_{5} \mathrm{H}_{4}\right\}(\mathrm{CO})_{2}\left(\eta^{6}-\mathrm{HMes}^{*}\right)\left(\mathrm{PMe}_{3}\right)\right]\left(\mathrm{BPh}_{4}\right)} \\
\left(\mathbf{5}^{\prime}\right)\end{array}$ & 1960 (m), 1881 (vs) & 107.5 & $19.6[24]$ & \\
\hline$\left[\mathrm{Mo}_{2} \mathrm{Cp}\left\{\mu-\kappa_{\mathrm{P}}^{1}: \kappa_{\mathrm{s}}^{1}, \eta^{5}-\mathrm{PMe}\left(\mathrm{CS}_{2}\right) \mathrm{C}_{5} \mathrm{H}_{4}\right\}(\mathrm{CO})_{2}\left(\eta^{6}-\mathrm{HMes}^{*}\right)\left(\mathrm{PMe}_{3}\right)\right]\left(\mathrm{BAr}_{4}{ }_{4}\right)(\mathbf{6 a})$ & $1971(\mathrm{~m}), 1892(\mathrm{vs})$ & 76.4 & $18.8[20]$ & $254.0[12]$ \\
\hline$\left[\mathrm{Mo}_{2} \mathrm{Cp}\left\{\mu-\kappa_{\mathrm{p}}^{1}: \kappa_{\mathrm{s}}^{1}, \eta^{5}-\mathrm{PMe}\left(\mathrm{CS}_{2}\right) \mathrm{C}_{5} \mathrm{H}_{4}\right\}(\mathrm{CO})_{2}\left(\eta^{6}-\mathrm{HMes}^{*}\right)\left(\mathrm{PMe}_{3}\right)\right]\left(\mathrm{BPh}_{4}\right)\left(\mathbf{6 a}^{\prime}\right)$ & $1973(\mathrm{~m}), 1894(\mathrm{vs})$ & 77.0 & $18.6[20]$ & \\
\hline $\begin{array}{l}{\left[\mathrm{Mo}_{2} \mathrm{Cp}\left\{\mu-\kappa_{\mathrm{p}}^{1}: \kappa_{\mathrm{s}}^{1}, \eta^{5}-\mathrm{PMe}(\mathrm{C}(\mathrm{NPh}) \mathrm{S}) \mathrm{C}_{5} \mathrm{H}_{4}\right\}(\mathrm{CO})_{2}\left(\eta^{6}-\mathrm{HMes}^{*}\right)\left(\mathrm{PMe}_{3}\right)\right]\left(\mathrm{BAr}_{4}{ }_{4}\right)} \\
(\mathbf{6 b})\end{array}$ & $1972(\mathrm{~m}), 1893$ (vs) & 59.2 & $18.5[20]$ & \\
\hline$\left[\mathrm{Mo}_{2} \mathrm{Cp}\left\{\mu-\kappa_{\mathrm{p}}^{1} \mathrm{~K}_{\mathrm{s}}, \eta^{5}-\mathrm{P}(\mathrm{C}(\mathrm{SMe}) \mathrm{S}) \mathrm{C}_{5} \mathrm{H}_{4}\right\}(\mathrm{CO})_{2}\left(\eta^{6}-\mathrm{HMes}^{*}\right)\left(\mathrm{PMe}_{3}\right)\right]\left(\mathrm{BAr}_{4}^{\prime}\right)(7)$ & 1947 (m), $1873(\mathrm{vs})$ & 64.6 & $20.4[13]$ & $243.4[51]$ \\
\hline $\begin{array}{l}{\left[\mathrm{Mo}_{2} \mathrm{Cp}\left\{\mu-\kappa_{\mathrm{p}}^{1}: \kappa_{\mathrm{S}}^{1}, \eta^{5}-\mathrm{P}\left(\mathrm{CH}_{2} \mathrm{Cl}\right)(\mathrm{C}(\mathrm{NPh}) \mathrm{S}) \mathrm{C}_{5} \mathrm{H}_{4}\right\}(\mathrm{CO})_{2}\left(\eta^{6}-\right.\right.} \\
\left.\text { HMes })\left(\mathrm{PMe}_{3}\right)\right]\left(\mathrm{BAr}_{4}^{\prime}\right)(\mathbf{8})\end{array}$ & 1977 (m), 1901 (vs) & 77.7 & $18.5[18]$ & $191.1[66]$ \\
\hline $\begin{array}{l}{\left[\mathrm{Mo}_{2} \mathrm{Cp}\left\{\mu-\kappa_{\mathrm{p}}^{1}: \kappa^{1} \mathrm{~s}, \eta^{5}-\mathrm{PMe}(\mathrm{C}(\mathrm{SMe}) \mathrm{S}) \mathrm{C}_{5} \mathrm{H}_{4}\right\}(\mathrm{CO})_{2}\left(\eta^{6}-\mathrm{HMes}^{*}\right)\left(\mathrm{PMe}_{3}\right)\right]\left(\mathrm{BAr}_{4}{ }_{4}\right)_{2}} \\
\text { (9) }\end{array}$ & $1981(\mathrm{~m}), 1908(\mathrm{vs})$ & 86.8 & $16.4[20]$ & $208.0[17]$ \\
\hline $\begin{array}{l}{\left[\mathrm{Mo}_{2} \mathrm{Cp}\left\{\mu-\kappa_{\mathrm{p}}^{1}: \kappa_{\mathrm{s}}^{1}, \eta^{5}-\mathrm{P}(\mathrm{C}(\mathrm{NHPh}) \mathrm{S}) \mathrm{C}_{5} \mathrm{H}_{4}\right\}(\mathrm{CO})_{2}\left(\eta^{6}-\mathrm{HMes}^{*}\right)\left(\mathrm{PMe}_{3}\right)\right]\left(\mathrm{BAr}_{4}{ }^{\prime}\right)} \\
(\mathbf{1 0}) .\end{array}$ & 1944 (m), 1871 (vs) & 30.5 & $20.1[14]$ & $225.9[51]$ \\
\hline
\end{tabular}

${ }^{a}$ Recorded in dichloromethane solution, with $\mathrm{C}-\mathrm{O}$ stretching bands $[v(\mathrm{CO})]$ in $\mathrm{cm}^{-1} .{ }^{b}$ Recorded in $\mathrm{CD}_{2} \mathrm{Cl}_{2}$ solution at $162.12\left({ }^{31} \mathrm{P}\right)$ or $100.62 \mathrm{MHz}\left({ }^{13} \mathrm{C}\right)$, and $298 \mathrm{~K}$ unless otherwise stated, with chemical shifts $(\delta)$ in ppm, and P-P and P-C couplings $\left(J_{\mathrm{PP}}\right.$ and $\left.J_{\mathrm{PC}}\right)$ in Hz. ${ }^{c}$ Data taken from reference $5 .{ }^{d}$ In toluene. ${ }^{e}$ In $\mathrm{C}_{6} \mathrm{D}_{6}$ solution.

\section{Reactions of compounds 2 with elemental oxygen and sulfur}

The phosphinidene-cumulene adducts $\mathbf{2 a , b}$ are quite air-sensitive species which readily react with adventitious dioxygen to give the corresponding derivatives $\left[\operatorname{Mo}_{2} \mathrm{Cp}\{\mu\right.$ $\left.\left.\kappa^{1}{ }_{\mathrm{O}}: \kappa_{\mathrm{S}}{ }_{\mathrm{S}}, \eta^{5}-\mathrm{OP}(\mathrm{O})(\mathrm{C}(\mathrm{X}) \mathrm{S}) \mathrm{C}_{5} \mathrm{H}_{4}\right\}(\mathrm{CO})_{2}\left(\eta^{6}-\mathrm{HMes}^{*}\right)\left(\mathrm{PMe}_{3}\right)\right](\mathrm{X}=\mathrm{S}(\mathbf{3 a}), \mathrm{NPh}(\mathbf{3 b}))$, these following from incorporation of two oxygen atoms, one inserted into the remaining Mo-P bond and one added to the $\mathrm{P}$ site in a terminal fashion, thus completing the formation of a phosphinate-like ligand (Scheme 3). This transformation was quite selective in the solid state, but in solution was accompanied by extensive decomposition and had no use for preparative purposes. Attempts to form compounds $\mathbf{3}$ from $\mathbf{2}$ in solution by using more selective oxygen sources such as ethylene oxide or nitrous oxide were unsuccessful.

Compound 2a also reacted readily with elemental sulfur $\left(\mathrm{S}_{8}\right)$, but only a single $\mathrm{S}$ atom was added to the structure in that case, specifically at the $\mathrm{P}$ site, to give the corresponding sulfide derivative $\left[\mathrm{Mo}_{2} \mathrm{Cp}\left\{\mu-\kappa^{1}{ }_{\mathrm{P}}: \kappa^{1}{ }_{\mathrm{S}}, \eta^{5}-\mathrm{P}(\mathrm{S})\left(\mathrm{CS}_{2}\right) \mathrm{C}_{5} \mathrm{H}_{4}\right\}(\mathrm{CO})_{2}\left(\eta^{6}-\right.\right.$ HMes*)( $\left.\mathrm{PMe}_{3}\right)$ ] (4). Although compound 4 could be purified in the usual way, it proved to be quite air-sensitive and progressively decomposed upon attempts of crystallization. 
However, it could be stabilized through selective methylation at the $\mathrm{C}=\mathrm{S}$ group upon reaction with $\mathrm{Me}_{2} \mathrm{SO}_{4}$ to give, after pertinent anion exchanges, more stable borate salts $\left[\mathrm{Mo}_{2} \mathrm{Cp}\left\{\mu-\kappa^{1}{ }_{\mathrm{P}}: \kappa^{1}{ }_{\mathrm{s}}, \eta^{5}-\mathrm{P}(\mathrm{S})(\mathrm{C}(\mathrm{SMe}) \mathrm{S}) \mathrm{C}_{5} \mathrm{H}_{4}\right\}(\mathrm{CO})_{2}\left(\eta^{6}-\mathrm{HMes}^{*}\right)\left(\mathrm{PMe}_{3}\right)\right]\left(\mathrm{BX}_{4}\right) \quad$ which could be fully characterized $\left(\mathrm{X}=\mathrm{Ar}^{\prime}(\mathbf{5}), \mathrm{Ph}\left(\mathbf{5}^{\prime}\right) ; \mathrm{Ar}^{\prime}=3,5-\mathrm{C}_{6} \mathrm{H}_{3}\left(\mathrm{CF}_{3}\right)_{2}\right)$. The isothiocyanate adduct $\mathbf{2 b}$ also reacted with elemental sulfur in a quite selective way, to give a product identified by ${ }^{31} \mathrm{P}$ NMR resonances at 83.8 and $22.2 \mathrm{ppm}\left(J_{\mathrm{PP}}=24 \mathrm{~Hz}\right)$, likely analogous to $4\left(\delta_{\mathrm{P}} 102.0\right.$ and $\left.22.2 \mathrm{ppm}, J_{\mathrm{PP}}=24 \mathrm{~Hz}\right)$, as concluded from their similar ${ }^{31} \mathrm{P}$ resonances. However, this product was much less stable than $\mathbf{4}$ and could not be isolated or properly characterized.

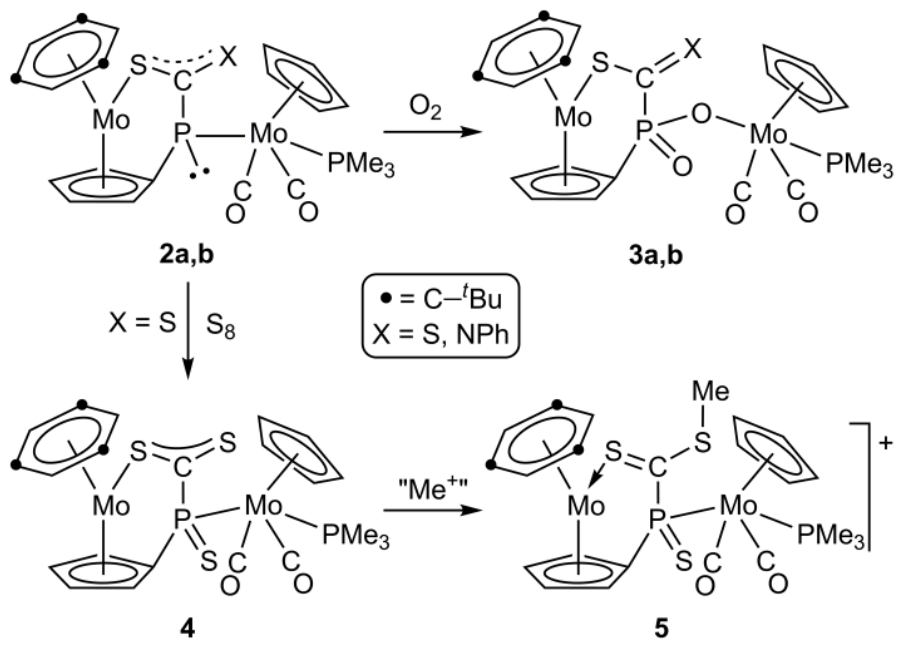

Scheme 3

\section{Structural characterization of complexes 3}

The molecule of $\mathbf{3 b}$ in the crystal (Figure 4 and Table 4) displays a polyfunctional phosphinate-like $\mathrm{RP}(\mathrm{O})(\mathrm{C}(\mathrm{NR}) \mathrm{S}) \mathrm{O}$ ligand bridging two molybdenum atoms, it being bound to the transoid $\mathrm{MoCp}(\mathrm{CO})_{2}\left(\mathrm{PMe}_{3}\right)$ fragment via an $\mathrm{O}$ atom $(\mathrm{Mo1}-\mathrm{O} 3=2.156(2)$ $\AA$ ) and to the arene-metal fragment as in the precursor $\mathbf{2 b}$, that is, via the $\mathrm{S}$ atom $\left(\mathrm{Mo} 2-\mathrm{S}=2.5455(8) \AA\right.$ ) and the $\mathrm{C}_{5} \mathrm{H}_{4}$ ring (in the usual $\eta^{5}$ fashion). The terminal oxygen at the $\mathrm{P}$ atom displays a short distance as expected $(\mathrm{P}-\mathrm{O} 4=1.484(2) \AA$ ), but the metal-bound oxygen also displays a quite short $\mathrm{P}-\mathrm{O}$ separation of 1.511(2) $\AA$. This is a feature commonly found for terminal phosphinato complexes in general (cf. 1.496 and $1.534 \AA$ in $\left.\left[\mathrm{Zr}_{2} \mathrm{Cp}_{2}(\mu-\mathrm{O})_{2}\left(\mu-\mathrm{O}_{2} \mathrm{PMePh}\right)_{2}\left(\kappa^{1}-\mathrm{O}_{2} \mathrm{PMePh}\right)_{2}\right]\right),{ }^{22}$ although we note that only a few organometallic complexes having this sort of ligands have been structurally characterized to date, none of them having group 6 metal atoms. We finally note that the presence of two additional $\mathrm{O}$ atoms at the organophosphorus ligand in $\mathbf{3 b}$ has little effect on the corresponding S-C-N chain, which displays S-C (1.755(3) $\AA$ ) and $\mathrm{C}-\mathrm{N}$ (1.276(4) $\AA$ ) lengths comparable to those computed for the precursor $\mathbf{2 b}$, in any case consistent with the formulation of essentially single and double bonds respectively, and a planar environment around the $\mathrm{C} 3$ atom. 


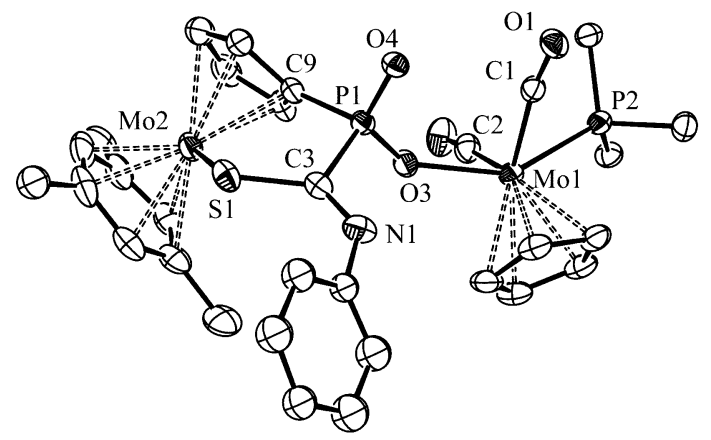

Figure 4. ORTEP diagram (30\% probability) of compound $\mathbf{3 b}$, with $\mathrm{H}$ atoms and ${ }^{t} \mathrm{Bu}$ groups (except their $\mathrm{C}^{1}$ atoms) omitted for clarity.

Table 4. Selected Bond Lengths $(\AA)$ and Angles $\left(^{\circ}\right)$ for Compound $\mathbf{3 b}$.

\begin{tabular}{llll}
\hline Mo1-P2 & $2.4741(7)$ & P2-Mo1-O3 & $142.5(1)$ \\
Mo1-O3 & $2.156(2)$ & C1-Mo1-C2 & $108.6(1)$ \\
Mo1-C1 & $1.983(3)$ & P2-Mo1-C1 & $77.5(1)$ \\
Mo1-C2 & $1.997(3)$ & P2-Mo1-C2 & $74.8(1)$ \\
Mo2-S1 & $2.5455(8)$ & O4-P1-C9 & $110.2(1)$ \\
P1-C3 & $1.824(3)$ & O4-P1-C3 & $110.6(1)$ \\
P1-C9 & $1.801(3)$ & O4-P1-O3 & $120.1(1)$ \\
P1-O3 & $1.511(2)$ & Mo1-O3-P1 & $136.6(1)$ \\
P1-O4 & $1.484(2)$ & P1-C3-S1 & $114.7(2)$ \\
C3-S1 & $1.755(3)$ & P1-C3-N1 & $115.4(2)$ \\
C3-N1 & $1.276(4)$ & S1-C3-N1 & $129.8(2)$ \\
N1-C14 & $1.374(7)$ & C3-N1-C14 & $130.5(4)$ \\
\hline
\end{tabular}

Spectroscopic data in solution for compounds 3a,b (Table 3 and Experimental Section) are consistent with the structure found in the solid state for $\mathbf{3 b}$, but again indicate the presence of dynamic effects for the $\mathrm{CS}_{2}$ derivative 3a. Their IR spectra in dichloromethane solution display in each case two $\mathrm{C}-\mathrm{O}$ stretching bands comparable to those of the precursors $\mathbf{2 a , b}$, but their frequency is some $35 \mathrm{~cm}^{-1}$ higher, as expected from the replacement of a $P$-donor with an $O$-donor group at the dicarbonyl metal fragment. In contrast, the ${ }^{31} \mathrm{P}$ chemical shift of the $\mathrm{PC}_{5} \mathrm{H}_{4}$ group undergoes different changes upon oxidation, a slight decrease for the $\mathrm{CS}_{2}$ adduct, by some $10 \mathrm{ppm}$, and a more significant increase for the SCNPh adduct, by some $40 \mathrm{ppm}$. However, in both cases the oxidation process is accompanied by disappearance of coupling between the $\mathrm{P}$ nuclei, consistent with insertion of oxygen into the Mo-P bond at the corresponding precursors 2.

The ${ }^{1} \mathrm{H}$ NMR spectrum of $\mathbf{3 b}$ displays four separated resonances for the $\mathrm{C}_{5} \mathrm{H}_{4}$ group of the bridging ligand, in agreement with the solid-state structure of the molecule, which is devoid of any symmetry element. In contrast, the room temperature ${ }^{1} \mathrm{H}$ NMR spectrum of the $\mathrm{CS}_{2}$ derivative 3a displays just two resonances at 5.22 and 4.78 ppm for this group, each of them corresponding to $2 \mathrm{H}$ atoms. In line with this, the corresponding ${ }^{13} \mathrm{C}\left\{{ }^{1} \mathrm{H}\right\}$ NMR spectrum displays just two well-resolved doublets at 90.3 $\left(J_{\mathrm{PC}}=10 \mathrm{~Hz}\right)$ and $84.1 \mathrm{ppm}\left(J_{\mathrm{PC}}=9 \mathrm{~Hz}\right)$ for the corresponding carbon atoms, and a 
doublet at $233.1 \mathrm{ppm}\left(J_{\mathrm{PC}}=27 \mathrm{~Hz}\right)$ for the two carbonyl ligands of the molecule. All of this is indicative of the occurrence in solution of a fast dynamic process generating an apparent symmetry plane bisecting the $\mathrm{C}_{5} \mathrm{H}_{4}$ group of the bridging ligand and the transoid $\mathrm{MoCp}(\mathrm{CO})_{2}\left(\mathrm{PMe}_{3}\right)$ fragment. For this we propose an exchange process whereby both $\mathrm{O}$ atoms of the bridging ligand would be alternatively involved in $O$ binding to the dicarbonyl metal fragment (Figure 5). The kinetic barrier for such a process would be very low, since the $\mathrm{C}_{5} \mathrm{H}_{4}$ resonances of $\mathbf{3 a}$ did not undergo significant changes upon reducing the solution temperature down to $203 \mathrm{~K}$.

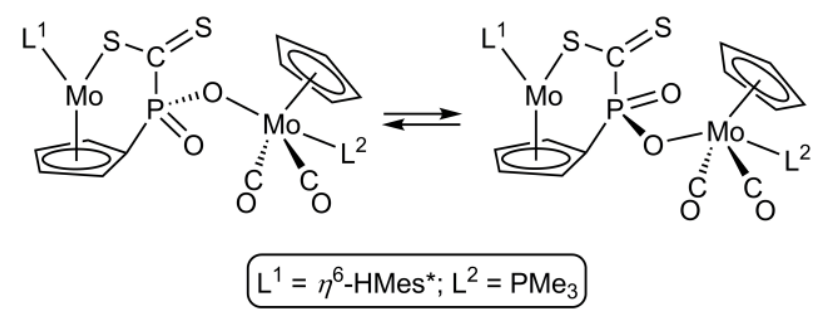

Figure 5. Simplified representation of the fluxional process proposed for $\mathbf{3 a}$ in solution.

\section{Structure of sulfido derivatives 4 and 5}

Although the high air-sensitivity of compound $\mathbf{4}$ prevented the growing of suitable crystals for an X-ray study, we were able to do it for the tetraphenylborate salt of its methylated derivative $\left(5^{\prime}\right)$. The structure of the cation in this salt (Figure 6 and Table 5) can be derived from that of the precursor $\mathbf{2 a}$ after adding a terminal sulfur atom at the $\mathrm{P}$ site $(\mathrm{P}-\mathrm{S} 1=1.987(1) \AA)$ and a methyl cation at the uncoordinated $\mathrm{S}$ atom of the $\mathrm{CS}_{2}$ group (S3-C4 = 1.794(3) Å). This yields a polyfunctional thiophosphinite ligand bound to the metal fragments much in the same way as the parent compound $\mathbf{2 a}$, but with Mo-S2 (2.4547(7) A) and Mo-P1 (2.4797(7) Å) distances shortened by ca. $0.07 \AA$. The environment around the central $\mathrm{C} 3$ atom remains planar, but the $\pi$-bonding interaction at the $\mathrm{CS}_{2}$ moiety is more localized on the $\mathrm{C} 3-\mathrm{S} 2$ bond, since the corresponding length of 1.646(3) $\AA$ approaches the reference double-bond length of $1.62 \AA$, while the C3-S3 length of 1.723(3) $\AA$ correspondingly moves towards the reference single-bond length of $1.78 \AA$. We finally note that only a few $P$-bound thiophosphinito complexes have been structurally characterized so far, only two of them involving group 6 metals. ${ }^{23}$ As found in $\mathbf{5}^{\prime}$, they all expectedly display short P-S distances (in the range 1.97-2.03 $\AA$ ), well below the reference single-bond length of $2.12 \AA{ }^{11}$ consistent with substantial multiplicity in those bonds. 


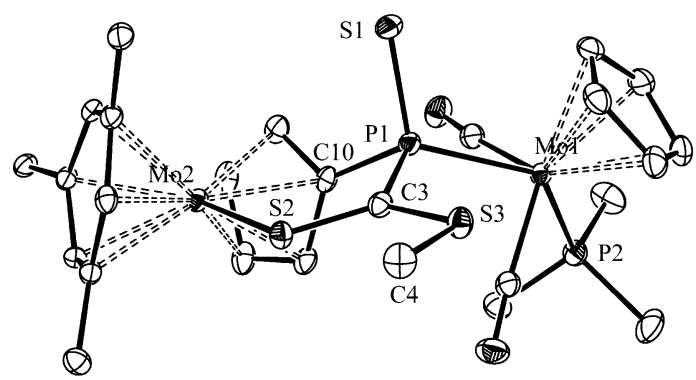

Figure 6. ORTEP diagram (30\% probability) of the cation in compound $\mathbf{5}^{\prime}$, with $\mathrm{H}$ atoms and ${ }^{t} \mathrm{Bu}$ groups (except their $\mathrm{C}^{1}$ atoms) omitted for clarity.

Table 5. Selected Bond Lengths ( $(\AA)$ and Angles $\left({ }^{\circ}\right)$ for Compound $5^{\prime}$.

\begin{tabular}{llll}
\hline Mo1-P1 & $2.4797(7)$ & P1-Mo1-P2 & $133.01(2)$ \\
Mo1-P2 & $2.4740(7)$ & C1-Mo1-C2 & $109.0(1)$ \\
Mo1-C1 & $1.979(3)$ & C1-Mo1-P1 & $75.2(1)$ \\
Mo1-C2 & $1.976(3)$ & C2-Mo1-P1 & $80.0(1)$ \\
Mo2-S2 & $2.4547(7)$ & S1-P1-Mo1 & $116.5(4)$ \\
P1-S1 & $1.987(1)$ & S1-P1-C10 & $108.8(1)$ \\
P1-C3 & $1.842(3)$ & S1-P1-C3 & $104.5(1)$ \\
P1-C10 & $1.821(3)$ & P1-C3-S2 & $119.5(2)$ \\
C3-S2 & $1.646(3)$ & P1-C3-S3 & $116.6(2)$ \\
C3-S3 & $1.723(3)$ & S2-C3-S3 & $123.8(2)$ \\
S3-C4 & $1.794(3)$ & C3-S3-C4 & $102.6(1)$ \\
\hline
\end{tabular}

Spectroscopic data in solution for $\mathbf{5}$ and 5' (Table 3 and Experimental Section) are similar to each other and consistent with the structure found in the solid state for the latter salt. In particular, the IR spectra display in each case two $\mathrm{C}-\mathrm{O}$ stretches comparable to those of the parent compound $\mathbf{2 a}$, but some $30 \mathrm{~cm}^{-1}$ more energetic, an expected effect of the oxidation operated at the $\mathrm{P}$ atom and methylation at one of the $\mathrm{S}$ atoms of the bridging ligand. This ligand gives rise to a ${ }^{31} \mathrm{P}$ NMR resonance significantly deshielded ( $\left.\delta_{\mathrm{P}} 107.5 \mathrm{ppm}\right)$ when compared to the parent complex, an effect attributed to the presence of the $\mathrm{P}=\mathrm{S}$ moiety, while the coupling of $24 \mathrm{~Hz}$ to the phosphine ligand denotes the retention of the $\mathrm{P}-\mathrm{Mo}$ bond in the bridging ligand. This ligand also gives rise to a quite deshielded ${ }^{13} \mathrm{C}$ NMR resonance at $233 \mathrm{ppm}$, which is consistent with the planar environment of the $\mathrm{CS}_{2}$ moiety featured in the solid state. Other NMR resonances of the cation are as expected and deserve no particular comment.

Spectroscopic data in solution for compound 4 (Table 3 and Experimental Section) are comparable to those of the methylated derivatives $\mathbf{5}$ and $\mathbf{5}^{\prime}$ discussed above, indicating a strong structural relationship between all these species. Almost no change in the ${ }^{31} \mathrm{P}$ NMR parameters takes place upon methylation at the uncoordinated $\mathrm{S}$ atom of 4 , while this causes a moderate increase of some $12 \mathrm{~cm}^{-1}$ on the $\mathrm{C}-\mathrm{O}$ stretching bands of the dicarbonyl metal fragment, as expected. However, the cumulene carbon atom of 4 gives rise to a quite deshielded ${ }^{13} \mathrm{C}$ NMR resonance at $268.4 \mathrm{ppm}$, actually much closer 
to that of $\mathbf{2 a}$ (279.3 ppm vs. 233 ppm for $\mathbf{5}$ ), this suggesting the retention of extensive $\pi$ bonding delocalization over the $\mathrm{S}-\mathrm{C}-\mathrm{S}$ backbone in this compound.

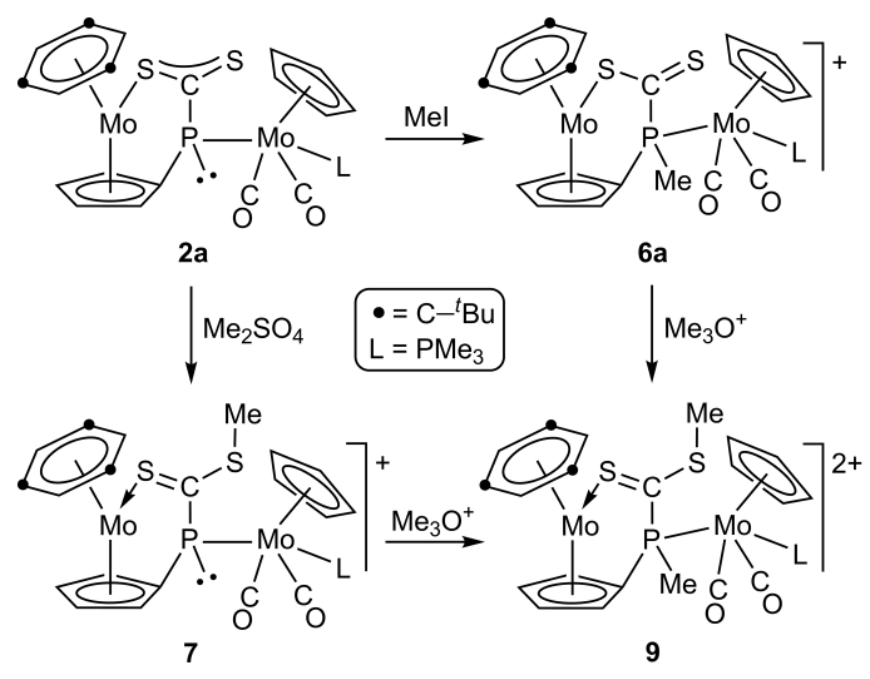

Scheme 4

\section{Methylation and related reactions of complexes 2}

The $\mathrm{CS}_{2}$ adduct $2 \mathbf{a}$ can be methylated at either the $\mathrm{P}$ atom or at the uncoordinated $\mathrm{S}$ atom of its bridging ligand, depending on the reagent used. Methylation at the P site occurs preferentially when using a mild reagent as MeI; this reaction actually takes place rapidly at room temperature to give the phosphanyldithioformato derivative $\left[\mathrm{Mo}_{2} \mathrm{Cp}\left\{\mu-\kappa_{\mathrm{P}}^{1}: \kappa^{1}{ }_{\mathrm{S}}, \eta^{5}-\mathrm{PMe}\left(\mathrm{CS}_{2}\right) \mathrm{C}_{5} \mathrm{H}_{4}\right\}(\mathrm{CO})_{2}\left(\eta^{6}-\mathrm{HMes}^{*}\right)\left(\mathrm{PMe}_{3}\right)\right] \mathrm{I}$ as major product which, after pertinent anion exchanges, could be purified and isolated as the corresponding borate salts $\left[\mathrm{Mo}_{2} \mathrm{Cp}\left\{\mu-\kappa_{\mathrm{p}}^{1}: \kappa_{\mathrm{S}}^{1}, \eta^{5}-\mathrm{PMe}\left(\mathrm{CS}_{2}\right) \mathrm{C}_{5} \mathrm{H}_{4}\right\}(\mathrm{CO})_{2}\left(\eta^{6}-\right.\right.$ $\left.\left.\mathrm{HMes}^{*}\right)\left(\mathrm{PMe}_{3}\right)\right]\left(\mathrm{BX}_{4}\right)\left(\mathrm{X}=\mathrm{Ar}^{\prime}(\mathbf{6 a}), \mathrm{Ph}\left(\mathbf{6 \mathbf { a } ^ { \prime }}\right) ; \mathrm{Ar}^{\prime}=3,5-\mathrm{C}_{6} \mathrm{H}_{3}\left(\mathrm{CF}_{3}\right)_{2}\right.$ or $)$ in yields close to $60 \%$ (Scheme 4). However, small amounts of the corresponding $S$-methylated derivatives $\quad\left[\mathrm{Mo}_{2} \mathrm{Cp}\left\{\mu-\kappa^{1}{ }_{\mathrm{p}}: \kappa_{\mathrm{S}}, \eta^{5}-\mathrm{P}(\mathrm{C}(\mathrm{SMe}) \mathrm{S}) \mathrm{C}_{5} \mathrm{H}_{4}\right\}(\mathrm{CO})_{2}\left(\eta^{6}-\mathrm{HMes}^{*}\right)\left(\mathrm{PMe}_{3}\right)\right]\left(\mathrm{BX}_{4}\right)$ $\left(\mathbf{7 a}, 7 \mathbf{a}^{\prime}\right)($ ca. $20 \%)$ were also obtained in these reactions. In contrast, reaction of $\mathbf{2 a}$ with the stronger reagent $\mathrm{Me}_{2} \mathrm{SO}_{4}$ gave exclusively the above $S$-methylated derivative, which was isolated analogously as the corresponding borate salt 7a in ca. 90\% yield. Finally, reaction of $\mathbf{2 a}$ with 2 equiv of the oxonium salt $\left[\mathrm{Me}_{3} \mathrm{O}\right] \mathrm{BF}_{4}$ accomplished methylation at both nucleophilic sites of this neutral molecule, to yield the dipositive cation $\left[\mathrm{Mo}_{2} \mathrm{Cp}\left\{\mu-\kappa^{1}{ }_{\mathrm{P}}: \kappa_{\mathrm{s}}^{1}, \eta^{5}-\mathrm{PMe}(\mathrm{C}(\mathrm{SMe}) \mathrm{S}) \mathrm{C}_{5} \mathrm{H}_{4}\right\}(\mathrm{CO})_{2}\left(\eta^{6} \text {-HMes } *\right)\left(\mathrm{PMe}_{3}\right)\right]^{2+}$, which was conveniently isolated as the corresponding borate salt $\left[\operatorname{Mo}_{2} \operatorname{Cp}\left\{\mu-\kappa^{1}{ }_{\mathrm{p}}^{1} \kappa_{\mathrm{S}}^{1}, \eta^{5}-\right.\right.$ $\left.\left.\mathrm{PMe}(\mathrm{C}(\mathrm{SMe}) \mathrm{S}) \mathrm{C}_{5} \mathrm{H}_{4}\right\}(\mathrm{CO})_{2}\left(\eta^{6}-\mathrm{HMes}^{*}\right)\left(\mathrm{PMe}_{3}\right)\right]\left(\mathrm{BAr}_{4}{ }_{4}\right)_{2}(\mathbf{9})$ in $80 \%$ yield. As expected, compound 9 was also obtained when reacting either $6 \mathbf{a}$ or $7 \mathbf{a}$ with the above oxonium salt (Scheme 4).

In contrast to the above behaviour, the $\mathrm{SCNPh}$ adduct $\mathbf{2 b}$ was only methylated at the $\mathrm{P}$ site when using any of the above reagents, to give the corresponding derivative 
$\left[\mathrm{Mo}_{2} \mathrm{Cp}\left\{\mu-\kappa_{\mathrm{P}}^{1}: \kappa^{1}{ }_{\mathrm{S}}, \eta^{5}-\mathrm{PMe}(\mathrm{C}(\mathrm{NPh}) \mathrm{S}) \mathrm{C}_{5} \mathrm{H}_{4}\right\}(\mathrm{CO})_{2}\left(\eta^{6}-\mathrm{HMes}^{*}\right)\left(\mathrm{PMe}_{3}\right)\right]^{+}$, which was conveniently isolated as the borate salt $\left[\mathrm{Mo}_{2} \mathrm{Cp}\left\{\mu-\kappa_{\mathrm{p}}^{1}: \kappa_{\mathrm{S}}^{1}, \eta^{5}-\right.\right.$ $\left.\left.\mathrm{PMe}(\mathrm{C}(\mathrm{NPh}) \mathrm{S}) \mathrm{C}_{5} \mathrm{H}_{4}\right\}(\mathrm{CO})_{2}\left(\eta^{6}-\mathrm{HMes}^{*}\right)\left(\mathrm{PMe}_{3}\right)\right]\left(\mathrm{BAr}_{4}{ }_{4}\right) \quad(\mathbf{6 b}) \quad($ Scheme $\quad 5)$. This reluctance of $\mathbf{2 b}$ for methylation at the uncoordinated $\mathrm{N}$-site of the bridging ligand can be rationalized on the basis of lack of high-energy orbitals having significant N-based lone-pair character, as noted above, although steric effects might also play a role here. In contrast, compound $\mathbf{2} \mathbf{b}$ was readily protonated at the $\mathbf{N}$ atom, as will be discussed later on, this being in agreement with the high electrostatic charge at this site, already mentioned. Finally, it is interesting to note that this complex effectively increases its reactivity in the presence of the borate salt $\mathrm{Na}\left(\mathrm{BAr}_{4}^{\prime}\right)$ (because of the precipitation of sodium salts), then being able to react even with the solvent used in all these reactions (dichloromethane) to give the corresponding chloromethylated derivative $\left[\mathrm{Mo}_{2} \mathrm{Cp}\{\mu\right.$ $\left.\left.\kappa_{\mathrm{p}: \kappa^{1}}^{1}, \eta^{5}-\mathrm{P}\left(\mathrm{CH}_{2} \mathrm{Cl}\right)(\mathrm{C}(\mathrm{NPh}) \mathrm{S}) \mathrm{C}_{5} \mathrm{H}_{4}\right\}(\mathrm{CO})_{2}\left(\eta^{6}-\mathrm{HMes}^{*}\right)\left(\mathrm{PMe}_{3}\right)\right]\left(\mathrm{BAr}_{4}{ }_{4}\right)(8)$, which was isolated in ca. $80 \%$ yield. This reaction had to be carried out in the presence of a noncoordinating base such as DBU (1,8-diazabicyclo[5.4.0]undec-7-ene) to suppress any competitive protonation (by trace water present in the solvent) at the $\mathrm{N}$ site (Scheme 5 , see later).

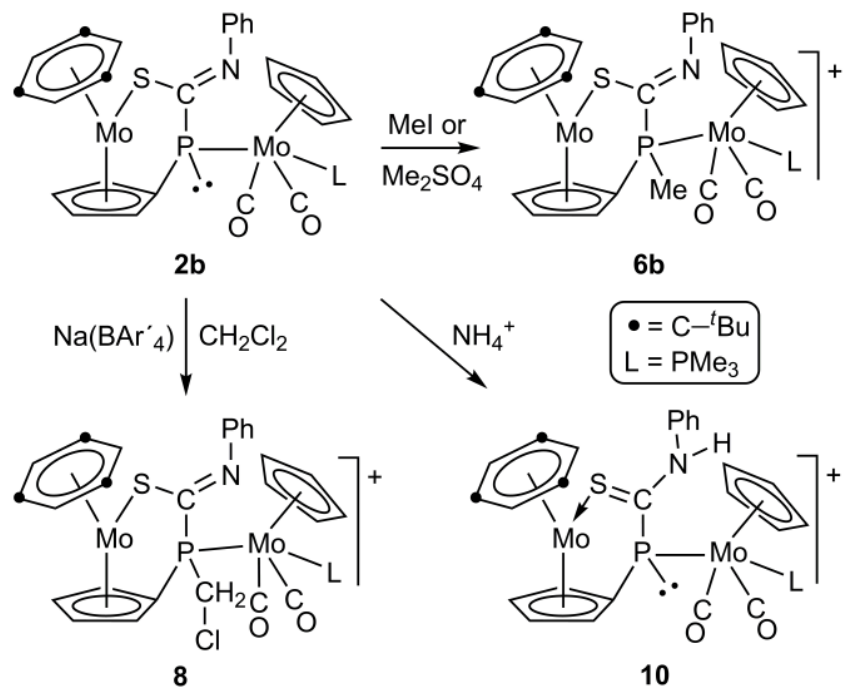

Scheme 5

\section{Solid-state and solution structure of $P$-alkylated derivatives 6 and 8}

We were able to grow suitable crystals for X-ray diffraction from borate salts of $P$ alkylated derivatives of both cumulene adducts $\mathbf{2 a}$ and $\mathbf{2 b}$, the methyl derivative $\mathbf{6 a}^{\prime}$ and the chloromethyl derivative $\mathbf{8}$, although the quality of diffraction data for the latter was not very high (Figure 7 and Table 6). As far as comparisons are possible, we can conclude that the structures of the cations in these two salts are similar to each other, and can be derived from those of the corresponding neutral precursors after alkylation at the $\mathrm{P}$ atom, which is enabled by the presence of a lone electron pair at that site. The 
metal fragments are little perturbed in the process, so it is the cumulene $\mathrm{S}-\mathrm{C}-\mathrm{N}$ backbone of the $\mathrm{SCNPh}$ derivative 8 , which displays essentially single $\mathrm{S}-\mathrm{C}$ and double $\mathrm{C}-\mathrm{N}$ bond lengths of 1.75(1) and 1.28(1) $\AA$ respectively, as computed for the neutral precursor $\mathbf{2 b}$, and a planar environment around the cumulene $\mathrm{C} 4$ atom. In contrast, the $\pi$-bonding interaction along the $\mathrm{S}-\mathrm{C}-\mathrm{S}$ backbone in the $\mathrm{CS}_{2}$ derivative $\mathbf{6 a}^{\prime}$ appears to be partially localized, with the C3-S2 length of 1.641(3) A approaching the reference double-bond length of $1.62 \AA$, although the C3-S1 length of 1.706(3) $\AA$ still is far from the reference single-bond length of $1.78 \AA \AA^{11,12}$ We recall here that such a $\pi$-bonding interaction was fully delocalized in the neutral precursor $\mathbf{2 a}$, but seemed to be localized to a similar extent (but in a different bond) for the sulfide derivative $\mathbf{5}^{\prime}$.

The bridging groups in compounds $\mathbf{6}$ and $\mathbf{8}$ can be assimilated to the phosphanyldithioformate $\left(\mathrm{R}_{2} \mathrm{PCS}_{2}^{-}\right)$and phosphanylthioformamidate $\left(\mathrm{R}_{2} \mathrm{PC}(\mathrm{S}) \mathrm{NR}^{--}\right)$ ligands, respectively, a sort of polydentate donors which are also accessible through insertion reactions of $\mathrm{CS}_{2}$ and SCNR molecules into the $\mathrm{M}-\mathrm{P}$ bonds of mononuclear complexes having pyramidal phosphanyl ligands, as noted above, ${ }^{2 \mathrm{i}, 9,10}$ but the number of binuclear species having this sort of ligands is much more limited. Actually, even after ignoring the $\eta^{5}$-coordination of the $\mathrm{C}_{5} \mathrm{H}_{4}$ ring in our compounds, we can only quote the anion $\left[\mathrm{W}_{2}\left\{\mu-\kappa^{1}{ }_{\mathrm{P}}: \kappa^{1}{ }_{\mathrm{S}}-\mathrm{P}\left(\mathrm{CF}_{3}\right)_{2} \mathrm{C}(\mathrm{S}) \mathrm{S}\right\}(\mathrm{CO})_{10}\right]^{-}$as the only other structurally characterized complex with a related $\mu-P: S$-bound phosphanyldithioformate ligand. ${ }^{24}$ The $\mathrm{W}-\mathrm{P}$ and $\mathrm{W}-\mathrm{S}$ lengths of ca. 2.52 and $2.47 \AA$ in the latter anion actually are very similar to the corresponding lengths in $\mathbf{6 a}^{\mathbf{\prime}}$, but the $\pi$-bonding interaction at the $\mathrm{S}-\mathrm{C}-\mathrm{S}$ backbone in the ditungsten anion seems to be fully delocalized, as judged from the relatively short and similar (to each other) $\mathrm{C}-\mathrm{S}$ lengths of ca. $1.67 \AA$. As concerning the thioformamidato complex $\mathbf{8}$, we note again the limited number of binuclear species structurally characterized with this sort of ligands. Actually, the only other structurally characterized complexes with a $\mu-P: S$-bound phosphanylthioformamidate ligand are digold complexes of general formula $\left[\mathrm{Au}_{2}\left\{\mu-\kappa^{1} \mathrm{P}: \kappa^{1}{ }_{\mathrm{S}}-\mathrm{PR}_{2} \mathrm{C}\left(\mathrm{NR}^{\prime}\right) \mathrm{S}\right\}_{2}\right]\left(\mathrm{R}=\mathrm{Ph}, \mathrm{Cy} ; \mathrm{R}^{\prime}=\right.$ $\mathrm{Me}, \mathrm{Ph}) .^{25,26}$ 

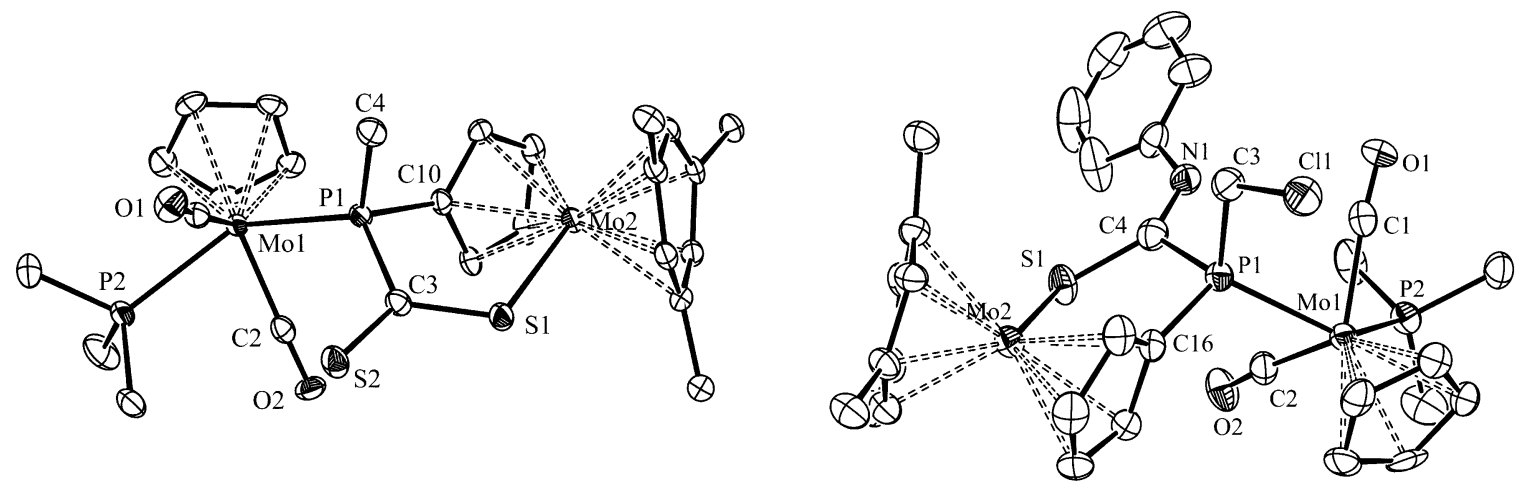

Figure 7. ORTEP diagram (30\% probability) of the cations in compounds $\mathbf{6 a} \mathbf{a}^{\prime}$ (left) and $\mathbf{8}$ (right), with $\mathrm{H}$ atoms and ${ }^{t} \mathrm{Bu}$ groups (except their $\mathrm{C}^{1}$ atoms) omitted for clarity.

Table 6. Selected Bond Lengths $(\AA)$ and Angles $\left(^{\circ}\right)$ for Compounds $6 \mathbf{a}^{\prime}$ and $\mathbf{8}$.

\begin{tabular}{lll}
\hline & \multicolumn{1}{c}{$\mathbf{6 a}^{\prime}$} & \multicolumn{1}{c}{$\mathbf{8}$} \\
\hline Mo1-P1 & $2.4426(7)$ & $2.455(3)$ \\
Mo1-P2 & $2.4708(8)$ & $2.472(3)$ \\
Mo1-C1 & $1.992(4)$ & $2.01(1)$ \\
Mo1-C2 & $1.974(3)$ & $1.99(1)$ \\
Mo2-S1 & $2.5260(8)$ & $2.529(3)$ \\
P1-C3 & $1.842(3)$ & $1.84(1)$ \\
P1-C4 & $1.822(3)$ & $1.85(1)$ \\
P1-C10/16 & $1.800(3)$ & $1.80(1)$ \\
C3/4-S1 & $1.706(3)$ & $1.75(1)$ \\
C3-S2 & $1.641(3)$ & \\
C4-N1 & & $1.28(1)$ \\
P1-Mo1-P2 & $133.59(3)$ & $130.9(1)$ \\
C1-Mo1-C2 & $108.7(1)$ & $109.6(4)$ \\
C1-Mo1-P1 & $77.0(1)$ & $76.1(3)$ \\
C2-Mo1-P1 & $77.5(1)$ & $78.2(3)$ \\
Mo1-P1-C3 & $120.4(1)$ & $117.9(3)$ \\
Mo1-P1-C4 & $117.4(1)$ & $115.8(4)$ \\
Mo1-P1-C(10/16) & $111.8(1)$ & $115.2(3)$ \\
P1-C3/4-S1 & $115.0(2)$ & $113.9(6)$ \\
P1-C3-S2 & $120.9(2)$ & \\
P1-C4-N1 & & $112.4(7)$ \\
S1-C3-S2 & $124.0(2)$ & \\
S1-C4-N1 & & $133.4(8)$ \\
\hline
\end{tabular}

Spectroscopic data in solution for compounds $\mathbf{6 a}, \mathbf{6 b}$ and $\mathbf{8}$ are consistent with the solid-state structures discussed above, and deserve no detailed comments. We should note, however, that these compounds display in each case two $\mathrm{C}-\mathrm{O}$ stretches with the same pattern as their neutral precursors, but displaced some $40-50 \mathrm{~cm}^{-1}$ towards higher frequencies, thus denoting the strong reduction in electron density operated at the transoid dicarbonyl fragment upon alkylation at the $\mathrm{P}$ site of the bridging ligand, an effect of magnitude larger than the ones operated upon oxidation with oxygen or sulfur. Moreover, the phosphorus atom of the bridging ligand in these cations give rise to a NMR resonance in the range 60-78 ppm, expectedly deshielded with respect to the parent compounds because of the removal of the lone electron pair at the $\mathrm{P}$ site, an effect comparable to the coordination chemical shift of $P$-donor ligands. ${ }^{27}$ Finally, we 
note that the cumulene ${ }^{13} \mathrm{C}$ NMR resonance of $\mathbf{6 a}$ appears at $254.0 \mathrm{ppm}$, some $25 \mathrm{ppm}$ below the corresponding resonance in the neutral precursor $\mathbf{2 a}$, a shielding effect that might be related to the partial delocalization of the $\pi$-bonding interaction along the $\mathrm{S}-\mathrm{C}-\mathrm{S}$ chain that can be guessed from the X-ray data discussed above.

\section{Solution structure of the phosphanyl complex 7}

The IR spectrum of compound 7 displays two $\mathrm{C}-\mathrm{O}$ stretches with the characteristic pattern of transoid $\mathrm{M}(\mathrm{CO})_{2}$ oscillators, but less energetic than those of its isomer $\mathbf{6 a}$, and only some $20 \mathrm{~cm}^{-1}$ higher in frequency than the bands of the neutral precursor $\mathbf{2 a}$, thus indicating that the methyl cation has been incorporated to a site more remote from the metal fragment. The attachment of the added methyl group to an $\mathrm{S}$ (rather than $\mathrm{P}$ ) atom is indicated by the corresponding ${ }^{1} \mathrm{H} \mathrm{NMR}$ resonance $\left(\delta_{\mathrm{H}} 2.76 \mathrm{ppm}, J_{\mathrm{PH}}=1 \mathrm{~Hz}\right)$, which appears more deshielded and almost uncoupled from the $\mathrm{P}$ atom, when compared to the corresponding resonance in isomer $6 \mathbf{a}\left(\delta_{\mathrm{H}} 2.10 \mathrm{ppm}, J_{\mathrm{PH}}=9 \mathrm{~Hz}\right)$; in a similar vein, the ${ }^{13} \mathrm{C}$ NMR resonance of the added methyl group in 7 appears uncoupled from the $\mathrm{P}$ atom (cf. $J_{\mathrm{PC}}=31 \mathrm{~Hz}$ for $6 \mathbf{a}$ ). Surprisingly, the ${ }^{31} \mathrm{P} \mathrm{NMR}$ resonance of the bridging ligand in $7\left(\delta_{\mathrm{P}} 64.6 \mathrm{ppm}\right)$ is only some $10 \mathrm{ppm}$ more shielded than the corresponding resonance in isomer $\mathbf{6 a}$, despite the presence of a lone electron pair at $\mathrm{P}$ in the former complex.

The cumulene $\mathrm{C}$ atom in compound 7 gives rise to a resonance at $243.4 \mathrm{ppm}$, not far from the corresponding resonance in its isomer $6 \mathbf{a}(254.0 \mathrm{ppm})$, but its coupling to the $\mathrm{P}$ atom is considerably higher ( 51 vs. $12 \mathrm{~Hz}$ ), which suggests a stronger $\mathrm{P}-\mathrm{C}$ binding in that case. Finally we note that, since the structure of $\mathbf{7}$ is devoid of any symmetry element, this complex should give rise to separated resonances for all $\mathrm{CH}\left(\mathrm{C}_{5} \mathrm{H}_{4}\right)$ groups and the carbonyl ligands. However, as observed for the parent compound $\mathbf{2 a}$, the room temperature ${ }^{1} \mathrm{H}$ and ${ }^{13} \mathrm{C}$ NMR spectra of 7 display just one carbonyl and two $\mathrm{CH}$ resonances, thus suggesting the occurrence of a dynamic process which we assume to be similar to the one operating at the parent compound, that is, fast pyramidal inversion at the $\mathrm{P}$ atom, although we have not studied this process in detail.

\section{Structural characterization of the dimethylated derivative 9}

Although the X-ray structural refinement for this compound was rather poor because of the presence in the crystal of disorder for many of the $\mathrm{CF}_{3}$ groups of the anions and even many heavy atoms of the cation, we still could develop a model that reveals the essential structural features of the dipositive cation in this salt (Figure 8 and Table 7). The structure of the cation can be derived from that of the parent compound $\mathbf{2 a}$ after adding a methyl group to the $\mathrm{P}$ atom of the bridging ligand $(\mathrm{P} 1-\mathrm{C} 5=1.81(1) \AA)$ and another methyl group to the uncoordinated $\mathrm{S}$ atom of that ligand $(\mathrm{S} 2-\mathrm{C} 4=1.83(2) \AA)$. This does not disturb the planarity of the $\mathrm{CS}_{2}$ moiety, but seems to partially localize the 
$\pi$-bonding interaction along the $\mathrm{S}-\mathrm{C}-\mathrm{S}$ chain, in the direction observed for compound $5^{\prime}$ (shorter S-C length for the Mo-bound S atom), with the corresponding C-S lengths having values of $1.59(2)$ and 1.68(2) $\AA$, although the low precision of these data precludes a more conclusive analysis. We also note that, as found for $\mathbf{5}^{\mathbf{\prime}}$, the Mo-S (2.430(2) $\AA$ ) and Mo-P (2.446(3) $\AA$ ) lengths of the bridging ligand in 9 are significantly shortened (by ca. $0.09 \AA$ ) with respect to the corresponding distances in the neutral precursor 2a.

The bridging ligand in compound 9 can be viewed as a phosphanyldithioformate ester $\left(\mathrm{R}_{2} \mathrm{PC}(\mathrm{S}) \mathrm{SR}\right)$. Complex $\left[\mathrm{Co}_{2} \mathrm{Fe}\left(\mu-\kappa^{1}{ }_{\mathrm{P}}: \kappa^{1}{ }_{\mathrm{S}}-\mathrm{PPh}_{2} \mathrm{C}(\mathrm{SMe}) \mathrm{S}\right\}\left(\mu_{3}-\mathrm{S}\right)(\mathrm{CO})_{7}\right]$, a cluster formed in a process involving stepwise treatment of the phosphine cluster $\left[\mathrm{Co}_{2} \mathrm{Fe}\left(\mu_{3}-\right.\right.$ $\left.\mathrm{S})(\mathrm{CO})_{8}\left(\mathrm{PPh}_{2} \mathrm{H}\right)\right]$ with ${ }^{n} \mathrm{BuLi}, \mathrm{CS}_{2}$ and $\mathrm{MeI}$, appears to be the only other complex structurally characterized with this sort of ligand in a $\mu-P: S$ - coordination mode. ${ }^{28}$ Interestingly, this cluster displays a partial localization of the $\pi$ bonding interaction over the $\mathrm{S}-\mathrm{C}-\mathrm{S}$ chain similar to the one apparent for $\mathbf{9}$, as judged from the dissimilar $\mathrm{C}-\mathrm{SCo}$ and C-SMe lengths of 1.651(9) and 1.699(9) $\AA$ in that case.

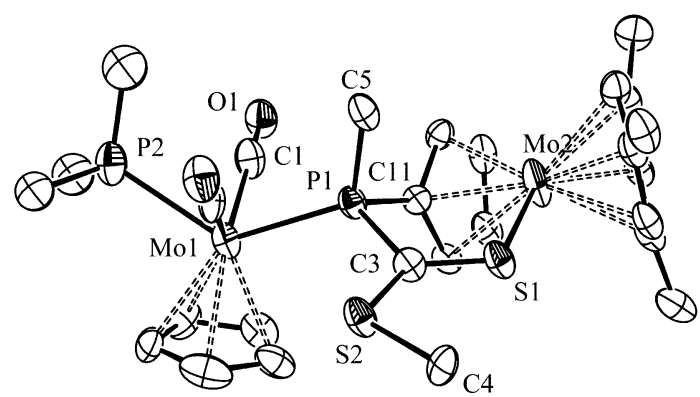

Figure 8. ORTEP diagram (30\% probability) of the cation in compound $\mathbf{9}$, with $\mathrm{H}$ atoms and ${ }^{t} \mathrm{Bu}$ groups (except their $\mathrm{C}^{1}$ atoms) omitted for clarity.

Table 7. Selected Bond Lengths $(\AA)$ and Angles $\left({ }^{\circ}\right)$ for Compound 9.

\begin{tabular}{llll}
\hline Mo1-P1 & $2.446(3)$ & P1-Mo1-P2 & $128.5(3)$ \\
Mo1-P2 & $2.47(1)$ & C1-Mo1-C2 & $110.8(6)$ \\
Mo1-C1 & $1.98(2)$ & C1-Mo1-P1 & $76.0(4)$ \\
Mo1-C2 & $2.00(2)$ & C2-Mo1-P1 & $75.9(4)$ \\
Mo2-S1 & $2.430(2)$ & Mo1-P1-C11 & $115.5(3)$ \\
P1-C3 & $1.85(1)$ & Mo1-P1-C3 & $118.9(5)$ \\
P1-C5 & $1.81(1)$ & Mo1-P1-C5 & $117.4(4)$ \\
P1-C11 & $1.817(6)$ & C3-P1-C11 & $96.4(6)$ \\
C3-S1 & $1.59(2)$ & P1-C3-S1 & $115.2(8)$ \\
C3-S2 & $1.68(2)$ & P1-C3-S2 & $115.1(9)$ \\
S2-C4 & $1.83(2)$ & S1-C3-S2 & $129.6(9)$ \\
& & C3-S2-C4 & $100.5(8)$ \\
\hline
\end{tabular}

Spectroscopic data in solution for compound 9 (Table 3 and Experimental Section) are fully consistent with the structure found in the crystal. The presence of added methyl groups at both the $\mathrm{P}$ and $\mathrm{S}$ sites is denoted by the appearance of ${ }^{1} \mathrm{H}$ NMR resonances at $1.95\left(J_{\mathrm{PH}}=8 \mathrm{~Hz}\right)$ and $2.77(\mathrm{~s})$ ppm respectively, while the high positive charge of the cation is reflected in a strong increase of ca. $55 \mathrm{~cm}^{-1}$ in the frequency of the $\mathrm{C}-\mathrm{O}$ 
stretches of the transoid dicarbonyl fragment, compared to the neutral parent substrate. The cumulene $\mathrm{C}$ atom gives rise to an NMR resonance at $208.0 \mathrm{ppm}$, consistent with the trigonal environment apparent in the solid-state structure. This chemical shift is lower than those measured for any other cationic $\mathrm{CS}_{2}$-derivative reported in this work, perhaps another reflection of the high positive charge of the cation in 9.

\section{Protonation reactions of compounds 2}

As discussed above, the electronic properties of the SCNPh adduct $\mathbf{2} \mathbf{b}$ do not favour electrophilic attack at the $\mathrm{N}$ site under conditions of orbital control, thus justifying our inability to incorporate a methyl cation at that site. Perhaps we should add that any electrophilic attack at this site is also somewhat disfavoured on steric grounds, due to the spatial proximity of the phenyl substituent already present at the site. In contrast, we should recall that, according to our DFT calculations, the atomic charge at this site in $\mathbf{2 b}$ is quite negative, thus favouring reactions under conditions of charge control, as usually is the case with protonation reactions. Therefore, it is not surprising that $\mathbf{2} \mathbf{b}$ can be protonated easily at this site. Actually, $\mathbf{2 b}$ reacts readily with the weak acid $\left(\mathrm{NH}_{4}\right) \mathrm{PF}_{6}$, even in toluene solution at room temperature, to give the corresponding phosphanylthioformamide-like complex $\quad\left[\mathrm{Mo}_{2} \mathrm{Cp}\left\{\mu-\kappa^{1}{ }_{\mathrm{p}: \kappa^{1}}{ }_{\mathrm{s}}, \eta^{5}\right.\right.$ $\left.\left.\mathrm{P}(\mathrm{C}(\mathrm{NHPh}) \mathrm{S}) \mathrm{C}_{5} \mathrm{H}_{4}\right\}(\mathrm{CO})_{2}\left(\eta^{6}-\mathrm{HMes}^{*}\right)\left(\mathrm{PMe}_{3}\right)\right]^{+}$, which was conveniently isolated, after the pertinent anion exchange, as the borate salt $\left[\mathrm{Mo}_{2} \mathrm{Cp}\left\{\mu-\kappa_{\mathrm{p}}^{1}: \kappa_{\mathrm{S}}^{1}, \eta^{5}-\right.\right.$ $\left.\left.\mathrm{P}(\mathrm{C}(\mathrm{NHPh}) \mathrm{S}) \mathrm{C}_{5} \mathrm{H}_{4}\right\}(\mathrm{CO})_{2}\left(\eta^{6}-\mathrm{HMes}^{*}\right)\left(\mathrm{PMe}_{3}\right)\right]\left(\mathrm{BAr}^{\prime}{ }_{4}\right)$ (10) (Scheme 5). This product was even formed at a small extent when a dichloromethane solution of $\mathbf{2} \mathbf{b}$ was stirred in the presence of $\mathrm{Na}\left(\mathrm{BAr}^{\prime}{ }_{4}\right)$, due to reaction with trace amounts of water in the solvent, as noted above. In contrast, the $\mathrm{CS}_{2}$ adduct $\mathbf{2 a}$, lacking a highly charged site at the bridging ligand, failed to react with $\left(\mathrm{NH}_{4}\right) \mathrm{PF}_{6}$ under similar conditions. Of course, protonation did take place when using a stronger acid such as $\mathrm{HBF}_{4} \cdot \mathrm{OEt}_{2}$, but the products formed in these reactions where quite unstable and could not be characterized.

From a structural point of view, compound $\mathbf{1 0}$ can be related to the phosphanyl complex 7, the $S$-methylated derivative of the $\mathrm{CS}_{2}$ adduct $\mathbf{2 a}$. Indeed, the IR spectrum of 10 displays $\mathrm{C}-\mathrm{O}$ stretches some $24 \mathrm{~cm}^{-1}$ above those of its neutral precursor (cf. some $20 \mathrm{~cm}^{-1}$ for 7), and the $\mathrm{P}$ atom of the bridging ligand undergoes a comparable upfrequency shift of some $50 \mathrm{ppm}$. The cumulene $\mathrm{C}$ atom gives rise to an NMR resonance at $223.9 \mathrm{ppm}$, a chemical shift even higher than the one measured in the neutral precursor (205.9 ppm), which suggests preservation of the planarity around that atom, and even some delocalization of the $\pi$-bonding interaction over the $\mathrm{S}-\mathrm{C}-\mathrm{N}$ chain, which is essentially absent in the neutral precursor $\mathbf{2 b}$, as noted already. The above conclusions are in agreement with the structural data of $\left[\mathrm{Au}_{2}\left(\mathrm{C}_{6} \mathrm{~F}_{5}\right)_{2}\left\{\mu-\kappa^{1}{ }_{\mathrm{P}}: \kappa^{1} \mathrm{~S}^{-}\right.\right.$ $\left.\left.\mathrm{PPh}_{2} \mathrm{C}(\mathrm{NHMe}) \mathrm{S}\right\}\right],{ }^{26}$ which appears to be the only structurally characterized complex displaying the related $\mu-P: S$-bound phosphanylthioformamide ligand. Indeed the $\mathrm{C}-\mathrm{S}$ 
$(1.680 \AA)$ and $\mathrm{C}-\mathrm{N}(1.31 \AA)$ lengths in the latter complex have intermediate values between the reference figures for double and single bonds between these atoms (1.62/1.78 and 1.27/1.44 $\AA$, respectively), ${ }^{11,12}$ which suggests partial delocalization of a $\pi$-bonding interaction over the $\mathrm{S}-\mathrm{C}-\mathrm{N}$ backbone of the bridging ligand.

As it is the case of $\mathbf{7}$, compound $\mathbf{1 0}$ is devoid of any symmetry element, but its ${ }^{13} \mathrm{C}\left\{{ }^{1} \mathrm{H}\right\}$ NMR spectrum at room temperature displays a single carbonyl resonance and just two resonances for the $\mathrm{CH}$ atoms of the $\mathrm{C}_{5} \mathrm{H}_{4}$ group, thus revealing the operation of a dynamic process in solution that analogously is proposed to be a pyramidal inversion at the $\mathrm{P}$ atom, not further investigated. We note that, in this case, the neutral precursor $\mathbf{2 b}$ does not exhibit dynamic behaviour. So it seems that protonation at the $\mathrm{N}$ site of this ligand reduces the barrier for pyramidal inversion at the $\mathrm{P}$ site. In any case, we note that pyramidal inversion at all derivatives of the phosphinidene 1 retaining a lone electron pair at the phosphorus atom is a relatively easy process.

\section{Conclusions}

The reactions of the phosphinidene complex 1 with the heterocumulenes $\mathrm{CS}_{2}$ and $\mathrm{SCNPh}$ proceed with formal insertion of the $\mathrm{S}=\mathrm{C}$ bond of the latter molecules into the metallocene $\mathrm{Mo}-\mathrm{P}$ bond of $\mathbf{1}$, with specific formation of a new $\mathrm{P}-\mathrm{C}$ bond. The resulting phosphinidene-cumulene adducts retain a pyramidal environment around the $\mathrm{P}$ atom and a $\pi$-bonding interaction at the cumulene, essentially delocalized over the $\mathrm{S}-\mathrm{C}-\mathrm{S}$ backbone in the $\mathrm{CS}_{2}$ derivative, but localized at the $\mathrm{C}-\mathrm{N}$ bond in the second case. These adducts are highly nucleophilic species displaying both $\mathrm{P}$ - and $\mathrm{S}$ (or $\mathrm{N}$ )-based reactivity, with the latter sites being favoured under conditions of charge control. The $\mathrm{CS}_{2}$ adduct thus can be methylated at either the $\mathrm{P}$ or $\mathrm{S}$ sites (or both) by using reagents of different strength and polarity. In contrast, the SCNPh adduct can be only methylated at the P site, but is readily protonated at its $\mathrm{N}$ atom, thanks to the high electrostatic charge of the latter. These adducts expectedly react with sulfur by forming a new $\mathrm{P}=\mathrm{S}$ bond, but their reaction with oxygen results in the incorporation of two oxygen atoms, one expectedly forming a new $\mathrm{P}=\mathrm{O}$ bond, while a second one is inserted into the remaining $\mathrm{Mo}-\mathrm{P}$ bond of the bridging ligand to yield a phosphinato-like derivative. Most of the above derivatives of $\mathbf{1}$ which retain a lone electron pair at phosphorus display fast (on the NMR time scale) pyramidal inversion at this site, thus paralleling the dynamic behaviour of different mononuclear complexes bearing pyramidal phosphanyl ligands.

\section{Experimental Section}

\section{General procedures and starting materials}


All manipulations and reactions were carried out under an argon (99.995\%) atmosphere using standard Schlenk techniques. All experiments were carried out using Schlenk tubes equipped with Young's valves. Solvents were purified according to literature procedures and distilled prior to use. ${ }^{29}$ Petroleum ether refers to that fraction distilling in the range 338-343 K. Compounds $\left[\mathrm{Mo}_{2} \mathrm{Cp}\left(\mu-\kappa^{1}: \kappa^{1}, \eta^{5}-\mathrm{PC}_{5} \mathrm{H}_{4}\right)(\mathrm{CO})_{2}\left(\eta^{6}-\mathrm{HMes}^{*}\right)\left(\mathrm{PMe}_{3}\right)\right]$ (1) $\left(\mathrm{Mes}^{*}=2,4,6-\mathrm{C}_{6} \mathrm{H}_{2}{ }^{t} \mathrm{Bu}_{3}\right),{ }^{5}$ and $\mathrm{Na}\left(\mathrm{BAr}^{\prime}{ }_{4}\right)\left(\mathrm{Ar}^{\prime}=3,5-\mathrm{C}_{6} \mathrm{H}_{3}\left(\mathrm{CF}_{3}\right)_{2}\right),{ }^{30}$ were prepared as described previously, while all other reagents were obtained from the usual commercial suppliers and used as received, unless otherwise stated. Chromatographic separations were carried out using jacketed columns cooled by tap water (ca. $288 \mathrm{~K}$ ) or by a closed 2-propanol circuit, kept at the desired temperature with a cryostat. Commercial aluminium oxide (activity I, 70-290 mesh) was degassed under vacuum prior to use. The latter was mixed under argon with the appropriate amount of water to reach activity IV. IR stretching frequencies were measured in solution and are referred to as $v$ (solvent) and given in wave numbers $\left(\mathrm{cm}^{-1}\right)$. Nuclear magnetic resonance (NMR) spectra were routinely recorded at $400.13\left({ }^{1} \mathrm{H}\right), 162.12\left({ }^{31} \mathrm{P}\left\{{ }^{1} \mathrm{H}\right\}\right)$, or 100.62 $\mathrm{MHz}\left({ }^{13} \mathrm{C}\left\{{ }^{1} \mathrm{H}\right\}\right)$ at $290 \mathrm{~K}$ unless otherwise stated. Chemical shifts $(\delta)$ are given in ppm, relative to internal tetramethylsilane $\left({ }^{1} \mathrm{H},{ }^{13} \mathrm{C}\right)$ or external $85 \%$ aqueous $\mathrm{H}_{3} \mathrm{PO}_{4}\left({ }^{31} \mathrm{P}\right)$. Coupling constants $(J)$ are given in $\mathrm{Hz}$.

Preparation of $\left[\mathrm{Mo}_{2} \mathrm{Cp}\left\{\mu-\kappa^{1}{ }_{\mathrm{p}}: \kappa_{\mathrm{s}}^{1}, \eta^{5}-\mathrm{P}\left(\mathrm{CS}_{2}\right) \mathrm{C}_{5} \mathrm{H}_{4}\right\}(\mathrm{CO})_{2}\left(\eta^{6}-\mathrm{HMes}^{*}\right)\left(\mathrm{PMe}_{3}\right)\right]$ (2a). Neat $\mathrm{CS}_{2}(4 \mu \mathrm{L}, 0.066 \mathrm{mmol})$ was added to a toluene solution $(2 \mathrm{~mL})$ of compound 1 $(0.023 \mathrm{~g}, 0.031 \mathrm{mmol})$ at $223 \mathrm{~K}$, and the mixture was stirred for $2 \mathrm{~min}$ to give a red solution. The solvent was then removed under vacuum and the residue was chromatographed on alumina at $263 \mathrm{~K}$. Elution with dichloromethane/petroleum ether (1/1) gave a red fraction yielding, upon removal of solvents, compound $\mathbf{2 a}$ as a microcrystalline solid $(0.022 \mathrm{~g}, 88 \%)$. The crystals used in the X-ray diffraction study were grown through the slow diffusion of a layer of petroleum ether into a concentrated toluene solution of the complex at $253 \mathrm{~K}$. Anal. Calcd for $\mathrm{C}_{34} \mathrm{H}_{48} \mathrm{Mo}_{2} \mathrm{O}_{2} \mathrm{P}_{2} \mathrm{~S}_{2}: \mathrm{C}, 50.62$; $\mathrm{H}, 6.00 ; \mathrm{S}, 7.95$. Found: $\mathrm{C}, 50.21 ; \mathrm{H}, 5.56 ; \mathrm{S}, 8.11 .{ }^{1} \mathrm{H}$ NMR $\left(300.13 \mathrm{MHz}, \mathrm{C}_{6} \mathrm{D}_{6}\right): \delta$ $5.36\left(\mathrm{~m}, 2 \mathrm{H}, \mathrm{C}_{5} \mathrm{H}_{4}\right), 5.12(\mathrm{~s}, 5 \mathrm{H}, \mathrm{Cp}), 4.77\left(\mathrm{~s}, 3 \mathrm{H}, \mathrm{C}_{6} \mathrm{H}_{3}\right), 4.51\left(\mathrm{~m}, 2 \mathrm{H}, \mathrm{C}_{5} \mathrm{H}_{4}\right), 1.19$ (s, $\left.27 \mathrm{H},{ }^{t} \mathrm{Bu}\right), 0.92\left(\mathrm{~d}, J_{\mathrm{PH}}=9,9 \mathrm{H}, \mathrm{PMe}\right) .{ }^{31} \mathrm{P} \mathrm{NMR}\left(\mathrm{C}_{6} \mathrm{D}_{6}\right): \delta 23.6(\mathrm{~m}, \mathrm{PMe}), 21.6\left(\mathrm{~d}, J_{\mathrm{PP}}=\right.$ $\left.18, \mathrm{PC}_{5} \mathrm{H}_{4}\right) \cdot{ }^{13} \mathrm{C}\left\{{ }^{1} \mathrm{H}\right\} \operatorname{NMR}\left(\mathrm{C}_{6} \mathrm{D}_{6}\right): \delta 279.3$ (d, $\left.J_{\mathrm{CP}}=60, \mathrm{SCS}\right), 234.9$ (br, 2MoCO), $105.2\left[\mathrm{dd}, J_{\mathrm{CP}}=27,4, \mathrm{C}^{1}\left(\mathrm{C}_{5} \mathrm{H}_{4}\right)\right], 101.9\left[\mathrm{~s}, \mathrm{C}\left(\mathrm{C}_{6} \mathrm{H}_{3}\right)\right], 93.1$ (s, Cp), $92.6[\mathrm{~m}, \mathrm{br}$, $2 \mathrm{CH}\left(\mathrm{C}_{5} \mathrm{H}_{4}\right)$ ], $82.3\left[\mathrm{~m}, \mathrm{br}, 2 \mathrm{CH}\left(\mathrm{C}_{5} \mathrm{H}_{4}\right)\right], 79.2$ [s, $\left.\mathrm{CH}\left(\mathrm{C}_{6} \mathrm{H}_{3}\right)\right], 34.5\left[\mathrm{~s}, \mathrm{C}^{1}\left({ }^{t} \mathrm{Bu}\right)\right], 32.1[\mathrm{~s}$, $\left.\mathrm{C}^{2}\left({ }^{t} \mathrm{Bu}\right)\right], 20.2\left(\mathrm{~d}, J_{\mathrm{CP}}=31, \mathrm{PMe}\right) .{ }^{1} \mathrm{H} \mathrm{NMR}\left(400.13 \mathrm{MHz}\right.$, toluene- $\left.d_{8}, 223 \mathrm{~K}\right): \delta 5.71$, 5.26, 4.85, 3.45 (4m, br, 4 x 1H, $\left.\mathrm{C}_{5} \mathrm{H}_{4}\right), 5.09$ (s, 5H, Cp), 4.69 (s, 3H, $\left.\mathrm{C}_{6} \mathrm{H}_{3}\right), 1.13$ (s, $\left.27 \mathrm{H},{ }^{t} \mathrm{Bu}\right), 0.90\left(\mathrm{~d}, J_{\mathrm{PH}}=9,9 \mathrm{H}, \mathrm{PMe}\right) .{ }^{13} \mathrm{C}\left\{{ }^{1} \mathrm{H}\right\}$ NMR (toluene- $\left.d_{8}, 223 \mathrm{~K}\right): \delta 105.0$ [dd, $\left.J_{\mathrm{CP}}=27,4, \mathrm{C}^{1}\left(\mathrm{C}_{5} \mathrm{H}_{4}\right)\right], 100.9$ [s, $\left.\mathrm{C}\left(\mathrm{C}_{6} \mathrm{H}_{3}\right)\right], 93.1$ (s, Cp), 96.2, 88.1, 87.5, 77.0 [4m, br, $\left.\mathrm{CH}\left(\mathrm{C}_{5} \mathrm{H}_{4}\right)\right], 79.3\left[\mathrm{~s}, \mathrm{CH}\left(\mathrm{C}_{6} \mathrm{H}_{3}\right)\right], 34.3\left[\mathrm{~s}, \mathrm{C}^{1}\left({ }^{t} \mathrm{Bu}\right)\right], 32.0\left[\mathrm{~s}, \mathrm{C}^{2}\left({ }^{t} \mathrm{Bu}\right)\right], 19.6\left(\mathrm{~d}, J_{\mathrm{CP}}=31\right.$, 
$\mathrm{PMe}$ ); the resonances for the $\mathrm{CO}$ and $\mathrm{CS}_{2}$ groups were not observed at this temperature, likely due to broadness.

Preparation of $\left[\mathrm{Mo}_{2} \mathrm{Cp}\left\{\mu-\kappa_{\mathrm{p}}^{1}: \kappa^{1}{ }_{s}, \eta^{5}-\mathrm{P}(\mathrm{C}(\mathrm{NPh}) \mathrm{S}) \mathrm{C}_{5} \mathrm{H}_{4}\right\}(\mathrm{CO})_{2}\left(\eta^{6}-\mathrm{HMes}^{*}\right)\left(\mathrm{PMe}_{3}\right)\right]$ (2b). Neat $\mathrm{SCNPh}(8 \mu \mathrm{L}, 0.066 \mathrm{mmol})$ was added to a toluene solution $(2 \mathrm{~mL})$ of compound $1(0.023 \mathrm{~g}, 0.031 \mathrm{mmol})$ and the mixture was stirred at room temperature for 2 min to give a brown solution. The solvent was then removed under vacuum, and the residue was washed with petroleum ether $(3 \times 5 \mathrm{~mL})$ and extracted with toluene $(6 \mathrm{~mL})$. The extract was then filtered using a cannula, and the solvent removed from the filtrate to give compound $\mathbf{2 b}$ as a yellowish, essentially pure solid (0.023 g, 89\%). All attempts to further purify this very air-sensitive complex resulted in its progressive decomposition. $v(\mathrm{CN})$ (Nujol mull): $1512(\mathrm{~m}) .{ }^{1} \mathrm{H}$ NMR $\left(300.13 \mathrm{MHz}, \mathrm{C}_{6} \mathrm{D}_{6}\right): \delta 7.60-$ $7.10(\mathrm{~m}, 5 \mathrm{H}, \mathrm{Ph}), 5.84,5.51,5.16\left(3 \mathrm{~m}, 3 \times 1 \mathrm{H}, \mathrm{C}_{5} \mathrm{H}_{4}\right), 5.03$ (s, 5H, Cp), $4.66(\mathrm{~s}, 3 \mathrm{H}$, $\left.\mathrm{C}_{6} \mathrm{H}_{3}\right), 3.56\left(\mathrm{~m}, 1 \mathrm{H}, \mathrm{C}_{5} \mathrm{H}_{4}\right), 1.19\left(\mathrm{~s}, 27 \mathrm{H},{ }^{t} \mathrm{Bu}\right), 0.96\left(\mathrm{~d}, J_{\mathrm{PH}}=9,9 \mathrm{H}, \mathrm{PMe}\right) .{ }^{13} \mathrm{C}\left\{{ }^{1} \mathrm{H}\right\}$ NMR (75.47 MHz, $\mathrm{C}_{6} \mathrm{D}_{6}$ ): $\delta$ 236.5, 234.0 (2s, br, MoCO), 204.9 (d, $J_{\mathrm{CP}}=25, \mathrm{SCN}$ ), $155.6\left[\mathrm{~d}, J_{\mathrm{CP}}=13, \mathrm{C}^{1}(\mathrm{Ph})\right], 122.3,121.6\left[2 \mathrm{~s}, \mathrm{C}^{2,3}(\mathrm{Ph})\right], 119.7\left[\mathrm{~s}, \mathrm{C}^{4}(\mathrm{Ph})\right], 104.2[\mathrm{~m}$, $\left.\mathrm{CH}\left(\mathrm{C}_{5} \mathrm{H}_{4}\right)\right], 103.0\left[\mathrm{dd}, J_{\mathrm{CP}}=26,3, \mathrm{C}^{1}\left(\mathrm{C}_{5} \mathrm{H}_{4}\right)\right], 101.2$ [s, $\left.\mathrm{C}\left(\mathrm{C}_{6} \mathrm{H}_{3}\right)\right], 92.5(\mathrm{~s}, \mathrm{Cp}), 89.8$, $88.0\left[2 \mathrm{~m}, \mathrm{CH}\left(\mathrm{C}_{5} \mathrm{H}_{4}\right)\right], 78.1\left[\mathrm{~s}, \mathrm{CH}\left(\mathrm{C}_{6} \mathrm{H}_{3}\right)\right], 75.9$ [m, $\left.\mathrm{CH}\left(\mathrm{C}_{5} \mathrm{H}_{4}\right)\right], 34.6\left[\mathrm{~s}, \mathrm{C}^{1}\left({ }^{t} \mathrm{Bu}\right)\right], 32.0$ $\left[\mathrm{s}, \mathrm{C}^{2}\left({ }^{t} \mathrm{Bu}\right)\right], 20.6\left(\mathrm{~d}, J_{\mathrm{CP}}=35, \mathrm{PMe}\right)$.

Formation of $\left[\mathrm{Mo}_{2} \mathrm{Cp}\left\{\mu-\kappa^{1}{ }_{0}: \kappa^{1}{ }_{s}, \eta^{5}-\mathrm{OP}(\mathrm{O})\left(\mathrm{CS}_{2}\right) \mathrm{C}_{5} \mathrm{H}_{4}\right\}(\mathrm{CO})_{2}\left(\eta^{6}-\mathrm{HMes}^{*}\right)\left(\mathrm{PMe}_{3}\right)\right]$ (3a). Compound 2a $(0.025 \mathrm{~g}, 0.031 \mathrm{mmol})$ was allowed to stay in a Schlenk tube under an air atmosphere for $4 \mathrm{~h}$, then washed with toluene $(2 \times 2 \mathrm{~mL})$ and dried under vacuum to give complex 3a as a dark blue powder $(0.022 \mathrm{~g}, 85 \%)$. Anal. Calcd for $\mathrm{C}_{34} \mathrm{H}_{48} \mathrm{Mo}_{2} \mathrm{O}_{4} \mathrm{P}_{2} \mathrm{~S}_{2}$ : C, 48.69; H, 5.77; S, 7.65. Found: C, 48.55; H, 5.56; S, 7.30. ${ }^{1} \mathrm{H}$ $\operatorname{NMR}\left(\mathrm{CD}_{2} \mathrm{Cl}_{2}\right): \delta 5.23\left(\mathrm{~d}, J_{\mathrm{PH}}=2,5 \mathrm{H}, \mathrm{Cp}\right), 5.22\left(\mathrm{~m}, 2 \mathrm{H}, \mathrm{C}_{5} \mathrm{H}_{4}\right), 4.94\left(\mathrm{~s}, 3 \mathrm{H}, \mathrm{C}_{6} \mathrm{H}_{3}\right)$, $4.78\left(\mathrm{~m}, 2 \mathrm{H}, \mathrm{C}_{5} \mathrm{H}_{4}\right), 1.62\left(\mathrm{~d}, J_{\mathrm{PH}}=10,9 \mathrm{H}, \mathrm{PMe}\right), 1.31\left(\mathrm{~s}, 27 \mathrm{H},{ }^{t} \mathrm{Bu}\right) .{ }^{13} \mathrm{C}\left\{{ }^{1} \mathrm{H}\right\} \mathrm{NMR}$ $\left(\mathrm{CD}_{2} \mathrm{Cl}_{2}\right): \delta 233.1\left(\mathrm{~d}, J_{\mathrm{CP}}=27,2 \mathrm{MoCO}\right), 204.5$ (s, SCS), 119.8 [s, $\left.\mathrm{C}\left(\mathrm{C}_{6} \mathrm{H}_{3}\right)\right], 105.2$ [s, $\left.\mathrm{C}^{1}\left(\mathrm{C}_{5} \mathrm{H}_{4}\right)\right], 93.4(\mathrm{~s}, \mathrm{Cp}), 90.3\left[\mathrm{~d}, J_{\mathrm{CP}}=10,2 \mathrm{CH}\left(\mathrm{C}_{5} \mathrm{H}_{4}\right)\right], 84.1\left[\mathrm{~d}, J_{\mathrm{CP}}=9,2 \mathrm{CH}\left(\mathrm{C}_{5} \mathrm{H}_{4}\right)\right]$, $80.9\left[\mathrm{~s}, \mathrm{CH}\left(\mathrm{C}_{6} \mathrm{H}_{3}\right)\right], 35.2\left[\mathrm{~s}, \mathrm{C}^{1}\left({ }^{t} \mathrm{Bu}\right)\right], 31.7\left[\mathrm{~s}, \mathrm{C}^{2}\left({ }^{t} \mathrm{Bu}\right)\right], 20.2\left(\mathrm{~d}, J_{\mathrm{CP}}=33, \mathrm{PMe}\right)$.

\section{Formation of $\left[\mathrm{Mo}_{2} \mathrm{Cp}\left\{\mu-\kappa^{1}{ }_{0}: \kappa^{1}{ }_{s}, \eta^{5}-\mathrm{OP}(\mathrm{O})(\mathrm{C}(\mathrm{NPh}) \mathrm{S}) \mathrm{C}_{5} \mathrm{H}_{4}\right\}(\mathrm{CO})_{2}\left(\eta^{6}-\right.\right.$} HMes*)(PMe $)$ ] (3b). Compound $2 \mathbf{b}(0.026 \mathrm{~g}, 0.030 \mathrm{mmol})$ was allowed to stay in a Schlenk tube under an air atmosphere for $2 \mathrm{~h}$, then washed with petroleum ether $(2 \times 2$ $\mathrm{mL}$ ) and dried under vacuum to give reasonably pure compound $\mathbf{3 b}$ as a red powder. All attempts to further purify this product resulted in their progressive transformation into a mixture of uncharacterized species. The crystals used in the X-ray study of this complex were actually grown during attempts to crystallize compound $\mathbf{2 b}$ from toluene/petroleum ether solutions, which yielded instead tiny amounts of crystalline complex 3b. $v(\mathrm{CN})$ (Nujol mull): $1538(\mathrm{~m}) .{ }^{1} \mathrm{H}$ NMR (400.13 MHz, $\left.\mathrm{C}_{6} \mathrm{D}_{6}\right): \delta 7.61-7.10$ $(\mathrm{m}, 5 \mathrm{H}, \mathrm{Ph}), 5.98\left(\mathrm{~m}, 1 \mathrm{H}, \mathrm{C}_{5} \mathrm{H}_{4}\right), 5.22\left(\mathrm{~d},{ }^{3} J_{\mathrm{HP}}=2.5,5 \mathrm{H}, \mathrm{Cp}\right), 5.03,4.72(2 \mathrm{~m}, 2 \mathrm{x} 1 \mathrm{H}$, 
$\left.\mathrm{C}_{5} \mathrm{H}_{4}\right), 4.61\left(\mathrm{~s}, 3 \mathrm{H}, \mathrm{C}_{6} \mathrm{H}_{3}\right), 3.75\left(\mathrm{~m}, 1 \mathrm{H}, \mathrm{C}_{5} \mathrm{H}_{4}\right), 1.12\left(\mathrm{~s}, 27 \mathrm{H},{ }^{t} \mathrm{Bu}\right), 0.62\left(\mathrm{~d}, J_{\mathrm{PH}}=9,9 \mathrm{H}\right.$, $\mathrm{PMe})$.

Preparation of $\left[\mathrm{Mo}_{2} \mathrm{Cp}\left\{\mu-\kappa_{\mathrm{p}}^{\mathbf{1}} \mathbf{\kappa}_{\mathrm{s}}{ }_{\mathrm{s}}, \eta^{\mathbf{5}}-\mathrm{P}(\mathrm{S})\left(\mathrm{CS}_{2}\right) \mathrm{C}_{5} \mathrm{H}_{4}\right\}(\mathrm{CO})_{2}\left(\eta^{\mathbf{6}}-\mathrm{HMes}^{*}\right)\left(\mathrm{PMe}_{3}\right)\right]$ (4). A $0.0078 \mathrm{M}$ solution of $\mathrm{S}_{8}$ in toluene $(0.5 \mathrm{~mL}, 0.031 \mathrm{mmol})$ was added to a toluene solution $(2 \mathrm{~mL})$ of compound $2 \mathrm{a}(0.025 \mathrm{~g}, 0.031 \mathrm{mmol})$, whereby a purple precipitate appeared rapidly. The solvent was then removed under vacuum and the residue was chromatographed on alumina at $263 \mathrm{~K}$. Elution with neat dichloromethane gave a purple fraction yielding, upon removal of solvent, compound $\mathbf{4}$ as a purple microcrystalline solid $(0.020 \mathrm{~g}, 77 \%)$. No satisfactory elemental analysis was obtained for this highly sensitive material. ${ }^{1} \mathrm{H}$ NMR (300.13 MHz, $\left.\mathrm{C}_{6} \mathrm{D}_{6}\right): \delta 6.22,5.56\left(2 \mathrm{~m}, 2 \times 1 \mathrm{H}, \mathrm{C}_{5} \mathrm{H}_{4}\right), 5.34$ $(\mathrm{s}, 5 \mathrm{H}, \mathrm{Cp}), 4.84\left(\mathrm{~s}, 3 \mathrm{H}, \mathrm{C}_{6} \mathrm{H}_{3}\right), 4.43,4.05\left(2 \mathrm{~m}, 2 \times 1 \mathrm{H}, \mathrm{C}_{5} \mathrm{H}_{4}\right), 1.54\left(\mathrm{~d}, J_{\mathrm{PH}}=9,9 \mathrm{H}\right.$, $\mathrm{PMe}$ ), 1.28 (s, 27H, $\left.{ }^{t} \mathrm{Bu}\right) .{ }^{13} \mathrm{C}\left\{{ }^{1} \mathrm{H}\right\} \mathrm{NMR}\left(\mathrm{C}_{6} \mathrm{D}_{6}\right): \delta 268.4$ (s, SCS), 234.9 (d, $J_{\mathrm{CP}}=25$, $2 \mathrm{MoCO}), 114.0\left[\mathrm{~d}, J_{\mathrm{CP}}=31, \mathrm{C}^{1}\left(\mathrm{C}_{5} \mathrm{H}_{4}\right)\right], 104.9\left[\mathrm{~s}, \mathrm{C}\left(\mathrm{C}_{6} \mathrm{H}_{3}\right)\right], 95.6(\mathrm{~s}, \mathrm{Cp}), 90.6\left[\mathrm{~d}, J_{\mathrm{CP}}=\right.$ $\left.10, \mathrm{CH}\left(\mathrm{C}_{5} \mathrm{H}_{4}\right)\right], 89.0\left[\mathrm{~d}, J_{\mathrm{CP}}=6, \mathrm{CH}\left(\mathrm{C}_{5} \mathrm{H}_{4}\right)\right], 86.7\left[\mathrm{~d}, J_{\mathrm{CP}}=7, \mathrm{CH}\left(\mathrm{C}_{5} \mathrm{H}_{4}\right)\right], 79.4$ [s, $\left.\mathrm{CH}\left(\mathrm{C}_{6} \mathrm{H}_{3}\right)\right], 77.6\left[\mathrm{~d}, J_{\mathrm{CP}}=8, \mathrm{CH}\left(\mathrm{C}_{5} \mathrm{H}_{4}\right)\right], 35.3\left[\mathrm{~s}, \mathrm{C}^{1}\left({ }^{t} \mathrm{Bu}\right)\right], 31.8\left[\mathrm{~s}, \mathrm{C}^{2}\left({ }^{t} \mathrm{Bu}\right)\right], 20.6\left(\mathrm{~d}, J_{\mathrm{CP}}\right.$ $=33, \mathrm{PMe})$.

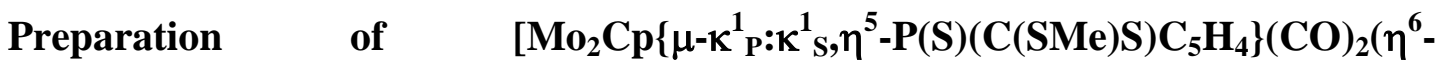
HMes*)(PMe $\left.\left.{ }^{*}\right)\right]\left(\mathbf{B A r}^{\prime}{ }_{4}\right)$ (5). Neat $\mathrm{Me}_{2} \mathrm{SO}_{4}(4 \mu \mathrm{L}, 0.40 \mathrm{mmol})$ was added to a solution of compound $4(0.025 \mathrm{~g}, 0.030 \mathrm{mmol})$ in dichloromethane $(2 \mathrm{~mL})$, and the mixture was stirred for $1 \mathrm{~min}$ to give a blue solution. Solid $\mathrm{Na}\left(\mathrm{BAr}^{\prime}{ }_{4}\right)(0.027 \mathrm{~g}, 0.030 \mathrm{mmol})$ was then added, and the mixture was stirred for a further 2 min and then chromatographed on alumina at $263 \mathrm{~K}$. Elution with dichloromethane/petroleum ether (1/3) gave a blue fraction yielding, upon removal of solvents, compound $\mathbf{5}$ as a blue microcrystalline solid (0.045 g, 87\%). Anal. Calcd for $\mathrm{C}_{67} \mathrm{H}_{63} \mathrm{BMo}_{2} \mathrm{O}_{2} \mathrm{P}_{2} \mathrm{~S}_{3} \mathrm{~F}_{24}: \mathrm{C}, 46.87 ; \mathrm{H}, 3.70 ; \mathrm{S}, 5.60$. Found: C, 46.55; H, 3.40; S, 5.35. ${ }^{1} \mathrm{H}$ NMR $\left(\mathrm{CD}_{2} \mathrm{Cl}_{2}\right): \delta 7.72\left(\mathrm{~m}, 8 \mathrm{H}, \mathrm{Ar}^{\prime}\right), 7.56(\mathrm{~m}, 4 \mathrm{H}$, $\left.\mathrm{Ar}^{\prime}\right), 6.39,5.54\left(2 \mathrm{~m}, 2\right.$ x 1H, $\left.\mathrm{C}_{5} \mathrm{H}_{4}\right), 5.34(\mathrm{~s}, 5 \mathrm{H}, \mathrm{Cp}), 5.19$ (s, 3H, $\left.\mathrm{C}_{6} \mathrm{H}_{3}\right), 4.38,4.30$ $\left(2 \mathrm{~m}, 2 \times 1 \mathrm{H}, \mathrm{C}_{5} \mathrm{H}_{4}\right), 2.73$ (s, 3H, SMe), 1.58 (d, $\left.J_{\mathrm{PH}}=10,9 \mathrm{H}, \mathrm{PMe}\right), 1.29$ (s, 27H, $\left.{ }^{t} \mathrm{Bu}\right)$. ${ }^{13} \mathrm{C}\left\{{ }^{1} \mathrm{H}\right\} \mathrm{NMR}\left(\mathrm{CD}_{2} \mathrm{Cl}_{2}\right): \delta 234.9\left(\mathrm{t}, J_{\mathrm{CP}}=24, \mathrm{MoCO}\right), 234.7\left(\mathrm{t}, J_{\mathrm{CP}}=27, \mathrm{MoCO}\right), 233.7$ $(\mathrm{s}, \mathrm{SCS}), 162.2\left[\mathrm{q}, J_{\mathrm{CB}}=50, \mathrm{C}^{1}\left(\mathrm{Ar}^{\prime}\right)\right], 135.2\left[\mathrm{~s}, \mathrm{C}^{2}\left(\mathrm{Ar}^{\prime}\right)\right], 129.3\left[\mathrm{q}, J_{\mathrm{CF}}=32, \mathrm{C}^{3}\left(\mathrm{Ar}^{\prime}\right)\right]$, $125.0\left(\mathrm{q}, J_{\mathrm{CF}}=272, \mathrm{CF}_{3}\right), 117.9\left[\mathrm{~s}, \mathrm{C}^{4}\left(\mathrm{Ar}^{\prime}\right)\right], 112.1\left[\mathrm{~s}, \mathrm{C}\left(\mathrm{C}_{6} \mathrm{H}_{3}\right)\right], 102.8\left[\mathrm{~d}, J_{\mathrm{CP}}=30\right.$, $\left.\mathrm{C}^{1}\left(\mathrm{C}_{5} \mathrm{H}_{4}\right)\right], 95.6(\mathrm{~s}, \mathrm{Cp}), 89.6\left[\mathrm{~d}, J_{\mathrm{CP}}=10, \mathrm{CH}\left(\mathrm{C}_{5} \mathrm{H}_{4}\right)\right], 88.9$ [d, $\left.J_{\mathrm{CP}}=7, \mathrm{CH}\left(\mathrm{C}_{5} \mathrm{H}_{4}\right)\right], 88.7$ $\left[\mathrm{d}, J_{\mathrm{CP}}=11, \mathrm{CH}\left(\mathrm{C}_{5} \mathrm{H}_{4}\right)\right], 82.6\left[\mathrm{~s}, \mathrm{CH}\left(\mathrm{C}_{6} \mathrm{H}_{3}\right)\right], 80.9\left[\mathrm{~d}, J_{\mathrm{CP}}=10, \mathrm{CH}\left(\mathrm{C}_{5} \mathrm{H}_{4}\right)\right], 36.0[\mathrm{~s}$, $\left.\mathrm{C}^{1}\left({ }^{t} \mathrm{Bu}\right)\right], 31.6\left[\mathrm{~s}, \mathrm{C}^{2}\left({ }^{t} \mathrm{Bu}\right)\right], 21.5\left(\mathrm{~d}, J_{\mathrm{CP}}=4, \mathrm{SMe}\right), 20.4\left(\mathrm{~d}, J_{\mathrm{CP}}=34, \mathrm{PMe}\right)$.

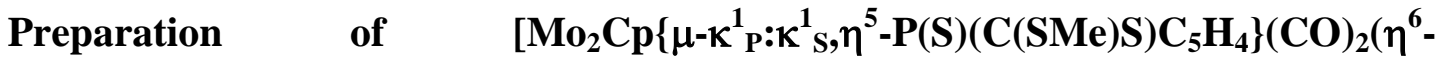

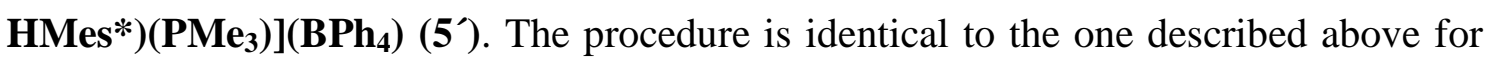
5, but using $\mathrm{Na}\left(\mathrm{BPh}_{4}\right)(0.010 \mathrm{~g}, 0.030 \mathrm{mmol})$ instead of $\mathrm{Na}\left(\mathrm{BAr}^{\prime}{ }_{4}\right)$ and elution with dichloromethane/petroleum ether (3/1). This yielded compound $\mathbf{5}^{\prime}$ as a blue microcrystalline solid $(0.030 \mathrm{~g}, 85 \%)$. The crystals used in the X-ray diffraction study 
were grown through the slow diffusion of layers of diethyl ether and petroleum ether into a concentrated dichloromethane solution of the complex at $253 \mathrm{~K}$. Anal. Calcd for $\mathrm{C}_{59} \mathrm{H}_{71} \mathrm{BMo}_{2} \mathrm{O}_{2} \mathrm{P}_{2} \mathrm{~S}_{3}$ : C, 60.41; H, 6.10; S, 8.20. Found: C, 60.08; H, 5.86; S, 7.85. ${ }^{1} \mathrm{H}$ NMR $\left(\mathrm{CD}_{2} \mathrm{Cl}_{2}\right): \delta 7.31\left[\mathrm{~m}, 8 \mathrm{H}, \mathrm{H}^{2}(\mathrm{Ph})\right], 7.02\left[\mathrm{t}, J_{\mathrm{HH}}=7,8 \mathrm{H}, \mathrm{H}^{3}(\mathrm{Ph})\right], 6.87[\mathrm{~m}, 4 \mathrm{H}$, $\left.\mathrm{H}^{4}(\mathrm{Ph})\right], 6.37,5.50\left(2 \mathrm{~m}, 2 \mathrm{x} \mathrm{1H}, \mathrm{C}_{5} \mathrm{H}_{4}\right), 5.31$ (s, 5H, Cp), 5.18 (s, 3H, $\left.\mathrm{C}_{6} \mathrm{H}_{3}\right), 4.37,4.28$ $\left(2 \mathrm{~m}, 2 \times 1 \mathrm{H}, \mathrm{C}_{5} \mathrm{H}_{4}\right), 2.71(\mathrm{~s}, 3 \mathrm{H}, \mathrm{SMe}), 1.55\left(\mathrm{~d}, J_{\mathrm{PH}}=10,9 \mathrm{H}, \mathrm{PMe}\right), 1.30\left(\mathrm{~s}, 27 \mathrm{H},{ }^{t} \mathrm{Bu}\right)$.

\section{Preparation of $\left[\mathrm{Mo}_{2} \mathrm{Cp}\left\{\mu-\kappa^{1}{ }_{\mathrm{p}}: \kappa^{1}{ }_{\mathrm{s}}, \eta^{5}-\mathrm{PMe}\left(\mathrm{CS}_{2}\right) \mathrm{C}_{5} \mathrm{H}_{4}\right\}(\mathrm{CO})_{2}\left(\eta^{6}\right.\right.$ -} HMes*)(PMe 3$)]\left(\right.$ BAr $\left.^{\prime}{ }_{4}\right)$ (6a). Neat MeI $(10 \mu \mathrm{L}, 0.160 \mathrm{mmol})$ was added to a solution of compound $2 \mathbf{a}(0.025 \mathrm{~g}, 0.031 \mathrm{mmol})$ in dichloromethane $(2 \mathrm{~mL})$ at $223 \mathrm{~K}$, and the mixture was stirred at this temperature for $1 \mathrm{~min}$ to give a blue solution. Solid $\mathrm{Na}\left(\mathrm{BAr}_{4}{ }_{4}\right)(0.028 \mathrm{~g}, 0.031 \mathrm{mmol})$ was then added, and the mixture was stirred for a further $2 \mathrm{~min}$ and then chromatographed on alumina at $263 \mathrm{~K}$. Elution with dichloromethane/petroleum ether (1/3) gave a purple fraction yielding, upon removal of solvents, compound 7 as a purple microcrystalline solid $(0.010 \mathrm{~g}, 19 \%)$. Elution with dichloromethane/petroleum ether (1/1) gave a blue fraction yielding analogously compound 6a as a blue microcrystalline solid $(0.032 \mathrm{~g}, 61 \%)$. Anal. Calcd for $\mathrm{C}_{67} \mathrm{H}_{63} \mathrm{BMo}_{2} \mathrm{O}_{2} \mathrm{P}_{2} \mathrm{~S}_{2} \mathrm{~F}_{24}: \mathrm{C}, 47.76 ; \mathrm{H}, 3.77 ; \mathrm{S}, 3.81$. Found: $\mathrm{C}, 47.32 ; \mathrm{H}, 3.35 ; \mathrm{S}, 3.50 .{ }^{1} \mathrm{H}$ NMR (300.09 MHz, $\left.\mathrm{CD}_{2} \mathrm{Cl}_{2}\right): \delta 7.72\left(\mathrm{~m}, 8 \mathrm{H}, \mathrm{Ar}^{\prime}\right), 7.56\left(\mathrm{~m}, 4 \mathrm{H}, \mathrm{Ar}^{\prime}\right), 5.64,5.60(2 \mathrm{~m}, 2$ x $\left.1 \mathrm{H}, \mathrm{C}_{5} \mathrm{H}_{4}\right), 5.33\left(\mathrm{~s}, J_{\mathrm{PH}}=1.4,5 \mathrm{H}, \mathrm{Cp}\right), 5.01\left(\mathrm{~s}, 3 \mathrm{H}, \mathrm{C}_{6} \mathrm{H}_{3}\right), 4.50,4.35(2 \mathrm{~m}, 2 \mathrm{x} 1 \mathrm{H}$, $\left.\mathrm{C}_{5} \mathrm{H}_{4}\right), 2.01\left(\mathrm{~d}, J_{\mathrm{PH}}=9,3 \mathrm{H}, \mathrm{PMe}\right), 1.68\left(\mathrm{~d}, J_{\mathrm{PH}}=10,9 \mathrm{H}, \mathrm{PMe}_{3}\right), 1.29\left(\mathrm{~s}, 27 \mathrm{H},{ }^{t} \mathrm{Bu}\right)$. ${ }^{13} \mathrm{C}\left\{{ }^{1} \mathrm{H}\right\} \mathrm{NMR}\left(\mathrm{CD}_{2} \mathrm{Cl}_{2}\right): \delta 254.0\left(\mathrm{~d}, J_{\mathrm{CP}}=12, \mathrm{SCS}\right), 232.6(\mathrm{~m}, 2 \mathrm{MoCO}), 162.2\left[\mathrm{q}, J_{\mathrm{CB}}\right.$ $\left.=50, \mathrm{C}^{1}\left(\mathrm{Ar}^{\prime}\right)\right], 135.2\left[\mathrm{~s}, \mathrm{C}^{2}\left(\mathrm{Ar}^{\prime}\right)\right], 129.1\left[\mathrm{q}, J_{\mathrm{CF}}=32, \mathrm{C}^{3}\left(\mathrm{Ar}^{\prime}\right)\right], 125.0\left(\mathrm{q}, J_{\mathrm{CF}}=272\right.$, $\left.\mathrm{CF}_{3}\right), 117.8$ [s, $\left.\mathrm{C}^{4}\left(\mathrm{Ar}^{\prime}\right)\right], 100.1\left[\mathrm{~d}, J_{\mathrm{CP}}=41, \mathrm{C}^{1}\left(\mathrm{C}_{5} \mathrm{H}_{4}\right)\right], 93.2(\mathrm{~s}, \mathrm{Cp}), 92.5$ [s, C( $\left.\left.\mathrm{C}_{6} \mathrm{H}_{3}\right)\right]$, $90.9\left[\mathrm{~d}, J_{\mathrm{CP}}=13, \mathrm{CH}\left(\mathrm{C}_{5} \mathrm{H}_{4}\right)\right], 88.9\left[\mathrm{~d}, J_{\mathrm{CP}}=8, \mathrm{CH}\left(\mathrm{C}_{5} \mathrm{H}_{4}\right)\right], 82.9\left[\mathrm{~d}, J_{\mathrm{CP}}=4, \mathrm{CH}\left(\mathrm{C}_{5} \mathrm{H}_{4}\right)\right]$, $80.3\left[\mathrm{~d}, J_{\mathrm{CP}}=7, \mathrm{CH}\left(\mathrm{C}_{5} \mathrm{H}_{4}\right)\right], 79.8\left[\mathrm{~s}, \mathrm{CH}\left(\mathrm{C}_{6} \mathrm{H}_{3}\right)\right], 35.7\left[\mathrm{~s}, \mathrm{C}^{1}\left({ }^{t} \mathrm{Bu}\right)\right], 31.6\left[\mathrm{~s}, \mathrm{C}^{2}\left({ }^{t} \mathrm{Bu}\right)\right]$, $20.5\left[\mathrm{~d}, J_{\mathrm{CP}}=35, \mathrm{PMe}_{3}\right], 18.8\left(\mathrm{~d}, J_{\mathrm{CP}}=31, \mathrm{PMe}\right)$.

\section{Preparation of $\left[\mathrm{Mo}_{2} \mathrm{Cp}\left\{\mu-\kappa^{1}{ }_{\mathrm{p}}: \kappa^{1}{ }_{\mathrm{S}}, \eta^{5}-\mathrm{PMe}\left(\mathrm{CS}_{2}\right) \mathrm{C}_{5} \mathrm{H}_{4}\right\}(\mathrm{CO})_{2}\left(\eta^{6}\right.\right.$ -} HMes*) $\left.\left(\mathbf{P M e}_{3}\right)\right]\left(\mathbf{B P h}_{4}\right)\left(\mathbf{6 a}^{\prime}\right)$. The procedure is identical to the one described above for 6a, but using $\mathrm{Na}\left(\mathrm{BPh}_{4}\right)(0.011 \mathrm{~g}, 0.031 \mathrm{mmol})$ instead of $\mathrm{Na}\left(\mathrm{BAr}_{4}{ }_{4}\right)$. Elution with dichloromethane/petroleum ether (2/1) gave a blue fraction yielding, upon removal of solvents, compound $7^{\prime}$ as a blue microcrystalline solid $(0.07 \mathrm{~g}, 20 \%)$. Elution with dichloromethane/petroleum ether (3/1) gave a blue fraction yielding analogously compound $\mathbf{6 a}^{\prime}$ as a blue microcrystalline solid (0.023 g, 65\%). The crystals used in the $\mathrm{X}$-ray diffraction study were grown through the slow diffusion of layers of diethyl ether and petroleum ether into a concentrated dichloromethane solution of the complex at 253 K. Anal. Calcd for $\mathrm{C}_{59} \mathrm{H}_{71} \mathrm{BMo}_{2} \mathrm{O}_{2} \mathrm{P}_{2} \mathrm{~S}_{2}$ : C, 62.11; H, 6.27; S, 5.62. Found: C, 61.77; H, 6.03; S, 5.12. ${ }^{1} \mathrm{H}$ NMR (300.09 MHz, $\left.\mathrm{CD}_{2} \mathrm{Cl}_{2}\right): \delta 7.31\left[\mathrm{~m}, 8 \mathrm{H}, \mathrm{C}^{2}(\mathrm{Ph})\right], 7.02\left[\mathrm{t}, J_{\mathrm{HH}}=7\right.$, $\left.8 \mathrm{H}, \mathrm{C}^{3}(\mathrm{Ph})\right], 6.87\left[\mathrm{~m}, 4 \mathrm{H}, \mathrm{C}^{4}(\mathrm{Ph})\right], 5.60,5.56\left(2 \mathrm{~m}, 2 \mathrm{x} 1 \mathrm{H}, \mathrm{C}_{5} \mathrm{H}_{4}\right), 5.19(\mathrm{~s}, 5 \mathrm{H}, \mathrm{Cp}), 4.99$ 
$\left(\mathrm{s}, 3 \mathrm{H}, \mathrm{C}_{6} \mathrm{H}_{3}\right), 4.47,4.31\left(2 \mathrm{~m}, 2 \times 1 \mathrm{H}, \mathrm{C}_{5} \mathrm{H}_{4}\right), 1.96\left(\mathrm{~d}, J_{\mathrm{PH}}=9,3 \mathrm{H}, \mathrm{PMe}\right), 1.59\left(\mathrm{~d}, J_{\mathrm{PH}}=\right.$ 10, 9H, $\left.\mathrm{PMe}_{3}\right), 1.29\left(\mathrm{~s}, 27 \mathrm{H},{ }^{t} \mathrm{Bu}\right)$.

\section{Preparation of $\left[\mathrm{Mo}_{2} \mathrm{Cp}\left\{\mu-\kappa^{1}{ }_{\mathrm{p}}: \kappa^{1}{ }_{\mathrm{s}}, \eta^{5}-\mathrm{PMe}(\mathrm{C}(\mathrm{NPh}) \mathrm{S}) \mathrm{C}_{5} \mathrm{H}_{4}\right\}(\mathrm{CO})_{2}\left(\eta^{6}-\right.\right.$} HMes*)(PMe $\left.\left.{ }^{*}\right)\right]\left(\mathbf{B A r}^{\prime}{ }_{4}\right)$ (6b). Neat MeI $(10 \mu \mathrm{L}, 0.160 \mathrm{mmol})$ was added to a solution of compound $\mathbf{2 b}(0.026 \mathrm{~g}, 0.030 \mathrm{mmol})$ in toluene $(2 \mathrm{~mL})$, and the mixture was stirred for $1 \mathrm{~min}$, whereupon a brown precipitate was formed. After removal of the solvent under vacuum, the residue was dissolved in dichloromethane $(3 \mathrm{~mL})$, then solid $\mathrm{Na}\left(\mathrm{BAr}_{4}{ }_{4}\right)(0.027 \mathrm{~g}, 0.030 \mathrm{mmol})$ was added, and the mixture was stirred for $2 \mathrm{~min}$ and then chromatographed on alumina at $263 \mathrm{~K}$. Elution with dichloromethane/petroleum ether (1/1) gave a green fraction yielding, upon removal of solvents, compound $\mathbf{6} \mathbf{b}$ as a green microcrystalline solid $(0.040 \mathrm{~g}, 76 \%)$. Anal. Calcd for $\mathrm{C}_{73} \mathrm{H}_{68} \mathrm{BMo}_{2} \mathrm{NO}_{2} \mathrm{P}_{2} \mathrm{SF}_{24}: \mathrm{C}$, 50.27; H, 3.93; N, 0.80; S, 1.84. Found: C, 49.85; H, 3.63; N, 0.70; S, 1.52. ${ }^{1} \mathrm{H}$ NMR (300.09 MHz, $\left.\mathrm{CD}_{2} \mathrm{Cl}_{2}\right): \delta 7.72\left(\mathrm{~m}, 8 \mathrm{H}, \mathrm{Ar}^{\prime}\right), 7.56\left(\mathrm{~m}, 4 \mathrm{H}, \mathrm{Ar}^{\prime}\right), 7.30-7.08(\mathrm{~m}, 5 \mathrm{H}, \mathrm{Ph})$, 5.77, $5.57\left(2 \mathrm{~m}, 2\right.$ x 1H, $\left.\mathrm{C}_{5} \mathrm{H}_{4}\right), 5.34(\mathrm{~s}, 5 \mathrm{H}, \mathrm{Cp}), 4.80\left(\mathrm{~s}, 3 \mathrm{H}, \mathrm{C}_{6} \mathrm{H}_{3}\right), 4.45,4.06(2 \mathrm{~m}, 2 \mathrm{x}$ $\left.1 \mathrm{H}, \mathrm{C}_{5} \mathrm{H}_{4}\right), 2.14\left(\mathrm{~d}, J_{\mathrm{PH}}=9,3 \mathrm{H}, \mathrm{PMe}\right), 1.65\left(\mathrm{~d}, J_{\mathrm{PH}}=10,9 \mathrm{H}, \mathrm{PMe}_{3}\right), 1.21\left(\mathrm{~s}, 27 \mathrm{H},{ }^{t} \mathrm{Bu}\right)$.

\section{Preparation of $\left[\mathrm{Mo}_{2} \mathrm{Cp}\left\{\mu-\kappa^{1}{ }_{\mathrm{p}}: \kappa^{\mathbf{1}}{ }_{\mathrm{s}}, \eta^{\mathbf{5}}-\mathrm{P}(\mathrm{C}(\mathrm{SMe}) \mathrm{S}) \mathrm{C}_{5} \mathrm{H}_{4}\right\}(\mathrm{CO})_{2}\left(\eta^{\mathbf{6}}\right.\right.$ -} HMes*)(PMe $\left.\left.{ }_{3}\right)\right]\left(\mathbf{B A r}_{4}{ }_{4}\right)$ (7). Neat $\mathrm{Me}_{2} \mathrm{SO}_{4}(3 \mu \mathrm{L}, 0.031 \mathrm{mmol})$ was added to a solution of compound $2 \mathbf{a}(0.025 \mathrm{~g}, 0.031 \mathrm{mmol})$ in dichloromethane $(2 \mathrm{~mL})$ at room temperature, and the mixture was stirred for $1 \mathrm{~min}$ to give a purple solution. Solid $\mathrm{Na}\left(\mathrm{BAr}_{4}{ }_{4}\right)(0.028 \mathrm{~g}, 0.031 \mathrm{mmol})$ was then added, and the mixture was stirred for a further 2 min and then chromatographed on alumina at $263 \mathrm{~K}$. A blue band was eluted with dichloromethane/petroleum ether (1/2) which gave, upon removal of solvents, compound 7 as a purple microcrystalline solid $(0.046 \mathrm{~g}, 88 \%)$. No elemental analysis was obtained for this very air-sensitive product. ${ }^{1} \mathrm{H} \mathrm{NMR}\left(300.09 \mathrm{MHz}, \mathrm{CD}_{2} \mathrm{Cl}_{2}\right): \delta 7.72$ (m, 8H, Ar'), $7.56\left(\mathrm{~m}, 4 \mathrm{H}, \mathrm{Ar}^{\prime}\right), 5.36(\mathrm{~s}, 5 \mathrm{H}, \mathrm{Cp}), 5.05\left(\mathrm{~s}, 3 \mathrm{H}, \mathrm{C}_{6} \mathrm{H}_{3}\right), 4.85(\mathrm{~m}, 2 \mathrm{H}$, $\left.\mathrm{C}_{5} \mathrm{H}_{4}\right), 4.70\left(\mathrm{~m}, 2 \mathrm{H}, \mathrm{C}_{5} \mathrm{H}_{4}\right), 2.76\left(\mathrm{~d}, J_{\mathrm{PH}}=1,3 \mathrm{H}, \mathrm{SMe}\right), 1.58$ (d, $\left.J_{\mathrm{PH}}=10,9 \mathrm{H}, \mathrm{PMe}\right)$, $1.26\left(\mathrm{~s}, 27 \mathrm{H},{ }^{t} \mathrm{Bu}\right) .{ }^{13} \mathrm{C}\left\{{ }^{1} \mathrm{H}\right\} \mathrm{NMR}\left(\mathrm{CD}_{2} \mathrm{Cl}_{2}\right): \delta 243.4\left(\mathrm{~d}, J_{\mathrm{CP}}=51, \mathrm{SCS}\right), 231.8\left(\mathrm{dd}, J_{\mathrm{CP}}=\right.$ $\left.28, J_{\mathrm{CP}}=11,2 \mathrm{MoCO}\right), 162.2\left[\mathrm{q}, J_{\mathrm{CB}}=50, \mathrm{C}^{1}\left(\mathrm{Ar}^{\prime}\right)\right], 135.2\left[\mathrm{~s}, \mathrm{C}^{2}\left(\mathrm{Ar}^{\prime}\right)\right], 129.1\left[\mathrm{q}, J_{\mathrm{CF}}=\right.$ $\left.32, \mathrm{C}^{3}\left(\mathrm{Ar}^{\prime}\right)\right], 125.0\left(\mathrm{q}, J_{\mathrm{CF}}=272, \mathrm{CF}_{3}\right), 117.8\left[\mathrm{~s}, \mathrm{C}^{4}\left(\mathrm{Ar}^{\prime}\right)\right], 101.6\left[\mathrm{~d}, J_{\mathrm{CP}}=16\right.$, $\left.\mathrm{C}^{1}\left(\mathrm{C}_{5} \mathrm{H}_{4}\right)\right], 95.1$ [s, $\left.\mathrm{C}\left(\mathrm{C}_{6} \mathrm{H}_{3}\right)\right], 93.1(\mathrm{~s}, \mathrm{Cp}), 89.2\left[\mathrm{~d}, J_{\mathrm{CP}}=13,2 \mathrm{CH}\left(\mathrm{C}_{5} \mathrm{H}_{4}\right)\right], 83.3\left[\mathrm{~d}, J_{\mathrm{CP}}=\right.$ 4, $\left.2 \mathrm{CH}\left(\mathrm{C}_{5} \mathrm{H}_{4}\right)\right], 81.6\left[\mathrm{~s}, \mathrm{CH}\left(\mathrm{C}_{6} \mathrm{H}_{3}\right)\right], 35.3\left[\mathrm{~s}, \mathrm{C}^{1}\left({ }^{t} \mathrm{Bu}\right)\right], 31.9$ [s, $\left.\mathrm{C}^{2}\left({ }^{t} \mathrm{Bu}\right)\right], 21.7$ (s, SMe), $20.6\left(\mathrm{~d}, J_{\mathrm{CP}}=34, \mathrm{PMe}\right)$.

Preparation of $\left[\mathrm{Mo}_{2} \mathrm{Cp}\left\{\mu-\kappa^{1}{ }_{\mathrm{P}}: \kappa^{1}{ }_{\mathrm{S}}, \eta^{\mathbf{5}}-\mathrm{P}\left(\mathrm{CH}_{2} \mathrm{Cl}\right)(\mathrm{C}(\mathrm{NPh}) \mathrm{S}) \mathrm{C}_{5} \mathrm{H}_{4}\right\}(\mathrm{CO})_{2}\left(\eta^{6}-\right.\right.$ HMes $\left.\left.^{*}\right)\left(\mathbf{P M e}_{3}\right)\right]\left(\mathrm{BAr}^{\prime}{ }_{4}\right)$ (8). Neat DBU (1,8-diazabicyclo[5.4.0]undec-7-ene, $4 \mu \mathrm{L}$, $0.026 \mathrm{mmol})$ was added to a solution of compound $\mathbf{2 b}(0.026 \mathrm{~g}, 0.030 \mathrm{mmol})$ in dichloromethane $(2 \mathrm{~mL})$. Solid $\mathrm{Na}\left(\mathrm{BAr}^{\prime}{ }_{4}\right)(0.027 \mathrm{~g}, 0.030 \mathrm{mmol})$ was then added, and the mixture was stirred at room temperature for $2 \mathrm{~h}$ to give a green solution which was chromatographed on alumina at $263 \mathrm{~K}$. Elution with dichloromethane/petroleum ether 
(1/1) gave a green fraction yielding, upon removal of solvents, compound $\mathbf{8}$ as a green microcrystalline solid $(0.043 \mathrm{~g}, 78 \%)$. The crystals used in the X-ray diffraction study were grown through by the slow diffusion of a layer of petroleum ether into a concentrated dichloromethane solution of the complex at $253 \mathrm{~K}$. Anal. Calcd for $\mathrm{C}_{73} \mathrm{H}_{67} \mathrm{BClMo}_{2} \mathrm{NO}_{2} \mathrm{P}_{2} \mathrm{SF}_{24}$ : C, 49.30; H, 3.80; N, 0.79; S, 1.80. Found: C, 48.95; H, 3.50; N, 0.98; S, 1.36. ${ }^{1} \mathrm{H}$ NMR (300.09 MHz, $\left.\mathrm{CD}_{2} \mathrm{Cl}_{2}\right): \delta 7.72\left(\mathrm{~m}, 8 \mathrm{H}, \mathrm{Ar}^{\prime}\right), 7.56(\mathrm{~m}$, $\left.4 \mathrm{H}, \mathrm{Ar}^{\prime}\right), 7.32-7.09$ (m, 5H, Ph), 5.88, $5.74\left(2 \mathrm{~m}, 2\right.$ x 1H, $\left.\mathrm{C}_{5} \mathrm{H}_{4}\right), 5.42$ (s, 5H, Cp), 4.86 $\left(\mathrm{d}, J_{\mathrm{PH}}=13,1 \mathrm{H}, \mathrm{CH}_{2} \mathrm{Cl}\right), 4.82\left(\mathrm{~s}, 3 \mathrm{H}, \mathrm{C}_{6} \mathrm{H}_{3}\right), 4.50\left(\mathrm{~m}, 1 \mathrm{H}, \mathrm{C}_{5} \mathrm{H}_{4}\right), 4.19\left(\mathrm{dd}, J_{\mathrm{PH}}=13\right.$, $\left.J_{\mathrm{PH}}=2,1 \mathrm{H}, \mathrm{CH}_{2} \mathrm{Cl}\right), 4.10\left(\mathrm{~m}, 1 \mathrm{H}, \mathrm{C}_{5} \mathrm{H}_{4}\right), 1.68\left(\mathrm{~d}, J_{\mathrm{PH}}=10,9 \mathrm{H}, \mathrm{PMe}\right), 1.21(\mathrm{~s}, 27 \mathrm{H}$, $\left.{ }^{t} \mathrm{Bu}\right) .{ }^{13} \mathrm{C}\left\{{ }^{1} \mathrm{H}\right\} \operatorname{NMR}\left(\mathrm{CD}_{2} \mathrm{Cl}_{2}\right): \delta 232.3(\mathrm{~m}, 2 \mathrm{MoCO}), 191.1\left(\mathrm{~d}, J_{\mathrm{CP}}=66, \mathrm{SCN}\right), 162.2$ $\left[\mathrm{q}, J_{\mathrm{CB}}=50, \mathrm{C}^{1}\left(\mathrm{Ar}^{\prime}\right)\right], 150.1\left[\mathrm{~d}, J_{\mathrm{CP}}=27, \mathrm{C}^{1}(\mathrm{Ph})\right], 135.2\left[\mathrm{~s}, \mathrm{C}^{2}\left(\mathrm{Ar}^{\prime}\right)\right], 129.1\left[\mathrm{q}, J_{\mathrm{CF}}=32\right.$, $\left.\mathrm{C}^{3}\left(\mathrm{Ar}^{\prime}\right)\right], 128.9[\mathrm{~s}, \mathrm{CH}(\mathrm{Ph})], 125.3\left[\mathrm{~s}, \mathrm{C}^{4}(\mathrm{Ph})\right], 125.0\left(\mathrm{q}, J_{\mathrm{CF}}=272, \mathrm{CF}_{3}\right), 121.6[\mathrm{~s}$, $\mathrm{CH}(\mathrm{Ph})], 117.9$ [s, $\left.\mathrm{C}^{4}\left(\mathrm{Ar}^{\prime}\right)\right], 110.6\left[\mathrm{~s}, \mathrm{C}\left(\mathrm{C}_{6} \mathrm{H}_{3}\right)\right], 97.7$ [d, $\left.J_{\mathrm{CP}}=13, \mathrm{CH}\left(\mathrm{C}_{5} \mathrm{H}_{4}\right)\right], 92.7$ [d, $\left.J_{\mathrm{CP}}=19, \mathrm{C}^{1}\left(\mathrm{C}_{5} \mathrm{H}_{4}\right)\right], 92.9(\mathrm{~s}, \mathrm{Cp}), 89.1\left[\mathrm{~d}, J_{\mathrm{CP}}=9, \mathrm{CH}\left(\mathrm{C}_{5} \mathrm{H}_{4}\right)\right], 83.4\left[\mathrm{~d}, J_{\mathrm{CP}}=4\right.$, $\left.\mathrm{CH}\left(\mathrm{C}_{5} \mathrm{H}_{4}\right)\right], 77.2\left[\mathrm{~d}, J_{\mathrm{CP}}=8, \mathrm{CH}\left(\mathrm{C}_{5} \mathrm{H}_{4}\right)\right], 77.0\left[\mathrm{~s}, \mathrm{CH}\left(\mathrm{C}_{6} \mathrm{H}_{3}\right)\right], 41.1\left(\mathrm{~d}, J_{\mathrm{CP}}=4, \mathrm{CH}_{2} \mathrm{Cl}\right)$, $35.7\left[\mathrm{~s}, \mathrm{C}^{1}\left({ }^{t} \mathrm{Bu}\right)\right], 31.3\left[\mathrm{~s}, \mathrm{C}^{2}\left({ }^{t} \mathrm{Bu}\right)\right], 20.4\left(\mathrm{~d}, J_{\mathrm{CP}}=35, \mathrm{PMe}\right)$.

Preparation of $\left[\mathrm{Mo}_{2} \mathrm{Cp}\left\{\mu-\kappa_{\mathrm{p}}^{1} \mathrm{\kappa}_{\mathrm{S}}{ }_{\mathrm{s}}, \eta^{5}-\mathrm{PMe}(\mathrm{C}(\mathrm{SMe}) \mathrm{S}) \mathrm{C}_{5} \mathrm{H}_{4}\right\}(\mathrm{CO})_{2}\left(\eta^{6}-\right.\right.$ HMes*)(PMe $\left.\left.{ }_{3}\right)\right]\left(\mathbf{B A r}^{\prime}{ }_{4}\right)_{2}$ (9). Solid $\left[\mathrm{Me}_{3} \mathrm{O}\right]\left(\mathrm{BF}_{4}\right)(0.009 \mathrm{~g}, 0.062 \mathrm{mmol})$ was added to a solution of compound $2 \mathbf{a}(0.025 \mathrm{~g}, 0.031 \mathrm{mmol})$ in dichloromethane $(2 \mathrm{~mL})$, and the mixture was stirred at room temperature for $15 \mathrm{~min}$ to give a blue solution. Solid $\mathrm{Na}\left(\mathrm{BAr}_{4}{ }_{4}\right)(0.055 \mathrm{~g}, 0.062 \mathrm{mmol})$ was then added, and the mixture was stirred for a further 2 min and then filtered using a cannula. Removal of the solvent from the filtrate gave compound 9 as a blue microcrystalline solid $(0.063 \mathrm{~g}, 80 \%)$. The crystals used in the X-ray diffraction study were grown through the slow diffusion of layers of diethyl ether and petroleum ether into a concentrated dichloromethane solution of the complex at $253 \mathrm{~K}$. Anal. Calcd for $\mathrm{C}_{100} \mathrm{H}_{78} \mathrm{~B}_{2} \mathrm{Mo}_{2} \mathrm{O}_{2} \mathrm{P}_{2} \mathrm{~S}_{2} \mathrm{~F}_{48}$ : C, 46.86; H, 3.07; S, 2.50. Found: $\mathrm{C}, 47.15 ; \mathrm{H}, 3.01 ; \mathrm{S}, 1.91 .{ }^{1} \mathrm{H}$ NMR $\left(300.09 \mathrm{MHz}, \mathrm{CD}_{2} \mathrm{Cl}_{2}\right): \delta 7.72\left(\mathrm{~m}, 16 \mathrm{H}, \mathrm{Ar}^{\prime}\right), 7.56$ $\left(\mathrm{m}, 8 \mathrm{H}, \mathrm{Ar}^{\prime}\right), 6.00,5.75\left(2 \mathrm{~m}, 2 \times 1 \mathrm{H}, \mathrm{C}_{5} \mathrm{H}_{4}\right), 5.46\left(\mathrm{~s}, 3 \mathrm{H}, \mathrm{C}_{6} \mathrm{H}_{3}\right), 5.35(\mathrm{~s}, 5 \mathrm{H}, \mathrm{Cp}), 4.57$, $4.23\left(2 \mathrm{~m}, 2 \times 1 \mathrm{H}, \mathrm{C}_{5} \mathrm{H}_{4}\right), 2.77(\mathrm{~s}, 3 \mathrm{H}, \mathrm{SMe}), 1.95\left(\mathrm{~d}, J_{\mathrm{PH}}=8,3 \mathrm{H}, \mathrm{PMe}\right), 1.72\left(\mathrm{~d}, J_{\mathrm{PH}}=\right.$ 10, 9H, $\left.\mathrm{PMe}_{3}\right), 1.28\left(\mathrm{~s}, 27 \mathrm{H},{ }^{\mathrm{t}} \mathrm{Bu}\right) .{ }^{13} \mathrm{C}\left\{{ }^{1} \mathrm{H}\right\} \mathrm{NMR}\left(\mathrm{CD}_{2} \mathrm{Cl}_{2}\right): \delta 208.0\left(\mathrm{~d}, J_{\mathrm{CP}}=17, \mathrm{SCS}\right)$, $162.2\left[\mathrm{q}, J_{\mathrm{CB}}=50, \mathrm{C}^{1}\left(\mathrm{Ar}^{\prime}\right)\right], 135.2\left[\mathrm{~s}, \mathrm{C}^{2}\left(\mathrm{Ar}^{\prime}\right)\right], 129.3\left[\mathrm{q}, J_{\mathrm{CF}}=32, \mathrm{C}^{3}\left(\mathrm{Ar}^{\prime}\right)\right], 125.0(\mathrm{q}$, $\left.J_{\mathrm{CF}}=272, \mathrm{CF}_{3}\right), 119.9\left[\mathrm{~s}, \mathrm{C}\left(\mathrm{C}_{6} \mathrm{H}_{3}\right)\right], 117.9\left[\mathrm{~s}, \mathrm{C}^{4}\left(\mathrm{Ar}^{\prime}\right)\right], 103.0\left[\mathrm{~d}, J_{\mathrm{CP}}=45, \mathrm{C}^{1}\left(\mathrm{C}_{5} \mathrm{H}_{4}\right)\right]$, 93.7 (s, Cp), $92.4\left[\mathrm{~d}, J_{\mathrm{CP}}=12, \mathrm{CH}\left(\mathrm{C}_{5} \mathrm{H}_{4}\right)\right], 89.9\left[\mathrm{~d}, J_{\mathrm{CP}}=8, \mathrm{CH}\left(\mathrm{C}_{5} \mathrm{H}_{4}\right)\right], 86.1\left[\mathrm{~d}, J_{\mathrm{CP}}=8\right.$, $\left.\mathrm{CH}\left(\mathrm{C}_{5} \mathrm{H}_{4}\right)\right], 84.5\left[\mathrm{~s}, \mathrm{CH}\left(\mathrm{C}_{6} \mathrm{H}_{3}\right)\right], 84.2\left[\mathrm{~d}, J_{\mathrm{CP}}=9, \mathrm{CH}\left(\mathrm{C}_{5} \mathrm{H}_{4}\right)\right], 36.5\left[\mathrm{~s}, \mathrm{C}^{1}\left({ }^{t} \mathrm{Bu}\right)\right], 31.5[\mathrm{~s}$, $\left.\mathrm{C}^{2}\left({ }^{t} \mathrm{Bu}\right)\right], 22.7\left(\mathrm{~d}, J_{\mathrm{CP}}=5, \mathrm{SMe}\right), 20.4\left[\mathrm{~d}, J_{\mathrm{CP}}=35, \mathrm{P}\left(\mathrm{CH}_{3}\right)_{3}\right], 17.5\left(\mathrm{~d}, J_{\mathrm{CP}}=31, \mathrm{PMe}\right)$; the carbonyl resonances could not be clearly identified in this spectrum.

Preparation of $\left[\mathrm{Mo}_{2} \mathrm{Cp}\left\{\mu-\kappa^{1}{ }_{\mathrm{P}}: \kappa^{1}{ }_{\mathrm{S}}, \eta^{\mathbf{5}}-\mathrm{P}(\mathrm{C}(\mathrm{NHPh}) \mathrm{S}) \mathrm{C}_{5} \mathrm{H}_{4}\right\}(\mathrm{CO})_{2}\left(\eta^{6}-\right.\right.$ HMes*)(PMe $\left.\left.{ }_{3}\right)\right]\left(\mathbf{B A r}^{\prime}{ }_{4}\right)$ (10). Solid $\left(\mathrm{NH}_{4}\right) \mathrm{PF}_{6}(0.025 \mathrm{~g}, 0.153 \mathrm{mmol})$ was added to a 
solution of compound $\mathbf{2 b}(0.026 \mathrm{~g}, 0.030 \mathrm{mmol})$ in toluene, and the mixture was stirred for $2 \mathrm{~min}$ to give a red solution. After removal of the solvent under vacuum, the residue was dissolved in dichloromethane $(3 \mathrm{~mL})$, then solid $\mathrm{Na}\left(\mathrm{BAr}^{\prime}{ }_{4}\right)(0.027 \mathrm{~g}, 0.030 \mathrm{mmol})$ was added, and the mixture was stirred for 2 min and then chromatographed on alumina at $263 \mathrm{~K}$. Elution with dichloromethane/petroleum ether (1/1) gave a red fraction yielding, upon removal of solvents, compound $\mathbf{1 0}$ as a red microcrystalline solid (0.043 g, 84\%). Anal. Calcd for $\mathrm{C}_{72} \mathrm{H}_{66} \mathrm{BMo}_{2} \mathrm{NO}_{2} \mathrm{P}_{2} \mathrm{SF}_{24}$ : C, 49.99; H, 3.85; N, 0.81; S, 1.85 . Found: C, 49.65; H, 3.50; N, 0.68; S, 1.55. ${ }^{1} \mathrm{H}$ NMR (300.09 MHz, $\mathrm{CD}_{2} \mathrm{Cl}_{2}$ ): $\delta 8.65$ (s, 1H, NH), 7.73 (m, 8H, Ar'), 7.56 (m, 4H, Ar'), 7.50-7.28 (m, 5H, Ph), 5.28 (s, 5H, Cp), $4.91\left(\mathrm{~s}, 3 \mathrm{H}, \mathrm{C}_{6} \mathrm{H}_{3}\right), 4.86\left(\mathrm{~s}, \mathrm{br}, 4 \mathrm{H}, \mathrm{C}_{5} \mathrm{H}_{4}\right), 1.60\left(\mathrm{~d}, J_{\mathrm{PH}}=10,9 \mathrm{H}, \mathrm{PMe}\right), 1.25(\mathrm{~s}, 27 \mathrm{H}$, $\left.{ }^{t} \mathrm{Bu}\right) .{ }^{13} \mathrm{C}\left\{{ }^{1} \mathrm{H}\right\}$ NMR $\left(\mathrm{CD}_{2} \mathrm{Cl}_{2}\right): \delta 231.5\left(\mathrm{dd}, J_{\mathrm{CP}}=28, J_{\mathrm{CP}}=8,2 \mathrm{MoCO}\right), 225.9\left(\mathrm{~d}, J_{\mathrm{CP}}=\right.$ $51, \mathrm{SCN}), 162.2\left[\mathrm{q}, J_{\mathrm{CB}}=50, \mathrm{C}^{1}\left(\mathrm{Ar}^{\prime}\right)\right], 139.6\left[\mathrm{~s}, \mathrm{C}^{1}(\mathrm{Ph})\right], 135.2\left[\mathrm{~s}, \mathrm{C}^{2}\left(\mathrm{Ar}^{\prime}\right)\right], 129.4$ [s, $\mathrm{CH}(\mathrm{Ph})], 129.1\left[\mathrm{q}, J_{\mathrm{CF}}=32, \mathrm{C}^{3}\left(\mathrm{Ar}^{\prime}\right)\right], 127.2\left[\mathrm{~s}, \mathrm{C}^{4}(\mathrm{CPh})\right], 125.0\left(\mathrm{q}, J_{\mathrm{CF}}=272, \mathrm{CF}_{3}\right)$, $122.7[\mathrm{~s}, \mathrm{CH}(\mathrm{Ph})], 117.8\left[\mathrm{~s}, \mathrm{C}^{4}\left(\mathrm{Ar}^{\prime}\right)\right], 105.8$ [s, $\left.\mathrm{C}\left(\mathrm{C}_{6} \mathrm{H}_{3}\right)\right], 97.7\left[\mathrm{dd}, J_{\mathrm{CP}}=13, J_{\mathrm{CP}}=2\right.$, $\left.\mathrm{C}^{1}\left(\mathrm{C}_{5} \mathrm{H}_{4}\right)\right], 92.5$ (s, Cp), 91.9 [d, $\left.J_{\mathrm{CP}}=15,2 \mathrm{CH}\left(\mathrm{C}_{5} \mathrm{H}_{4}\right)\right], 83.7$ [d, $\left.J_{\mathrm{CP}}=3,2 \mathrm{CH}\left(\mathrm{C}_{5} \mathrm{H}_{4}\right)\right]$, $80.4\left[\mathrm{~s}, \mathrm{CH}\left(\mathrm{C}_{6} \mathrm{H}_{3}\right)\right], 35.1\left[\mathrm{~s}, \mathrm{C}^{1}\left({ }^{t} \mathrm{Bu}\right)\right], 31.8\left[\mathrm{~s}, \mathrm{C}^{2}\left({ }^{t} \mathrm{Bu}\right)\right], 20.6\left(\mathrm{~d}, J_{\mathrm{CP}}=34, \mathrm{PMe}\right)$.

\section{$\mathrm{X}$-ray structure determination of compounds $2 \mathrm{a}, 3 \mathrm{~b}, 5^{\prime}, \mathbf{6}^{\prime}, 8$ and 9}

Data collection for all these compounds was performed at low temperatures (123 to 155 $\mathrm{K}$ ) on an Oxford Diffraction Xcalibur Nova single crystal diffractometer, using $\mathrm{Cu} \mathrm{K}_{\alpha}$ radiation. Images were collected at a $62 \mathrm{~mm}(63 \mathrm{~mm}$ for $\mathbf{2 a}$ and $\mathbf{3 b}$ ) fixed crystaldetector distance, using the oscillation method, with $0.9-1.3^{\circ}$ oscillation and variable exposure time per image. Data collection strategy was calculated with the program CrysAlis Pro $C C D,{ }^{31}$ and data reduction and cell refinement was performed with the program CrysAlis Pro RED. ${ }^{31}$ An empirical absorption correction was applied using the SCALE3 ABSPACK algorithm as implemented in the latter program. Using the program suite WINGX, ${ }^{32}$ the structures were generally solved by Patterson interpretation and phase expansion using SHELXL2016, ${ }^{33}$ and refined with full-matrix least squares on $F^{2}$ using SHELXL2016. All non-hydrogen atoms were refined anisotropically, except those involved in disorder (see below) and all hydrogen atoms were geometrically placed and refined using a riding model. In four of these complexes, highly disordered solvent molecules were found; therefore, the SQUEEZE procedure, ${ }^{34}$ as implemented in PLATON, ${ }^{35}$ was used. The results of final refinements corresponding to these structural studies can be found in Table 8 and in the ESI. Details of the treatment of disorder for each of these compounds are as follows: Compound 2a: the cyclopentadienyl ligand on $\operatorname{Mo}(1)$ was disordered over two sites, satisfactorily refined with $0.55 / 0.45$ occupancies; the complex crystallized with half a molecule of hexane (placed on a symmetry element) and with a highly disordered molecule of toluene which was removed with SQUEEZE. Compound $\mathbf{3 b}$ : one tert-butyl and the phenyl 
group were disordered over two sites, satisfactorily refined with $0.5 / 0.5$ occupancies; the complex crystallized with a heavily disordered molecule of hexane which was removed with SQUEEZE. Compound 5': the complex crystallized with a molecule of dichloromethane and with a heavily disordered molecule of an unidentified solvent (placed on a symmetry element) which was removed with SQUEEZE. Compound 8: most $\mathrm{CF}_{3}$ groups were substantially disordered, and three of them could be satisfactorily refined with 0.5/0.5 occupancy factors over two sites. Compound 9: In this case most of the heavy atoms of the cation were disordered and could be satisfactorily refined with 0.58/0.42 occupancies over two sites; the $\mathrm{CF}_{3}$ groups of the borate anions also showed their typical rotational disorder, but this was not modelled; moreover, the complex crystallized with a highly disordered molecule of hexane which was removed with SQUEEZE.

\section{Computational details}

All DFT computations were carried out using the GAUSSIAN03 package, ${ }^{36}$ in which the hybrid method B3LYP was used with the Becke three-parameter exchange functional $^{37}$ and the Lee-Yang-Parr correlation functional. ${ }^{38}$ An accurate numerical integration grid $(99,590)$ was used for all the calculations via the keyword Int=Ultrafine. Effective core potentials and their associated double- $\zeta$ LANL2DZ basis set were used for the metal atoms. ${ }^{39}$ The light elements $(\mathrm{P}, \mathrm{S}, \mathrm{O}, \mathrm{C}, \mathrm{N}$ and $\mathrm{H}$ ) were described with the 6-31G* basis. ${ }^{40}$ Geometry optimizations were performed under no symmetry restrictions, and frequency analyses were performed for all the stationary points to ensure that minimum structures with no imaginary frequencies were achieved. For interpretation purposes, natural population analysis charges were derived from the natural bond order analysis of the data (NBO charges). ${ }^{41}$ Molecular orbitals and vibrational modes were visualized using the Molekel program. ${ }^{42}$

\section{Acknowledgements}

We thank the Gobierno del Principado de Asturias for a grant (to I.G.A.) and financial support (Project GRUPIN14-011), the MINECO of Spain and FEDER for financial support (Project CTQ2015-63726-P), and the CMC of the Universidad de Oviedo for access 
Table 8. Crystal Data for New Compounds.

\begin{tabular}{|c|c|c|c|c|c|c|}
\hline & $2 \mathbf{a} \cdot 1 / 2 \mathrm{C}_{6} \mathrm{H}_{14}$ & $3 \mathbf{b}$ & $5^{\prime} \cdot \mathrm{CH}_{2} \mathrm{Cl}_{2}$ & $6 a^{\prime}$ & 8 & 9 \\
\hline mol formula & $\mathrm{C}_{37} \mathrm{H}_{55} \mathrm{Mo}_{2} \mathrm{O}_{2} \mathrm{P}_{2} \mathrm{~S}_{2}$ & $\mathrm{C}_{40} \mathrm{H}_{53} \mathrm{Mo}_{2} \mathrm{NO}_{4} \mathrm{P}_{2} \mathrm{~S}$ & $\begin{array}{l}\mathrm{C}_{60} \mathrm{H}_{73} \mathrm{BCl}_{2} \mathrm{Mo}_{2} \mathrm{O}_{2} \mathrm{P} \\
{ }_{2} \mathrm{~S}_{3}\end{array}$ & $\mathrm{C}_{59} \mathrm{H}_{71} \mathrm{BMo}_{2} \mathrm{O}_{2} \mathrm{P}_{2} \mathrm{~S}_{2}$ & $\begin{array}{l}\mathrm{C}_{{ }_{3}} \mathrm{H}_{67} \mathrm{BClF}_{24} \mathrm{Mo}_{2} \mathrm{~N} \\
\mathrm{O}_{2} \mathrm{P}_{2} \mathrm{~S}\end{array}$ & $\begin{array}{l}\mathrm{C}_{100} \mathrm{H}_{78} \mathrm{~B}_{2} \mathrm{~F}_{48} \mathrm{Mo}_{2} \mathrm{O}_{2} \\
\mathrm{P}_{2} \mathrm{~S}_{2}\end{array}$ \\
\hline mol wt & 849.75 & 897.73 & 1257.89 & 1140.90 & 1778.41 & 2563.18 \\
\hline cryst syst & monoclinic & monoclinic & triclinic & triclinic & monoclinic & triclinic \\
\hline space group & $P 2_{1} / c$ & $P 2_{1} / a$ & $P-1$ & $P-1$ & $P 2_{1}$ & $P-1$ \\
\hline radiation $(\lambda, \AA)$ & 1.54184 & 1.54184 & 1.54184 & 1.54184 & 1.54184 & 1.54184 \\
\hline$a, \AA$ & $17.5929(2)$ & $13.67660(10)$ & $9.5748(2)$ & $9.7425(4)$ & $14.4244(2)$ & $14.0227(6)$ \\
\hline$b, \AA$ & $14.32660(10)$ & $15.4391(2)$ & $14.8892(3)$ & $15.7020(6)$ & $16.8423(3)$ & $14.4107(3)$ \\
\hline$c, \AA$ & $18.1379(2)$ & $22.8288(3)$ & $22.5463(4)$ & $18.4172(6)$ & $16.8318(3)$ & $28.5960(10)$ \\
\hline$\alpha, \operatorname{deg}$ & 90 & 90 & 97.971(2) & $86.020(3)$ & 90 & $82.240(2)$ \\
\hline$\beta, \operatorname{deg}$ & $97.3970(10)$ & $104.5280(10)$ & $98.855(2)$ & $76.784(3)$ & $109.014(2)$ & $79.614(4)$ \\
\hline$\gamma, \operatorname{deg}$ & 90 & 90 & $97.007(2)$ & $89.573(3)$ & 90 & $79.716(3)$ \\
\hline$V, \AA^{3}$ & $4533.55(8)$ & $4666.27(9)$ & $3111.30(11)$ & $2736.07(18)$ & $3866.01(12)$ & $5560.9(3)$ \\
\hline $\mathrm{Z}$ & 4 & 4 & 2 & 2 & 2 & 2 \\
\hline calcd density, $\mathrm{g} \mathrm{cm}^{-3}$ & 1.245 & 1.278 & 1.343 & 1.385 & 1.528 & 1.531 \\
\hline absorp coeff, $\mathrm{mm}^{-1}$ & 6.253 & 5.739 & 5.814 & 5.329 & 4.529 & 3.616 \\
\hline temperature, $\mathrm{K}$ & $123.0(3)$ & $123.0(1)$ & $150.7(9)$ & $155(6)$ & $150.1(5)$ & $152(4)$ \\
\hline$\theta$ range $(\mathrm{deg})$ & $3.95-74.53$ & $3.45-74.62$ & $3.03-69.73$ & $2.82-69.80$ & $3.24-69.61$ & $3.16-73.83$ \\
\hline index ranges $(h, k, l)$ & $\begin{array}{l}-18,21 ;-16,17 \\
-19,22\end{array}$ & $\begin{array}{l}-17,13 ;-18,18 \\
-25,28\end{array}$ & $\begin{array}{l}-11,11 ;-18,17 \\
-27,27\end{array}$ & $\begin{array}{l}-11,11 ;-18,18 \\
-22,17\end{array}$ & $\begin{array}{l}-17,16 ;-20,17 \\
-20,20\end{array}$ & $\begin{array}{l}-16,16 ;-13,17 \\
-34,32\end{array}$ \\
\hline no. of reflns collected & 17765 & 42732 & 43280 & 24893 & 21417 & 47347 \\
\hline no. of indep reflns $\left(R_{\text {int }}\right)$ & $8899(0.0303)$ & $9350(0.0345)$ & $11576(0.0527)$ & $10120(0.0362)$ & $10974(0.0396)$ & $20596(0.0671)$ \\
\hline no. of reflns with $I>2 \sigma(I)$ & 7633 & 8015 & 10783 & 8811 & 10169 & 14140 \\
\hline $\begin{array}{l}R \text { indexes } \\
{[\text { data with } I>2 \sigma(I)]^{a}}\end{array}$ & $\begin{array}{l}R_{1}=0.0388 \\
\mathrm{w} R_{2}=0.1053^{b}\end{array}$ & $\begin{array}{l}R_{1}=0.0314 \\
\mathrm{w} R_{2}=0.0826^{c}\end{array}$ & $\begin{array}{l}R_{1}=0.0416 \\
\mathrm{w} R_{2}=0.1203^{d}\end{array}$ & $\begin{array}{l}R_{1}=0.0373 \\
\mathrm{w} R_{2}=0.0944^{e}\end{array}$ & $\begin{array}{l}R_{1}=0.0583 \\
\mathrm{w} R_{2}=0.1547^{f}\end{array}$ & $\begin{array}{l}R_{1}=0.0849 \\
\mathrm{w} R_{2}=0.2389^{g}\end{array}$ \\
\hline$R$ indexes (all data) ${ }^{a}$ & $\begin{array}{l}R_{1}=0.0458 \\
\mathrm{w} R_{2}=0.1111^{b}\end{array}$ & $\begin{array}{l}R_{1}=0.0384 \\
\mathrm{w} R_{2}=0.0874^{c}\end{array}$ & $\begin{array}{l}R_{1}=0.0440 \\
\mathrm{w} R_{2}=0.1249^{d}\end{array}$ & $\begin{array}{l}R_{1}=0.0440 \\
\mathrm{w} R_{2}=0.1000^{e}\end{array}$ & $\begin{array}{l}R_{1}=0.0627 \\
\mathrm{w} R_{2}=0.1607^{f}\end{array}$ & $\begin{array}{l}R_{1}=0.1184 \\
\mathrm{w} R_{2}=0.2797^{g}\end{array}$ \\
\hline GOF & 1.057 & 1.047 & 1.023 & 1.014 & 1.045 & 1.019 \\
\hline $\begin{array}{l}\text { no. of } \\
\text { restraints/parameters }\end{array}$ & $0 / 396$ & $3 / 450$ & $0 / 662$ & $0 / 626$ & $1 / 967$ & $0 / 1581$ \\
\hline$\Delta \rho(\max ., \min ),. \mathrm{e}^{-3}$ & $0.643,-0.918$ & $0.656 /-0.684$ & $1.076,-1.380$ & $1.029,-0.817$ & $1.157,-0.841$ & $1.134,-2.868$ \\
\hline CCDC deposition No & 1518224 & 1518225 & 1518226 & 1518227 & 1518228 & 1518229 \\
\hline
\end{tabular}

${ }^{a} R=\Sigma|| F_{o}|-| F_{c} \| / \Sigma\left|F_{o}\right| \cdot w R=\left[\Sigma w\left(\left|F_{o}\right|^{2}-\left|F_{c}\right|^{2}\right)^{2} / \sum w\left|\mathrm{~F}_{o}\right|^{2}\right]^{1 / 2} \cdot w=1 /\left[\sigma^{2}\left(F_{o}{ }^{2}\right)+(a P)^{2}+b P\right]$ where $P=\left(F_{o}{ }^{2}+2 F_{c}{ }^{2}\right) / 3 .{ }^{b} a=0.0650, b=1.3119 .{ }^{c} a=0.0453, b=$ 2.1469. ${ }^{d} a=0.0932, b=1.0084{ }^{e} a=0.0572, b=1.2152 .{ }^{f} a=0.0976, b=5.4008 .{ }^{g} a=0.1350, b=15.5302$. 


\section{Notes and References}

Departamento de Química Orgánica e Inorgánica / IUQOEM, Universidad de Oviedo, E-33071 Oviedo, Spain.E-mail: garciame@uniovi.es (M.E.G.), mara@uniovi.es (M.A.R.)

$\dagger$ Electronic supplementary information (ESI) available: A CIF file containing full crystallographic data for compounds $\mathbf{2 a}, \mathbf{3 b}, \mathbf{5}^{\prime}, \mathbf{6 a}^{\prime}, \mathbf{8}$ and 9 (CCDC 15182241518229) and a PDF file containing the complete reference 36 and results of DFT calculations (drawings, atomic coordinates, atomic charges and selected orbitals) for compounds 2a and 2b. See DOI: 10.1039/b000000x/

1. Recent reviews: (a) F. Mathey and Z. Duan, Dalton Trans., 2016, 45, 1804. (b) H. Aktas, J. C. Slootweg and K. Lammertsma, Angew. Chem. Int. Ed., 2010, 49, 2102. (c) R. Waterman, Dalton Trans., 2009, 18. (d) F. Mathey, Dalton Trans., 2007, 1861. (e) K. Lammertsma, Top. Curr. Chem., 2003, 229, 95. (f) K. Lammertsma and M. J. M. Vlaar, Eur. J. Org. Chem., 2002, 1127. (g) R. Streubel, Coord. Chem. Rev., 2002, 227, 175. (h) F. Mathey, N. H. T. Huy and A. Marinetti, Helv. Chim. Acta, 2001, 84, 2938. (i) D. W. Stephan, Angew. Chem. Int. Ed., 2000, 39, 314. (j) S. Shah and J. D. Protasiewicz, Coord. Chem. Rev., 2000, 210, 181.

2. K. B. Dillon, F. Mathey and J. F. Nixon, Phosphorus: The Carbon-Copy, Wiley, Chichester, 1998, p. 19.

3. M. E. García, D. García-Vivó, A. Ramos and M. A. Ruiz, Coord. Chem. Rev., 2017, 330, 1, and references therein.

4. (a) C. M. Alvarez, M. A. Alvarez, M. E. García, R. González, M. A. Ruiz, H. Hamidov and J. C. Jeffery, Organometallics, 2005, 24, 5503. (b) M. A. Alvarez, M. E. García, R. González and M. A. Ruiz, Organometallics, 2008, 27, 1037. (c) M. A. Alvarez, M. E. García, R. González and M. A. Ruiz, Organometallics, 2010, 29, 5140. (d) M. A. Alvarez, M. E. García, R. González and M. A. Ruiz, Dalton Trans., 2012, 417, 14498. (e) M. A. Alvarez, M. E. García, R. González and M. A. Ruiz, Organometallics, 2013, 32, 4601.

5. I. G. Albuerne, M. A. Alvarez, M. E. García, D. García-Vivó and M. A. Ruiz, Organometallics, 2013, 32, 6178.

6. I. G. Albuerne, M. A. Alvarez, I. Amor, M. E. García, D. García-Vivó and M. A. Ruiz, Inorg. Chem., 2016, 55, 10689.

7. Y. Lv, C. E. Kefalidis, J. Zhou, L. Maron, X. Leng and Y. Chen, J. Am. Chem. Soc., 2013, 135, 14784.

8. I. G. Albuerne, M. A. Alvarez, M. E. García, D. García-Vivó and M. A. Ruiz, Inorg. Chem., 2015, 54, 9810. 
9. A. Antiñolo, S. García-Yuste, A. Otero and E. Villaseñor, J. Organomet. Chem., 2007, 692, 4436.

10. (a) W. Yi, L. Hong, Z. Chen and X. Zhou, Organometallics, 2011, 30, 5809. (b) A. J. Roering, S. E. Leshinski, S. M. Chan, T. Shalumova, S. N. MacMillan, J. M. Tanski and R. Waterman, Organometallics, 2010, 29, 2557. (c) A. Antiñolo, S. García-Yuste, A. Otero and R. Reguillo-Carmona, Eur. J. Inorg. Chem., 2009, 539. (d) A. Antiñolo, S. García-Yuste, A. Otero, J. C. Pérez-Flores, R. ReguilloCarmona, A. M. Rodríguez and E. Villaseñor, Organometallics, 2006, 25, 1310. (e) A. Antiñolo, D. Evrard, S. García-Yuste, A. Otero, J. C. Pérez-Flores, R. ReguilloCarmona, A. M. Rodríguez and E.Villaseñor, Organometallics, 2006, 25, 3670. (f) K.-H. Yih and Y.-C. Lin, J. Organomet. Chem., 1999, 577, 134. (g) U. Segerer and E. Hey-Hawkins, Polyhedron, 1997, 16, 2537.

11. B. Cordero, V. Gómez, A. E. Platero-Prats, M. Revés, J. Echevarría, E. Cremades, F. Barragán and S. Alvarez, Dalton Trans., 2008, 2832.

12. P. Pyykkö and M. Atsumi, Chem. Eur. J., 2009, 15, 12770.

13. A. Galindo, D. Miguel and J. Perez, Coord. Chem. Rev., 1999, 193-195, 643.

14. (a) W. Koch and M. C. Holthausen, A Chemist's Guide to Density Functional Theory, 2nd ed., Wiley-VCH, Weinheim, Germany, 2002. (b) C. J. Cramer, Essentials of Computational Chemistry, 2nd ed., Wiley, Chichester, U. K., 2004.

15. P. S. Braterman, Metal Carbonyl Spectra, Academic Press, London, U. K., 1975.

16. L. Rosenberg, Coord. Chem. Rev., 2012, 256, 606.

17. W. Malisch, R. Maisch, I. J. Colquhoun and W. McFarlane, J. Organomet. Chem., 1981, 220, C1.

18. A value of $48 \mathrm{~kJ} / \mathrm{mol}$ can be estimated with the equation $\Delta G^{\#}{ }_{T c}=19.14 T_{c}[9.97+$ $\left.\log \left(T_{c} / \Delta v\right)\right]$ (in $\mathrm{J} / \mathrm{mol}$ ) by assuming a coalescence temperature $\left(T_{c}\right)$ of ca. $253 \mathrm{~K}$ for the pair of resonances at 5.71 and $4.85 \mathrm{ppm}$. See: H. Günter, NMR Spectroscopy, John Wiley, Chichester, U.K., 1980, p 243.

19. (a) R. D. Baechler and K. Mislow, J. Am. Chem. Soc., 1970, 92, 3090. (b) C. D. Montgomery, J. Chem. Ed., 2013, 90, 661, and references therein.

20. (a) P. S. Pregosin, NMR in Organometallic Chemistry, Wiley-VCH, Weinheim, Germany, 2012, chapter 8. (b) D. S. Glueck, Coord. Chem. Rev., 2008, 252, 2171.

21. (a) D. K. Wicht, D. S. Glueck, L. M. Liable-Sands and A. L. Rheingold, Organometallics, 1999, 18, 5130. (b) W. Malisch, R. Maisch, A. Meyer, D. Greissinger, E. Gross, E. J. Colquhoun and W. McFarlane, Phosphorus Sulfur, 1983, 18, 299.

22. R. Zhang, C. Li, Q. Wang and M. Chunlin, Struct. Chem., 2010, 21, 745. 
23. (a) N. H. T. Huy, B. Donnadieu, G. Bertrand and F. Mathey, Organometallics, 2010, 29, 1302. (b) E. Lidner, W. Kneissle, R. Fawzi, M. Steimann, H. A. Mayer and K. Gierling, Chem. Ber., 1995, 128, 973.

24. B. Hoge, C. Thösen, T. Herrmann, P. Panne and I. Pantenburg, J. Fluorine Chem., 2004, 125, 831.

25. D. Clajus, R. Kramolowsky, G. Siasios and E. R. T. Tiekink, Inorg. Chim. Acta, 1998, 281, 64.

26. O. Crespo, E. J. Fernandez, P. G. Jones, A. Laguna, J. M. Lopez-de-Luzuriaga, M. Monge, M. E. Olmos and J. Perez, Dalton Trans., 2003, 1076.

27. P. S. Pregosin, NMR in Organometallic Chemistry, Wiley-VCH, Weinheim, Germany, 2012, chapter 6.

28. J. D. King, M. J. Mays, C.-Y. Mo, G. A. Solan, G. Conole and M. McPartlin, J. Organomet. Chem., 2002, 64, 227.

29. W. L. F. Armarego and C. Chai, Purification of Laboratory Chemicals, 7th ed., Butterworth-Heinemann, Oxford, U. K, 2012.

30. N. A. Yakelis and R. G. Bergman, Organometallics, 2005, 24, 3579.

31. L. J. Farrugia, J. Appl. Crystallogr., 1999, 32, 837.

32. (a) G. M. Sheldrick, Acta Crystallogr. Sect. A, 2008, 64, 112. (b) G. M. Sheldrick, Acta Crystallogr. Sect. C, 2015, 71, 5.

33. CrysAlis Pro, Oxford Diffraction Limited, Ltd., Oxford, U. K., 2006.

34. A. L. Spek, Acta Crystallogr. Sect. C, 2015, 71, 9.

35. A. L. Spek, PLATON, A Multipurpose Crystallographic Tool, Utrecht University, Utrecht, The Netherlands, 2010.

36. M. J. Frisch, et al., Gaussian 03, Revision B.02, Gaussian, Inc., Wallingford, CT, 2004. See the ESI for the complete reference.

37. A. D. Becke, J. Chem. Phys., 1993, 98, 5648.

38. C. Lee, W. Yang and R. G. Parr, Phys. Rev. B, 1988, 37, 785.

39. P. J. Hay and W. R. Wadt, J. Chem. Phys., 1985, 82, 299.

40. (a) P. C. Hariharan and J. A. Pople, Theor. Chim. Acta, 1973, 28, 213. (b) G. A. Petersson and M. A. Al-Laham, J. Chem. Phys., 1991, 94, 6081. (c) G. A. Petersson, A. Bennett, T. G. Tensfeldt, M. A. Al-Laham, W. A. Shirley and J. Mantzaris, J. Chem. Phys., 1988, 89, 2193.

41. A. E. Reed, L. A. Curtis and F. Weinhold, Chem. Rev., 1988, 88, 899.

42. S. Portmann and H. P. Luthi, CHIMIA, 2000, 54, 766. 